\title{
Energy Efficiency Programs and Policies in the Industrial Sector in Industrialized Countries
}

\author{
Christina Galitsky, Lynn Price and Ernst Worrell
}

\author{
Energy Analysis Department \\ Environmental Energy Technologies Division \\ Ernest Orlando Lawrence Berkeley National Laboratory \\ University of California \\ Berkeley, CA 94720
}

June 2004

This work was supported by the Industrial Technologies Program, Office of Energy Efficiency and Renewable Energy, U.S. Department of Energy under Contract No. DE-AC03-76SF00098. 



\title{
Energy Efficiency Programs and Policies in the Industrial Sector in Industrialized Countries
}

\author{
Christina Galitsky, Lynn Price and Ernst Worrell \\ Energy Analysis Department \\ Environmental Energy Technologies Division \\ Ernest Orlando Lawrence Berkeley National Laboratory
}

June 2004

\begin{abstract}
About $37 \%$ of the primary energy consumed both in the U.S. and globally is used by the industrial sector. A variety of energy efficiency policies and programs have been implemented throughout the world in an effort to improve the energy efficiency of this sector. This report provides an overview of these policies and programs in twelve industrialized nations and the European Union (EU). We focus on energy efficiency products and services that are available to industrial consumers, such as reports, guidebooks, case studies, fact sheets, profiles, tools, demonstrations, roadmaps and benchmarking. We also focus on the mechanisms to communicate the availability and features of these products and services and to disseminate them to the industrial consumers who can use them. Communication channels include customer information centers and websites, conferences and trade shows, workshops and other training mechanisms, financial assistance programs, negotiated agreements, newsletters, publicity, assessments, tax and subsidy schemes and working groups. In total, over 30 types of industrial sector energy efficiency products, services and delivery channels have been identified in the countries studied. Overall, we found that the United States has a large variety of programs and offers industry a number of supporting programs for improving industrial energy efficiency. However, there are some products and services found in other industrialized countries that are not currently used in the U.S., including benchmarking programs, demonstration of commercialized technologies and provision of energy awareness promotion materials to companies. Delivery mechanisms found in other industrialized countries that are not employed in the U.S. include negotiated agreements, public disclosure and national-level tax abatement for energy-efficient technologies.
\end{abstract}




\section{Table of Contents}

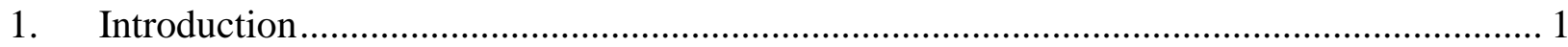

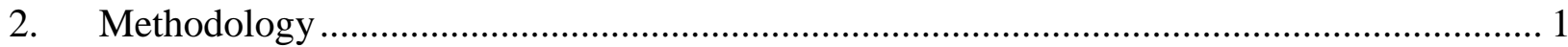

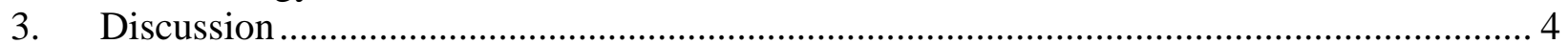

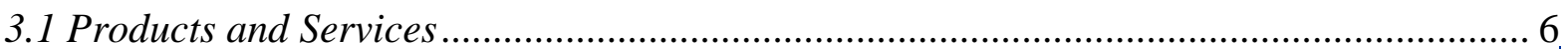

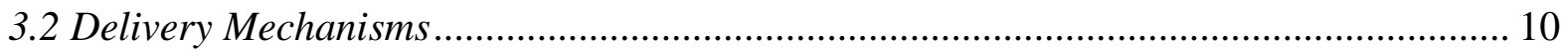

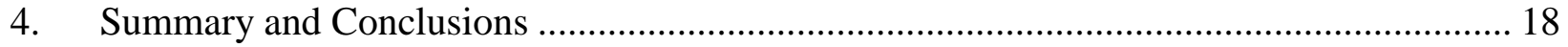

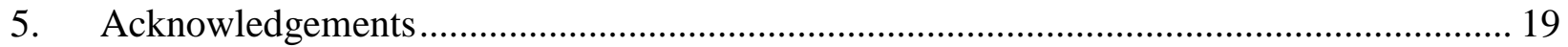

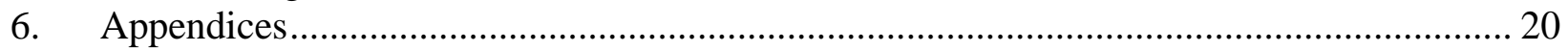

\section{Tables}

Table 1: Overview of the Industrial Sector Energy Efficiency Program Products and Services of Industrialized Countries.

Table 2: Overview of the industrial Sector Energy Efficiency Program Delivery Mechanisms of Industrialized Countries........................................................................................................ 3

Table 3: Industrial Energy Efficiency Products and Services by Country and the EU .................. 4

Table 4: Industrial Energy Efficiency Delivery Mechanisms by Each Country and the EU ......... 5 


\section{Introduction}

About $37 \%$ of the primary energy consumed both in the U.S. and globally is used by the industrial sector ${ }^{1}$. A variety of energy efficiency policies and programs have been implemented throughout the world in an effort to improve the energy efficiency of this sector. This report provides an overview of these policies and programs in twelve industrialized nations and the European Union (EU). We focus on energy efficiency products and services that are available to industrial consumers, such as reports, guidebooks, case studies, fact sheets, profiles, tools, demonstrations, roadmaps and benchmarking. We also focus on the mechanisms to communicate the availability and features of these products and services and to disseminate them to the industrial consumers who can use them. Communication channels include customer information centers and websites, conferences and trade shows, workshops and other training mechanisms, financial assistance programs, negotiated agreements, newsletters, publicity, assessments, tax and subsidy schemes and working groups. In total, over 30 types of industrial sector energy efficiency products, services and delivery channels have been identified in the countries studied. In the following report, we provide details on each of these products, services and delivery mechanisms and review how each country is utilizing them to promote energy efficiency in the industrial sector.

The methodology used for the compilation of this report is described in Section 2, along with the definitions of the industrial sector energy efficiency products, services and delivery mechanisms. General country or regional trends are explored in Section 3. Each program element is then examined in detail. Full reports on the industrial energy efficiency programs for each country and the European Union are given in Appendices A through L. References can be found in the appendices for each country, and are not listed again in the main body of the text.

\section{Methodology}

This report contains a compilation of the industrial sector energy efficiency programs and policies found throughout the industrialized world. We have focused on the European Union (EU) and twelve industrialized countries that represent the majority of current programs elements on industrial energy efficiency. The countries are: Australia, Canada, Denmark, France, Germany, Japan, the Netherlands, Norway, Sweden, Switzerland, the United Kingdom (U.K.) and the United States (U.S.). For each country and the EU, we compiled the elements of the energy efficiency programs focused (at least in part) on the industrial sector. We consulted several sources, including International Energy Agency (IEA) reports, United Nations Framework Convention reports, international energy and energy efficiency websites, and governmental, energy, environmental and programmatic websites specific to each country. After compiling a draft report for each country and the EU, the report was reviewed by an in-country

\footnotetext{
${ }^{1}$ International Energy Agency (IEA), Energy Balances of OECD Countries, published in Paris annually. IEA, Energy Balances of Non-OECD Countries, published in Paris annually. Oak Ridge National Laboratory and Lawrence Berkeley National Laboratory, Interlaboratory Working Group. 2000. Scenarios for a Clean Energy Future. Oak Ridge, TN and Berkeley, CA, ORNL/CON-476 and LBNL-44029.
} 
expert whose comments were incorporated into the final version. Each of these reports can be found in the appendices, arranged alphabetically.

After collecting data on each country or region, we grouped all of the energy efficiency program elements into two categories: (1) products and services and (2) delivery mechanisms. The products and services group consists of information, studies, demonstrations, tools and other forms of assistance supplied to an industry or a company. Delivery mechanisms are the channels by which the products and services are explained, communicated and disseminated to the customers. Many programs integrate a number of products, services and deliver mechanisms to ensure the highest level of energy efficiency and to serve most effectively their industrial customers.

Table 1 provides a brief definition of each of the products and services we identified. Table 2 shows the same for delivery mechanisms. All of the products and services and delivery mechanisms are analyzed in more detail in Section 3, below, in which we compile the data from each country and regional study to determine the products, services and delivery channels that are used most worldwide and those that are strong or lacking in the U.S. We then review each product and service and each delivery mechanism category in more detail to highlight the most innovative elements of each, with a focus on applicability in the U.S.

Table 1: Overview of the Industrial Sector Energy Efficiency Program Products and Services of Industrialized Countries.

\begin{tabular}{|c|c|}
\hline Product and/or Service & Description \\
\hline Audit or Assessment Reports & $\begin{array}{l}\text { Reviews that summarize an assessment of an industrial facility, potentially } \\
\text { containing suggestions for improvement }\end{array}$ \\
\hline Benchmarking & Studies or tools that compare energy use for a system, an industry or a sector \\
\hline Case Study & $\begin{array}{l}\text { A report of a (generally successful) implementation of a technology or } \\
\text { methodology }\end{array}$ \\
\hline $\begin{array}{l}\text { Demonstration, Commercialized } \\
\text { Technologies }\end{array}$ & $\begin{array}{l}\text { Example of an implementation of a commercialized available technology or } \\
\text { methodology }\end{array}$ \\
\hline $\begin{array}{l}\text { Demonstration, Emerging } \\
\text { Technologies }\end{array}$ & Example of an implementation of an emerging technology or methodology \\
\hline Fact Sheets & $\begin{array}{l}\text { Short informational pages on an energy efficiency method, technology, } \\
\text { process or system }\end{array}$ \\
\hline Industry Profile & $\begin{array}{l}\text { A description of an industry or sector, generally containing information on } \\
\text { energy use and energy efficiency }\end{array}$ \\
\hline $\begin{array}{l}\text { Energy Awareness Promotion } \\
\text { Materials }\end{array}$ & $\begin{array}{l}\text { Materials provided to energy or other managers within a company to be } \\
\text { distributed to their employees and used within the company to promote } \\
\text { energy efficiency, such as brochures, CDs, flyers or sign boards. }\end{array}$ \\
\hline Reports and Guidebooks & $\begin{array}{l}\text { A variety of informational texts that spans specific to general information on } \\
\text { energy efficiency and energy use in the industrial sector }\end{array}$ \\
\hline Tools and Software & $\begin{array}{l}\text { A variety of benchmarking, monitoring, modeling, optimization, reporting, } \\
\text { and assessment tools, tutorials, directories and searchable indices }\end{array}$ \\
\hline Verification and Validation & Tracking and reporting assistance for companies \\
\hline Visions and Roadmaps & Energy management, target setting and action plans \\
\hline
\end{tabular}


Table 2: Overview of the Industrial Sector Energy Efficiency Program Delivery Mechanisms of Industrialized Countries.

\begin{tabular}{|c|c|}
\hline Delivery Mechanism & Description \\
\hline $\begin{array}{l}\text { Conferences and Trade } \\
\text { Shows }\end{array}$ & Organized meetings for networking, training and disseminating information. \\
\hline $\begin{array}{l}\text { Customer Info Centers for } \\
\text { Industry }\end{array}$ & $\begin{array}{l}\text { Customer service centers including phone, web, e-mail, chat rooms, libraries and } \\
\text { office-based centers for information dissemination, query services about energy } \\
\text { efficiency. }\end{array}$ \\
\hline Directories & Collection of organizations, publications and programs involved in energy efficiency. \\
\hline $\begin{array}{l}\text { Financial and other } \\
\text { Assistance with Innovative } \\
\text { Technologies }\end{array}$ & $\begin{array}{l}\text { Subsidies and low interest loans or bonds for innovative R\&D, energy management } \\
\text { programs, workshops and training, evaluations and equipment. In rare cases, for } \\
\text { marketing. }\end{array}$ \\
\hline Industry Associations & $\begin{array}{l}\text { Agreements and networking events (on energy efficiency) with government and } \\
\text { industrial associations. }\end{array}$ \\
\hline Industry Experts & $\begin{array}{l}\text { People who provide expertise on energy efficiency technologies, systems and energy } \\
\text { management or who assist with system and plant evaluations. }\end{array}$ \\
\hline $\begin{array}{l}\text { Industry and/or Vendor } \\
\text { Partnerships }\end{array}$ & Projects joint with industry or vendors that expand and/or promote energy efficiency. \\
\hline Negotiated Agreements* & $\begin{array}{l}\text { Framework for reporting and undertaking actions to increase energy efficiency. } \\
\text { Agreements between government and industry can be voluntary but involve } \\
\text { repercussions if targets are unmet }\end{array}$ \\
\hline Newsletters & Periodic distribution of information on energy efficiency. \\
\hline Public Disclosure ${ }^{\mp / F i n e s}$ & $\begin{array}{l}\text { Fines and/or bad publicity for compliance failure. Generally used in conjunction with } \\
\text { negotiated agreements. }\end{array}$ \\
\hline Public Recognition & $\begin{array}{l}\text { Logos, awards or good publicity, often used in conjunction with negotiated } \\
\text { agreements. }\end{array}$ \\
\hline Regional Offices & Offices set up locally for networking and assistance with energy efficiency. \\
\hline Showcases & $\begin{array}{l}\text { Exhibits, training and demonstrations that highlight a particular technology or group } \\
\text { of technologies, generally executed at conferences, training sessions, workshops, } \\
\text { accessible info centers or other industry functions. }\end{array}$ \\
\hline Subsidized Assessments & $\begin{array}{l}\text { Audits of the energy efficiency of a facility that are partially or entirely funded by the } \\
\text { government. }\end{array}$ \\
\hline $\begin{array}{l}\text { Tax Abatement for Energy } \\
\text { Efficiency Technologies }\end{array}$ & $\begin{array}{l}\text { For countries with energy and/or } \mathrm{CO}_{2} \text { taxes, exemptions or reductions for installing } \\
\text { energy efficiency technologies, reducing emissions and/or saving energy. }\end{array}$ \\
\hline Trade Journals & $\begin{array}{l}\text { Public recognition, promotion and information dissemination through industry } \\
\text { journals. }\end{array}$ \\
\hline Training & $\begin{array}{l}\text { Seminars, workshops, courses, pamphlets, videos, CDs or other instructional } \\
\text { materials and methods about energy efficiency. }\end{array}$ \\
\hline Websites & $\begin{array}{l}\text { Web pages containing tools and information on and links to energy efficiency } \\
\text { programs, policies, technologies and assistance. }\end{array}$ \\
\hline Working Groups & $\begin{array}{l}\text { Networks to promote collaboration and information exchange and to develop } \\
\text { roadmaps. }\end{array}$ \\
\hline
\end{tabular}

In this report, we make the distinction between voluntary targets that are set by the industry with no repercussions if goals are not met, and negotiated agreements with built in rewards or punishments if negotiated targets are met or not met, respectively.

${ }^{\mp}$ Greenhouse gas emission inventories are not included in this category because we have chosen to focus on energy efficiency. 


\section{Discussion}

Table 3 shows the products and services offered by each country and the EU analyzed in this report. Table 4 lists the same for the delivery mechanisms evaluated. As shown in both tables, every country has a variety of components within their industrial energy efficiency programs, although some countries have more program elements than others do and some countries have established more detailed or comprehensive specific products, services or delivery mechanisms. In addition, upon examination of the components themselves, it is clear that some are more widespread throughout the countries studied than others are. We first consider these general trends of program components across all of the countries and more specifically in the U.S., and then we address the more specific innovations within each product, service and delivery mechanism category.

Table 3: Industrial Energy Efficiency Products and Services by Country and the EU

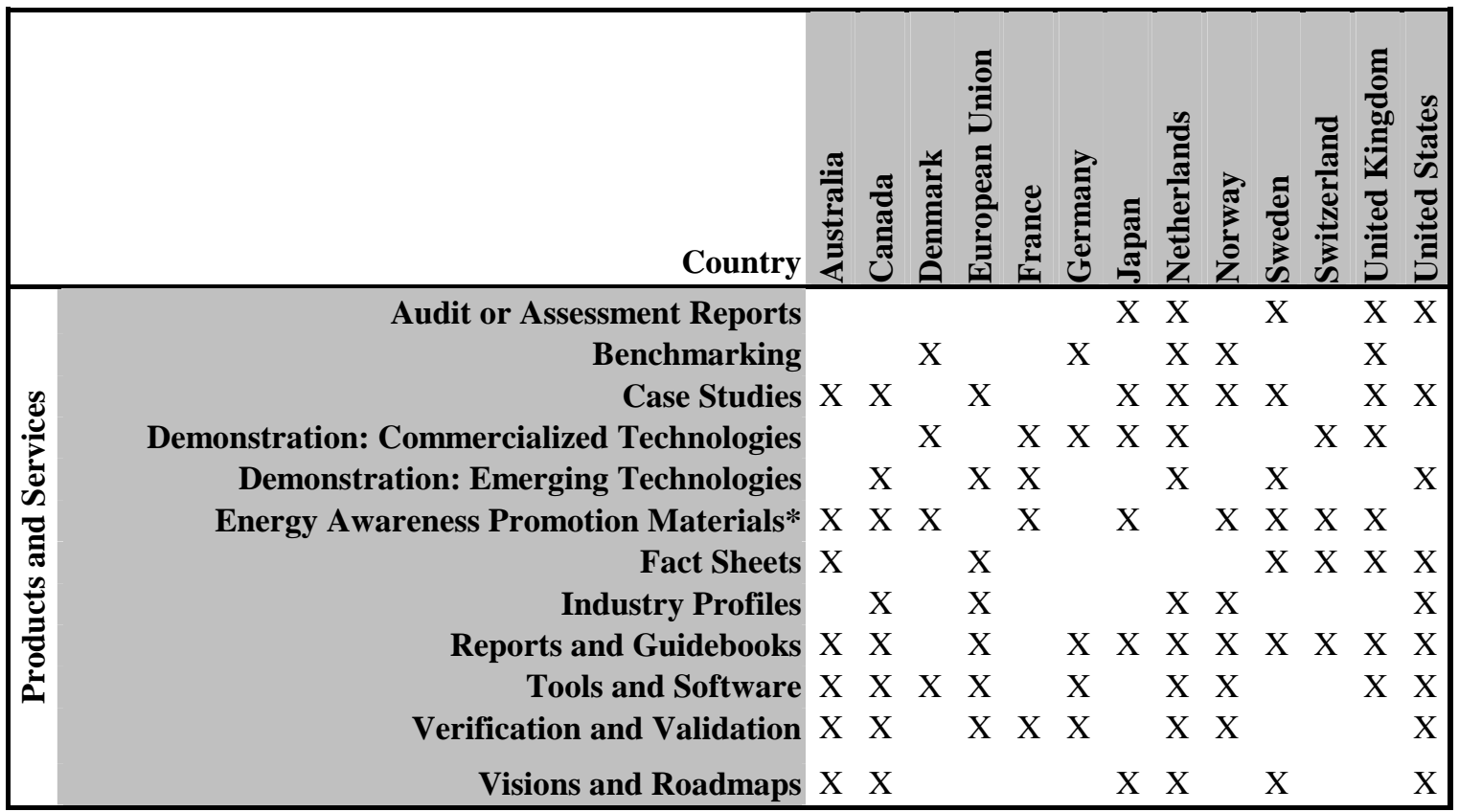

* Energy awareness promotion materials refer to materials that are provided to energy or other managers within a company to be distributed to their employees and used within the company to promote energy efficiency, such as brochures, CDs, flyers or sign boards. This may contain materials that can easily be tailored and formatted to the needs of the company.

All countries provide some combination of reports, case studies, energy awareness promotion materials, guidebooks, and tools and software on energy efficiency. Most also provide demonstrations of either commercialized or emerging technologies. The majority provides some form of verification and validation tools or assistance. The product categories that are not as frequently used are audits and assessment reports, benchmarking, fact sheets, industry profiles and visions and roadmaps.

Direct informational assistance and expertise is provided through customer help lines and informational centers, industry experts, directories, regional offices and websites. These compose the group of delivery mechanisms that are utilized most; each country employs at least two of 
these mechanisms for dissemination to industry, although the degree of innovation within each category varies among the countries within this group. Networking and training events such as conferences, trade shows, showcases, training and working groups are almost ubiquitous throughout the industrialized countries that were examined, with the exception of Denmark. Periodical publications like newsletters and articles in trade journals are also quite common. Financial or other assistance for energy-efficient technology or through assessments is available to industry in each of the countries examined. Partnerships with vendors or industry - directly with industry or through the associations - are common throughout the industrialized nations. For the U.S., delivery mechanisms that are absent are negotiated agreements and tax abatement strategies at the federal level. Though the U.S. industry has begun to set voluntary targets, negotiated agreements with incentives for compliance or repercussions for non-compliance are still absent. In addition, in the absence of an energy tax or $\mathrm{CO}_{2} \operatorname{tax}$, tax abatement schemes are limited to tax credits or reduced depreciation times for energy efficiency products or systems, as have been developed in specific states.

Table 4: Industrial Energy Efficiency Delivery Mechanisms by Each Country and the EU

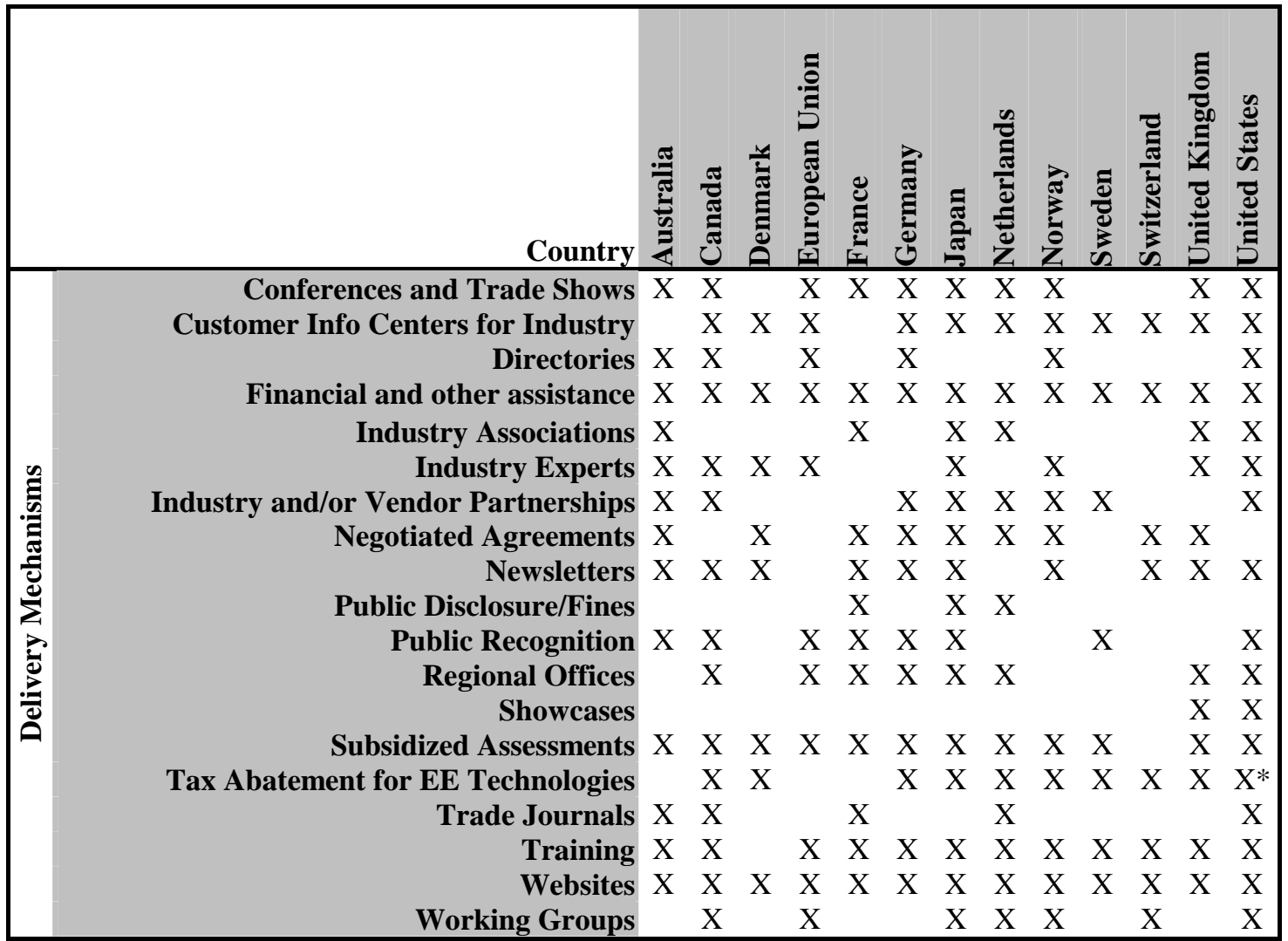

* Tax abatement schemes are only present in selected states. Although proposals have been developed for specific technologies on the federal level, none have been enacted at this time.

Next, we discuss each of the products, services and delivery mechanisms by category in more detail to uncover the innovations of all of the countries examined within each product, service and delivery channel throughout the industrialized world. For more information on each country, a report for each can be found in its corresponding appendix, arranged alphabetically. 


\subsection{Products and Services}

Audits or Assessment Reports. Assessment reports summarize the results of an audit of an industrial facility and often contain suggestions for improvement. Some include a comparison with a standard or with other companies (a benchmark) for the company. The Energy Conservation Center, Japan (ECC) prioritizes the areas that need improvement and suggest measures to address these areas within their reports. A cost benefit analysis is also made. The Netherlands provides detailed audits of industrial facilities that include both an assessment of energy consumption in a base year and an inventory of the sector-wide energy conservation potential. The Swedish National Energy Administration (STEM), as a part of the EKO Energi (Eco-energy) Agreements, provides a comprehensive inventory and analysis of energy use in a company's production and premises, and includes a list of possible actions to be taken. STEM also provides a comprehensive material flow analysis as well as an introductory comparison of the company's environmental awareness and management and guidelines based on EMAS or ISO 14001 standards. The U.K.'s Action Energy program will send an expert to assess a company's energy use and to prepare an action plan for improving energy efficiency. The U.S. Department of Energy provides confidential assessment reports through its Industrial Assessment Centers (IAC) within 60 days of the visit to the industrial site. These reports contain suggestions for improvement. In addition, summary reports are published to promote replication of recommendations across the industry. The U.S. DOE's Office of Industrial Technologies (OIT) also provides industrial assessments to large scale companies.

Benchmarking. Benchmarking provides a means to compare the energy use within one company or plant to that of other similar facilities producing similar products. Benchmarking can compare plants, processes or systems. Systems such as compressed air systems can be benchmarked to evaluate energy efficiency, such as is done in Germany's REN Strom Program. The Canadian Industry Program for Energy Conservation (CIPEC) provides guides to benchmarking for industries, for example, the "Energy Consumption Benchmark Guide: Cement Clinker Production." Canada's Office of Energy Efficiency (OEE) develops benchmarks for energy efficiency of facilities in each sub-sector that is targeted. Norway has developed an extensive benchmarking program modeled after Canada's programs. Germany provides benchmarking services for companies involved in negotiated agreements. The Netherlands has the most extensive program of benchmarking. Benchmarks are used as part of negotiated agreements and supplied to all participating companies. Participating companies agree to become among the top $10 \%$ of the most energy efficient plants in the world or one of the three most efficient regions (regions defined as geographic areas with a production capacity similar to the Netherlands). In return, no additional governmental regulations aimed at energy conservation or $\mathrm{CO}_{2}$ emission reductions will be implemented (This exemption does not include EU-wide emissions trading.). Beginning in 2006, all companies that are not yet among the top 10\% (or top 3 regionally) will have to take all economically feasible energy conservation measures (defined as those measures that generate enough savings to cover the costs of borrowed capital).

Case Studies. Case studies or success stories are small brochures or reports about successful implementations of energy efficiency measures in industry. They may include energy savings, financial data and other benefits. Many countries use case studies as a part of their energy efficiency programs for industry: Australia, Canada, Japan, the Netherlands, Norway, Sweden, 
the U.K., the U.S. and the EU. Most case studies are distributed through a program's website, in annual reports or as information handout sheets to members of voluntary or negotiated agreements or other energy efficiency programs. In addition, some programs provide searchable databases of case studies and success stories. Examples of these databases include Australia's Sustainable Energy Development Authority (SEDA), who provides database access to all members of the Energy Smart Business Program, Canada's InfoSource, which includes both Canadian case studies and those contained in the IEA's CADDET database, and the U.K.'s Energy Efficiency Best Practice Programme (EEBPP). Also, Canada's OEE publishes success stories in its newsletter while Sweden's EKO Energy publishes success stories in the media. The OIT and Allied Partners in the U.S. provide case studies to industry.

Demonstration: Commercialized Technologies. Demonstrations consist of presentations of the implementation of energy efficiency technologies commercially available in an industrial environment where the technology has been implemented successfully. These demonstrations are held for others in the same or similar industries. Industrial energy efficiency programs generally sponsor demonstration projects. France's Agency for the Environment and Energy Efficiency (ADEME) sponsors demonstration projects for energy intensive companies. In this program, additional funding for energy efficiency projects is awarded to demonstration projects. Denmark, Japan, the Netherlands, Switzerland and the U.K. also have demonstration programs. The U.S. IOF and Inventions and Innovations (I\&I) programs support demonstrations but are limited in scope.

Demonstration: Emerging Technologies. Emerging technology demonstrations are exhibits of energy-efficient technologies that are commercially available but not yet found extensively in industry. Generally, governmental programs help fund these demonstrations. Canada's Technology Early Action Measures (TEAM) of the Climate Change Action Fund has a sole function of offering financial support to fund technology projects to reduce greenhouse gas (GHG) emissions. The EU's SAVE Program helps to organize and finance pilot projects carried out by public and private companies, existing community networks, or networks formed solely for this purpose. Several other countries have emerging technology demonstration programs: France (ADEME), Germany, the Netherlands, Sweden and the U.S. Sweden's demonstration projects are a part of their technology procurement program, which, in addition to subsidies and demonstrations, aids in the marketing of projects (see also financial or other assistance in Section 3.2). In addition, the U.S. DOE field tests emerging technologies developed by the IOF program to validate the energy, economic, productivity and environmental benefits of emerging technologies under real-use conditions.

Energy Awareness Promotion Materials for Companies. These informational or instructional materials are used to promote awareness of energy efficiency within companies, to help companies strategize on energy efficiency, and/or to present results of a project or projects completed by a company. As opposed to other high-level materials provided to energy managers (see, e.g., fact sheets, reports and guidebooks, tools and software), these materials are generally given to energy or other managers within a company to be distributed to each of their employees or placed in "common" areas where employees will see them. They may include documents, brochures, CDs, flyers, sign boards and tip-pages. They may contain materials that can easily be tailored and formatted to the needs of the company. SEDA of Australia provides a whole 
"Energy Smart" toolbox that contains many of these materials, as well as a number of tools (see also Tools and Software, below). SwissEnergy has a public library with energy efficiency materials available for companies and their employees. Other countries that send out communication materials to promote energy efficiency within companies are Canada, Denmark, France, Japan, Norway and Sweden. These materials are generally sent to a company directly and can be handed out to the employees, while some are sent to members of specific programs only.

Fact Sheets. Fact sheets or brochures, which are often available on-line, contain information on energy efficiency methods, technologies, processes, systems and programs, or provide results from demonstration projects or annual reports. Countries that use fact sheets as a part of their energy efficiency programs include Australia, Sweden Switzerland, the U.K., the U.S. and the EU.

Industry Profiles. Industry profiles contain a description of an industry or sector and statistics, experiences, and data on energy use and energy efficiency. Some also contain financial information, like the EU's Organisations for the Promotion of Energy Technologies (OPET) market studies and analyses. Often they are provided as a benefit to members, such as the energy efficiency indices provided in the Netherlands for companies involved in long term agreements (LTAs) and the sector-specific reports compiled by the Industrial Energy Efficiency Network (IEEN) of Norway and distributed to members. In Canada, CIPEC provides industry profiles as part of the annual report. The U.S. IOF program provides profiles for nine energy-intensive industries and the U.S. ENERGY STAR Program provides profiles as a part of their Energy Guides for "focus" partners.

Reports and Guidebooks. Reports or guidebooks can be a variety of informational texts that span specific to general information on energy efficiency and energy use in the industrial sector. Generally they detail the activities of an organization, help promote energy efficiency, advise companies on new technologies, methods or management, and/or give sectoral information. Examples include Australia's EEBP's Best Practice Guides, CIPEC's sector-wide energy efficiency guides with information on each sector (Canada), OPET's technology profiles (EU), BMU's annual German Environmental Report, New Energy and Industrial Technology Development Organization (NEDO)'s compilations of current international work (Japan), the Netherlands's annual reports for long term agreement members, IEEN's sector reports containing statistics, results and experiences within the sector (Norway), EKO Energy's education package on energy efficiency industrial purchasing (Sweden), CHP club guide books (U.K.) and ENERGY STAR's Energy Guides for entire industries, which include both process specific and utility energy efficiency measures for ENERGY STAR partners (U.S.).

Tools and Software. There exist a myriad of benchmarking, monitoring, modeling, optimization, reporting, training, data management and assessment tools, tutorials, directories and searchable indices and databases. Most are available online. For example, Australia's Greenhouse Challenge Program supplies systems to collect, monitor and manage emissions data, with emissions calculators and reporting templates. Australia's EEBP provides training modules and benchmarking tools. CIPEC of Canada offers InfoSearch, a searchable CD on available informational, training and planning materials on energy efficiency. Denmark supplies a similar 
system online. It also includes a $\mathrm{CO}_{2}$ calculator. The EU's Community Research and Development Information Service (CORDIS) website furnishes tools and assistance with proposal submissions. Likewise, Germany's Projektträger Jülich (PTJ) EASY computer programs help with proposal preparations and the Environmental Commissions of the German Chamber of Commerce provide the database of all available environmental assistance programs for industry. The Netherlands's Light Manufacturing Strategy offers Process Integration tools. Norway's Institute for Energy Technology (IFE) program supplies mathematical models and simulation software for plant optimization in petroleum, petrochemical and other industries. The U.K.'s EEBPP provides a profit calculator, EMMA - a multimedia energy management advisor, benchmarking tools and clip art images relating to energy efficiency. The U.S. provides many tools for assessing motors, pumps, compressed air systems, process heating and steam systems.

Verification and Validation. Verification and validation assistance for companies help to track and report energy use or GHG emissions reductions. Environment Canada provides independent verification on energy-efficient technologies. Canada's Climate Action Fund's TEAM provides funding for formal verification. France's AERES is in charge of the definition and validation of common measurement, calculation, and verification guidelines for industries participating in the negotiated agreements. Germany's Rheinisch-Westphalian Economic Research Institute (RWI) performs third party validation as a part of the negotiated agreements. Norway's IFE carries out testing of energy efficiency equipment for third parties and has an energy auditing laboratory for energy measurements in industry. The U.S. provides verification and validation as a part of the DOE's showcases and emerging technology demonstrations. Australia, the Netherlands and the EU also provide verification and validation services.

Visions and Roadmaps. Visions and roadmaps generally include energy efficiency planning in the form of energy management, target setting and action plans. Australia's EEBP provides technology roadmaps to define industries' visions and goals for technology development. CIPEC of Canada offers energy management planning and target setting materials, action plans and tracking and reporting for companies. CIPEC members receive access to ON-SITE, a source of qualified low cost technicians who help design and implement energy efficiency plans. The audit reports from Japan's ECC feature future measures for problem areas within the plant and a costbenefit analysis. As a part of the LTAs, companies in the Netherlands first set up an energy conservation plan. Novem (Netherlands Organization for Energy and Environment), the agency in charge of implementation, checks these plans and advises companies on them. EKO Energy of Sweden with the help of STEM develops and reviews action plans for companies. They include a comprehensive material flow analysis as well as a comparison of the company's environmental awareness and management to EMAS or ISO 14001 standards. The U.S.'s OIT in DOE outlines visions for the future and maps a plan for achieving goals for nine energy intensive industries. The U.S.'s ENERGY STAR Program for industry also provides energy management strategies and free consultation to its partners. 


\subsection{Delivery Mechanisms}

Conferences and Trade Shows. Conferences and trade shows can both be organized by energy efficiency organizations or simply attended by them for networking, training and disseminating information on energy efficiency to companies. In the past, IEEN of Norway, for example, went to industry fairs, whereas the DOE of the U.S. currently hosts Energy Fairs (Allied Partners of the U.S. also attend conferences of industrial associations). The conferences and trade shows can be either national or international in scope and include energy managers or other people from industry, suppliers and researchers. As a part of the negotiated agreements in industry, Australia's Greenhouse Challenge Programme members become part of a national network of Greenhouse Challenge Businesses, which have workshops and conferences. ManagEnergy of the EU and the U.S. EPA's ENERGY STAR Program for Industry host free online conferencing for virtual conferences for those for whom traveling is not possible. Germany's PTJ organizes roundtables on specific topics (for example, membrane technology) for industry, suppliers and researchers to discuss needs, opportunities and directions in a specific area. Other similar programs are found in Canada, France, Japan, the Netherlands and the U.K.

Customer Info Centers for Industry. Customer service centers include phone, web, e-mail, chat rooms, libraries and office-based centers for information dissemination and query services about energy efficiency. The EU's CORDIS website not only provides information but also helps to find partners for energy efficiency projects. It also supports the formation of Internet discussion groups; both open forums for all users and closed members-only forums. ManagEnergy (EU) also provides online chat rooms, discussion boards and partner searches. The EU has Innovation Relay Centers (IRC) that are staffed with experts who help match partners and aid in technology transfer. PTJ of Germany supplies representatives who help with the preparation of proposals of projects on energy efficiency. Deutsche Energie Agentur (DEnA)'s Energy Hotline is a toll free phone service on energy efficiency available to both companies and individuals. A similar helpline exists through Norway's Enova agency. Questions requiring additional help are addressed through onsite consultants. The Energy Conservation Center, Japan (ECC) and the IOF Clearinghouse (U.S.) provide an email counseling service on energy efficiency technology, policies and measures. The IOF Clearinghouse provides answers to questions as well as information on the IOF program resources. Action Energy's Helpline (U.K.) provides an email and phone service, as well as a network of consultants. AIST (Japan) affords a technical support and collaboration office at each of its sites to serve small and medium companies. NEDO (Japan) and SwissEnergy sponsor a public library. SwissEnergy also provides Advice Centers.

Directories. Directories are a collection of organizations, publications and programs involved in energy efficiency. Many are available online, like Australia's SEDA's "Energy Smart Allies Directory" which includes over 270 organizations that provide energy efficiency products and services. PTJ also supplies a web directory of programs available in Germany. OEE of Canada provides InfoSearch, a CD with contact information about and hyperlinks to about 175 organizations around the world (as well as another online directory for Canada only). 
Financial and other Assistance with Innovative Technologies. Assistance with new technologies is provided in the form of subsidies and low interest loans or bonds for innovative R\&D, energy management programs, workshops and training, evaluations and equipment, and in rare cases, for marketing. The goal of these programs is to promote energy efficiency until they achieve market acceptance level. Many organizations provide financial assistance. Some provide subsidies or loans to small innovative companies like Australia's Renewable Energy Equity Fund (REEF). Most, however, provide grants or loans for companies engaging in energy efficiency projects, generally from 25 to 100\%. Numerous examples of these lending or subsidizing programs exist in Australia, Canada, Denmark, the EU, France, Germany, Japan, the Netherlands, Norway, Sweden, Switzerland, the U.K. and the U.S. Other projects contribute to viability studies, like the Canadian Initiative for International Technology Transfer (CIITT). Some programs have project management organizations that assist companies in submitting their proposals for funds, like Germany's PTJ and the Netherlands's MAP 2000 Program. Sweden's NUTEK Technology Procurement Program not only provides funding but also helps in entire the procurement procedure. NUTEK assembles potential buyers of a particular product with energy experts to draft energy efficiency performance parameters, together with other requirements for the equipment, process or system to be developed. The customers make functional demands in return for a promise to buy if conditions are met. Suppliers then compete on design and price. NUTEK also provides marketing assistance for the new product.

Industry Associations. Industry associations themselves can serve as excellent delivery mechanisms for promoting energy efficiency. Agreements can be made both with individual industries (see negotiated agreements) or with industrial associations such as Environment Australia's agreements, Keidanren's Voluntary Agreements (Japan), the Netherlands's Light Manufacturing Strategy and the U.K.'s Climate Change Agreements. In addition, some energy efficiency programs host networking and training events with government and industrial associations. ADEME of France partners with professional associations and consultancies for training, information dissemination and communication. The Netherlands's Cleaner Production Program and the Allied Partners Program in the U.S. perform similar tasks.

Industry Experts. Industry experts provide expertise on energy efficiency technologies, systems and energy management. They sometimes perform or assist with system and plant evaluations. Some negotiated agreement programs provide technical expertise as a benefit, like the Australian Greenhouse Challenge Programme. Some programs that provide funding for energy efficiency projects also provide expertise, such as Australia's REEF and Japan's Energy Conservation Programme. Accredited engineers or energy experts are available to perform audits as a part of the Enterprise Energy Audit Programme (EEAP) of Australia and Norway's Enova. Denmark's utilities, the EU's Information Relay Centres (IRC) and OPET, Canada's Voluntary Challenge and Registry Programme and its Industrial Research Assistance Program (IRAP) and the U.S.'s Allied Partners Program provide experts for advice on technical issues. The U.K.'s Action Energy Program, in conjunction with the Energy Savings Trust, and Envirowise, as well as the U.S. EPA's ENERGY STAR program maintain a network of advisors that has been set up to help companies at a local level. These experts work directly with businesses and may include on site visits. 
Industry and/or Vendor Partnerships. Partnerships with industry or vendors help expand and/or promote energy efficiency. Generally, these partnerships provide products and services to industry without requirements from industry (see negotiated agreements, below, for these types of contracts). SEDA's Energy Smart Business Program gives Australian businesses numerous energy efficiency products and services such as seminars, newsletters and promotional materials. Some programs such as CANMET and C3 of Canada work together with industry to develop opportunities for energy efficiency and promote implementation. The U.S. IOF, ENERGY STAR and "Challenge" Programs work directly with industry and provide them with information, training and tools. DEnA of Germany and the Industrial Energy Efficiency Analysis Model and Program of Norway work with industry to run pilot projects of new technologies.

Negotiated Agreements ${ }^{2}$. Negotiated agreements provide the framework for reporting and undertaking actions to increase energy efficiency. Agreements between government and industry are often voluntary but involve repercussions if targets are unmet. Negotiated agreements made between industry and government with a set target are the most effective type of voluntary agreement. ${ }^{3}$ As a part of negotiated agreements, companies or industry organizations set targets for reducing energy use or greenhouse gas emissions in exchange for certain types of government support including financial incentives, information dissemination, rewards, publicity, and relief from burdensome environmental or tax obligations. Progress made toward the negotiated targets is closely monitored and reported publicly, typically on an annual basis.

In Australia's Greenhouse Challenge Program, information, technical expertise, systems for data collection and reporting are provided to companies that enter into the agreements and who annually identify, monitor, manage, report and forecast expected abatement of GHG emissions.

The Danish Agreements on Industrial Energy Efficiency are based on the imposition of a mandatory $\mathrm{CO}_{2}$ emissions tax where the level of taxation depends on the purpose of the energy use, the type of energy used, and whether an agreement exists between the company and the Danish Energy Agency. The agreements, which are made by an individual company or an association of companies with the Energy Agency, are made for a period of three years in order to qualify for a lower $\mathrm{CO}_{2}$ tax rate. Under the agreements, the companies are required to implement all "profitable" energy savings projects that are defined as projects with payback periods of up to four years as identified in an energy audit. Authorized energy consultants or company staffs perform the energy audits that must be verified by an independent certified organization. In addition, companies must introduce energy management and motivate staff to ensure investments in new equipment will be energy efficient. Subsidies are provided for up to $30 \%$ of the cost of these investments in energy-efficient projects.

France's Ministry for the Environment negotiated agreements for $\mathrm{CO}_{2}$ reduction with five industrial sectors (aluminum, steel, fat and magnesia lime, cement, packaging glass) in 1996 and 1997. These relatively weak agreements are being superceded by new agreements under AERES (Association des Entreprises pour la Reduction de l'Effet de Serre: the French Association of Companies for the Reduction of the Greenhouse Effect). These agreements include 18 major

\footnotetext{
${ }^{2}$ Other partnerships are described under industry and/or vendor partnerships and industry organizations, above.

3 UNFCCC (2002). "Good Practices" In Policies and Measures Among Parties Included in Annex I to the Convention in their Third National Communications - Report by the Secretariat FCC/SBSTA/2002/INF.13
} 
companies operating in France that have committed to reducing their GHG emissions within a more rigorous negotiated agreement scheme that includes strict measurement, reporting, and verification, a registry, emissions trading, compliance mechanisms, and penalty fees for noncompliance.

Under the 1996 Declaration of German Industry on Global Warming Prevention, the German government withdrew plans to introduce a waste heat regulation and promised participating industries an exemption from a possible European energy tax. ${ }^{4}$ With the 2000 "Agreement on Climate Protection between the Government of the Federal Republic of Germany and German Business," the government promised not to take any initiative to achieve the climate protection targets through command and control measures and decided against introducing a binding energy audit. Under this agreement, there is regular implementation monitoring through an independent scientific institute and the Federal Government, represented by the Federal Ministry of Economics and the Federal Ministry for the Environment, contributing 50\% towards financing climate protection monitoring. ${ }^{5}$

Under Japan's Keidanren Voluntary Action Plan, industries voluntarily establish quantitative targets for adopted measures in an Action Plan. The Action Plan is made public and reviewed. Japan also provides low interest loans and bonds for businesses that voluntarily minimize energy use.

The Netherlands has an extensive program of long term agreements with industry. LTAs are signed by sector associations, individual firms in the sector, the Ministry of Economic Affairs and NOVEM, the implementing agency. Companies receive an agreement from the government not to impose further regulations on energy efficiency for their industry, tax abatement, financial assistance including subsidies and a quantified energy efficiency index for the sector involved. LTAs are legally binding in the Netherlands. As a part of a new negotiated agreement for energy intensive industries, companies in these sectors in the Netherlands may also participate in benchmarking whereby they agree to become among the best in the world in exchange for decreased future regulations (see benchmarking, Section 3.1).

The Swiss Energy Action Plan (formerly Energy 2000) provides energy management courses and motivational campaigns for the companies involved in negotiated agreements. Its strength is that it brings together all levels of government, utilities, supply companies industry, consumer groups and environmental organizations to form the agreements and interest groups to discuss controversial themes. Energie-Agentur der Wirtschaft (EnAW) provides possible exemption from the $\mathrm{CO}_{2}$ tax under certain conditions (like ambitious $\mathrm{CO}_{2}$ reductions).

The U.K.'s Climate Change Agreements grant an $80 \%$ levy discount for companies that agree to and meet carbon savings targets. The companies involved in the Making a Corporate Commitment Campaigns (MACC and MACC2) commit to reduce GHG emissions and publicly declare their commitment to achieve targets. All companies report annually on progress.

\footnotetext{
${ }^{4}$ Ramesohl, S., and Kristof, K. (2001). "The Declaration of German Industry on Global Warming Prevention - A Dynamic Analysis of Current Performance and Future Prospects for Development," Journal of Cleaner Production. 5 Anon. (2000). Agreement on Climate Protection between the Government of the Federal Republic of Germany and German Business, September 11, 2000.
} 
In addition to negotiated agreements, some countries have less-strict voluntary agreements whose targets are set only by the industry (and not negotiated with government or another third party organization) and generally do not have repercussions if targets are unmet. Canada, Sweden and the U.S. all have these types of agreement programs.

The Canadian Industry Program for Energy Conservation (CIPEC) is a completely voluntary program in which collective targets are set for each industrial sector. There are 21 sector tasks forces representing 31 trade associations and about 3000 companies. Under the program, the sector tasks forces identify energy efficiency opportunities, review and address the barriers associated with these opportunities, and develop and implement strategies for realization of the opportunities. The program includes annual measuring and reporting by industry participants.

Sweden's EKO-Energi (aka Eco-Energy) Programme is a pilot program that began in 1994. Agreements were signed with 42 energy-intensive companies. The government provided free energy audits by an external auditor, free environmental audits to help with EMAS or ISO 14001 certification, information related to energy-efficiency procurement, and promotional activities such as awards and the use of the EKO-Energi logo. The overall target of the program when started was to reduce $\mathrm{CO}_{2}$ emissions by $20 \%$ in 2000 compared to 1990 levels.

The U.S.'s Climate VISION is another completely voluntary program launched by the Department of Energy. It works primarily with industry associations. Business associations representing twelve industry sectors have become program partners with the federal government, which entails issuing a letter of intent to meet specific targets for reducing GHG emissions intensity. In return, DOE and EPA agencies provide tools, training, information and industrial assessments to industry.

Newsletters. Newsletters that contain periodic distribution of information on energy efficiency are distributed by several programs in Australia, Canada, Denmark, France, Germany, Japan, Norway, Switzerland, the U.K. and the U.S. These newsletters contain information on energy efficiency products and systems, case studies and calendars of events. Many are available online, some are distributed to the public or to program members. Some newsletters are used to showcase companies with exceptional energy efficiency performance or measures like Canada's VCR's "Champion News". The Australian Energy News has a readership of 12,000 with $90 \%$ of its readers believing the information to be useful for improving energy efficiency.

Public Disclosure/Fines. Public disclosure involves providing information to the public regarding a facility or association's compliance with the terms of a negotiated agreement. France's AERES negotiated agreement scheme includes penalties for participating companies that are found to be in non-compliance at the two review points in 2004 and 2007. Japan's Designated Energy Management Factories are required to hire a certified energy manager and to report the status of their energy consumption every year to the Ministry of Economy, Trade and Industry (METI) and the Ministry responsible for their sector. Any operator who fails to do these, have their case publicized and are subject to a penalty. The Netherlands's LTAs report annual progress publicly, providing information regarding each sector's progress toward their targets. 
Public Recognition. Public recognition provides positive publicity related to energy efficiency or GHG emission reduction achievements and can consist of logos, awards or articles in the newspapers or newsletters. Public recognition is often used in conjunction with negotiated agreements. SEDA (Australia) uses awards, trade publications and local media to promote its award winners. Canada's VCR program recognizes achievers through Leadership Awards. Other participants select award winners. EMAS awards are given to companies in Germany that have undergone an eco-audit. ECC holds contests and issues awards for designated energy management factories. Japan's New Energy Award is given at an award ceremony to a new energy equipment or system, which is then publicized on the New Energy Foundation (NEF) website. Sweden's EKO Energy recognizes a company of the year at a public ceremony held with the media, much like the EPA's annual ENERGY STAR award for industry.

Regional Offices. Regional offices can be set up locally for networking and assistance with energy efficiency. These offices can provide a number of the products and services listed in Section 3.1, and many other delivery mechanisms listed in this section. For example, CANMET Energy Technology Centers provide information and expertise, laboratory services, funding programs, publications, and software modeling and analysis tools (Canada). The EU's OPET centers provide both public and private enterprises with expertise in new and innovative energy technologies. They supply training, evaluations, exhibitions and partner searches. ADEME offices provide engineers to support demonstration projects (France). The U.K.'s Department of Environment, Food and Rural Affairs has regional offices through the country that administer various grants and schemes. The U.S. DOE has regional offices through the States Industries of the Future Program and other programs. In addition, there exist State Energy Offices in the U.S. Germany, Japan and the Netherlands also have regional offices with the same functions.

Showcases. Conferences, training, workshops, exhibits and demonstrations highlight a particular technology or group of technologies. The U.S. has extensive experience this field with its Envirowise showcases and its DOE tools, training, workshops, seminars, mini-conferences and technology exhibits that highlight certain technologies (like high efficiency motors) for industry. Many of the functions of highlighting a specific technology are carried out through other delivery mechanisms or in other products, such as tools, demonstrations, training, case studies, conferences, audits, reports and other communication materials. See those sections (within Sections 3.1 and 3.2) for more related information.

Subsidized Assessments. Subsidized assessments encompass audits of the energy efficiency of a facility that are partially or entirely funded by the government. Almost all the countries analyzed have some sort of audit program. Funding varies from 40 to $100 \%$ of the cost of the audit and many times audits are granted as a benefit for participation in voluntary agreements, such as in Denmark, the Netherlands and Sweden. Audit reports (see Section 3.1) are usually provided following the site visit. Other tools, informational materials and other energy efficiency products are often furnished during the audit. Some programs, like Australia's EEAP or Norway's IEEN and Enova agencies provide a directory or network of accredited auditors. Germany provides a consultancy service for energy conservation subsidized up to $40 \%$. The U.S. has plant-wide assessments and the IAC Program for small and medium-sized enterprises (SME's). 
Tax Abatement for Energy Efficiency Technologies. For countries with energy and/or $\mathrm{CO}_{2}$ levies, tax exemptions or reductions can be given for installing energy efficiency technologies, reducing overall emissions and/or saving energy. Tax rebates or shorter depreciation times can also be granted for energy efficient products, measures or implementation of renewable energy sources. Abatement is often granted as a part of negotiated agreements, as in Denmark's Green Tax Package or Japan's negotiated agreements with industry. Some tax abatement schemes phase in taxes to allow investments over time, such a Germany's taxes for manufacturing and electricity or Denmark's Green Tax Package. Denmark and the UK also recycle taxes back into the affected sector of the economy. Switzerland offers tax breaks to companies under certain conditions, such as ambitious $\mathrm{CO}_{2}$ reductions. Germany allows full exemption from petroleum and electricity taxes for cogeneration systems (also known as combined heat and power or CHP) with a utilization rate of $70 \%$ or more. Japan and the U.K. also grant tax breaks for CHP projects. The Netherlands provides tax incentives for selected energy efficiency equipment under its Energy Investment Tax Deduction (EIA). Canada, Norway and Sweden also grant some sort of tax abatement for energy efficiency. A few states in the U.S. provide tax incentives for specific technologies or energy efficiency, but no programs exist at the federal level at this time.

Trade Journals. Industry or trade journals can act as a mechanism to deliver public recognition, for promotion and for information dissemination to businesses and suppliers. For example, Australia publicizes its Energy Smart Green Globe Award Winners in the trade journals. Canada's CIPEC regularly features articles in industry's journals. NOVEM (the Netherlands) also contributes submissions to national and international trade journals. ADEME of France uses the trade journals to publicize its R\&D RFPs to solicit energy efficiency projects. The Allied Partners Program in the U.S. also uses trade journals for program promotion.

Training. Training can be made available in many forms, including seminars, workshops, courses, pamphlets, videos, CDs or other instructional materials and methods about energy efficiency. Almost every country has implemented some form of training program for energy efficiency.

Canada's CIPEC hosts a series of workshops called Dollars to \$ense that focus on energy management and efficiency. Canada's OEE publicizes its workshops in its InfoSearch CD that is distributed to industry. The EU's ManagEnergy Program hosts "study tours" that visit installation sites for firsthand training. ManagEnergy also hosts many workshops, training sessions, coaching seminars and online events that are free and virtual, avoiding the need to travel to a site to participate. France's ADEME initiates training events but the actual events are carried out by professional and technical organizations such as chambers of commerce and industry, technical centers and engineering associations. ADEME also partners with professional organizations and consultancies to train trainers for small and medium sized businesses and industries. PTJ of Germany organizes roundtables, seminars and workshops that bring together not only industry but also suppliers and researchers to discuss future R\&D needs, opportunities and directions for a specific area. Japan's ECC offers correspondence courses and short-term courses for future energy managers, and continued education for energy managers. In the past, IEEN of Norway held annual networking meeting for its auditing consultants. It also offered an internet-based course on energy management. Norway's Enova agency now provides programs for the development of teaching materials and learning concepts, for continuing education in 
energy for technical personnel and engineers (accredited) and for training of maintenance personnel in commercial buildings and industry. STEM runs courses on purchasing equipment using life cycle cost analyses instead of just payback or other methods that do not take into account energy efficiency. The U.K.'s CHP club provides site-specific advice for companies. The U.S. DOE provides a number of courses on best practices in steam, motors, pumps, compressed air and insulation.

Websites. Web pages contain tools, information and links on energy efficiency programs, policies, technologies and available financial and other assistance. Most programs have websites that provide some or all of these tools. Some programs, like the EU's CORDIS and ManagEnergy have online conferencing abilities. Many supply newsletters and case studies. Some serve as customer service centers (see Section 3.1). Others, like Sweden's STEM include a calendar of energy events online. The EU's CORDIS website serves as a one-stop-shop for access to information on available support programs, reports, databases and information. It provides tools to submit proposals and has a partner-finding search. It also supports the formation of Internet discussion groups. ManagEnergy has similar tools, including links to over 400 energy agencies and events and partner searching capabilities. PTJ of Germany offers a similar one-stop-shop describing all energy efficiency programs available in Germany. It also hosts a computer tool that assists in the development of project proposals, offering easy access to all forms in one place. The Environmental Commission of the German Chamber of Commerce (an independent industry and business organization) also hosts a database with all environmental assistance programs available to German industry.

Working Groups. Working groups or networks promote collaboration and information exchange and help to develop roadmaps. Several types of networking groups exist that perform different functions. Canada's CIPEC and the U.S. EPA's ENERGY STAR program provide networking events and meetings to help energy managers learn about energy efficiency and as a way for companies to share noncompetitive information. CIPEC also has an executive board that consists of senior executives from mining and manufacturing companies who work with the VCR voluntary program help to increase participation in the program. ManagEnergy (EU) working groups promote collaboration among agencies. The working group of the IPPC prepares the best available technologies document. Japan has an Energy Managers' Society managed by the EEJC. The consultative groups of the LTAs in the Netherlands meet annually to discuss aggregate results of energy monitoring in their sector. NOVEM, the agency in charge of the LTAs, also organizes meetings for the members to discuss specific technological challenges for their particular sector. Energy 2000 and Swiss Energy form interest groups for discussions of controversial themes related to energy. Envirowise hosts waste minimization clubs where companies share ideas. The U.S. DOE's OIT Vision Teams work with one of the nine Industries of the Future to develop research and technologies for their industry. 


\section{Summary and Conclusions}

This compilation of industrial sector energy efficiency products, services and delivery mechanisms demonstrates that there are a large number of such activities found in the industrialized countries that were surveyed. We identified twelve types of products and services and nineteen delivery mechanisms. Every country employed a variety of both in an effort to improve domestic industrial energy efficiency. The most popular products and services included case studies, reports and guidebooks, energy awareness promotional materials, tools and software and verification and validation services. The most widely used delivery mechanisms were customer information centers, financial and other assistance, negotiated agreements, newsletters, subsidized assessments, tax abatement for energy-efficient technologies, training, conferences and trade shows and websites.

Overall, we found that the United States has a large variety of programs and offers industry a number of supporting programs including the EPA ENERGY STAR and the Allied Partners Programs, funding and technical assistance for projects through its Inventions and Innovations, fully or partially funded assessments for a range of facilities through the BestPractices and Industrial Assessment Center Programs, and a variety of tools, case studies, fact sheets, reports and guidebooks through its Office of Industrial Technologies Programs like Industries of the Future and NICE ${ }^{3}$.

The products and services found in other industrialized countries that are not currently used in the U.S. are benchmarking programs, demonstration of commercialized technologies, and provision of energy awareness promotion materials to companies. Though some performance indicators are being developed in the U.S. by the EPA's ENERGY STAR Program, benchmarking has not generally been a tool used to track, monitor or compare energy use in the U.S. industry or within companies, though it has been proven to be useful in countries like Canada, Norway, the Netherlands and the U.K.

The delivery mechanisms found in other industrialized countries that are not employed in the U.S. include negotiated agreements, public disclosure and national-level tax abatement for energy-efficient technologies. Although the U.S. is beginning voluntary programs with industry, the targets, if any, are generally set by the industry and lack real motivation (like tax incentives or low interest loans) for energy efficiency improvement or repercussions for compliance failure. More successful programs, like those found in Australia, Denmark, France, Germany, Japan, the Netherlands, Norway, Switzerland and the U.K., have some sort of reward program applied when the companies or associations have met their targets or disciplinary action or tax levied when companies have not met their targets or choose not to participate in the negotiated agreements. In the absence of an energy tax or $\mathrm{CO}_{2}$ tax, abatement schemes in the U.S. will be limited to tax credits or reduced depreciation times for energy-efficient products or systems. These abatement schemes are currently only present in selected states in the U.S. Country-wide tax abatement programs have been implemented in Canada, Denmark, Germany (for cogeneration), Japan, the Netherlands, Norway, Switzerland, Sweden and the U.K. 


\section{Acknowledgements}

This work was supported by the Industrial Technologies Program, Office of Energy Efficiency and Renewable Energy, U.S. Department of Energy under Contract No. DE-AC03-76SF00098.

We acknowledge many people who helped in the compilation of this report. We thank Tim McIntosh for his comments on Canada, Meinrad Buerer for his comments on France, Barbara Schlomann and Wolfgang Eichhammer for their comments on Germany, Hiroki Kudo for his comments on Japan, Reinier Gerrits for his comments on the Netherlands, Hans Even Helgerud for his comments on Norway, Lars Nilsson for his comments on Sweden and further contacts in industry throughout the EU, Thomas Burki for his comments on Switzerland, Peter Mallaburn for his visit and insight on the programs in the U.K., and Ed Vine of LBNL for his overall review of the report.

Despite all their efforts, any remaining errors are the responsibility of the authors. The views expressed in this paper do not necessarily reflect those of the U.S. Department of Energy or the U.S. Government. 


\section{Appendices}

Australia

Canada

Denmark

European Union

France

Germany

Japan

Netherlands

Norway

Sweden

Switzerland

United Kingdom

United States 


\section{Australia}

\section{Country Goals}

Australia joined the UN Framework Convention on Climate Change in June 1992 and ratified it in December 1992. Australia's target is to reduce GHG emissions growth from $28 \%$ to $18 \%$ (excluding land use change), or $39 \mathrm{Mt}$ (from 494 to $455 \mathrm{Mt}$ ) emissions by 2010.

\section{Main agencies involved in energy}

Australian Greenhouse Office (AGO) [1] under the responsibility of the Ministerial Council on Greenhouse (Minister for the Environment and Heritage [2], Minister for Industry, Tourism and Resources [3] and the Minister for Agriculture, Fisheries and Forestry) is responsible for the coordination of domestic climate change policy and the delivery to Commonwealth Governments of A \$180 million (equivalent to \$100 million 2002 US) climate change package. Many AGO programs are managed through local governments.

Environment Australia/Department of the Environment and Heritage [2]

\section{Contacts:}

Minister: The Hon Dr David Kemp, MP

Secretary: Roger Beale

Phone: +6126274 1111

Department of Industry, Tourism and Resources [3]

Ministerial Council on Mineral and Petroleum Resources [4]

Ministerial Council on Energy, established June 2001 [5].

Australian Department of Foreign Affairs and Trade [6]

Of the Commonwealth, State and Territory Governments, local governments (state and territory) have responsibility for implementing planning policies and regulations which impact energy use and efficiency at local levels:

New South Wales_Environment Protection Authority [7]

\section{Contact:}

Minister: The Hon Robert Debus MP

Phone: +61 299955000

Queensland-Environmental Protection Agency [8]

Contact:

Minister: The Hon Dean MacMillan Wells

Phone: (07) 32277111

South Australia_-Department for Environment and Heritage [9]

\section{Contact:}

Minister: The Hon. Iain Evans MP

Phone: +61 882049000 (Switchboard)

South Australia-Environment Protection Agency [10]

\section{Contact:}


Phone: +61 882042004

Government Offices: 1800623445 (within Australia)

Tasmania—Department of Primary Industries, Water and Environment [11]

Contact:

Phone: +61362338011

Victoria—Department of Natural Resources and Environment [12]

Contact:

Phone: +61 396378000

Victoria—Environment Protection Authority [13]

Contact:

Phone: +61 396952700

Western Australia—Department of Environmental Protection [14]

Contact:

Phone: +61 892227000

\section{Relevant documents (general)}

National Greenhouse Strategy (NGS) (formerly the National Greenhouse Response Strategy, NGRS) is the main framework for response to GHG, a major policy initiative of the Commonwealth, State and Territory governments.

Measures for a Better Environment, A \$400 million (equivalent to \$225 million 2002 US) for a four-year GHG Abatement Programme (GGAP) begun in 2000.

\section{Programs, agencies}

\section{The Australian Greenhouse office- Greenhouse Challenge Programme [1]}

Description: Joint voluntary initiative between the Commonwealth Government and industry. The Greenhouse Challenge Programme will be expanded to include 100s of smaller companies through the Greenhouse Allies Programme. Identify, monitor, manage and report GHG emissions.

Goal: 500 large and medium-sized companies by 2000 and 1,000 by 2005 .

Achievements: Almost total emissions coverage in many energy intensive sectors (electricity generation, oil and gas extraction) and good coverage in a number of manufacturing sub-sectors (machinery, metals, iron and steel, aluminum and cement). $23.5 \mathrm{Mt} \mathrm{CO}_{2}$ abatement is achieved annually; $16 \%$ more than what would have occurred without program.

Products and Services: Program provides a framework for undertaking and reporting on actions to abate emissions. Workbooks and information are provided to members. Technical expertise on identifying, monitoring and forecasting greenhouse gas emissions, as well as the internal systems and structures to collect emissions data, monitor and manage it are also provided. Web-based tools like emissions calculators and reporting templates are available. Members have access to 
the Greenhouse Challenge Members' Logo to use on products and corporate information. The Greenhouse Challenge itself also promotes the achievements of the program, building public awareness and recognition for all members.

Delivery Mechanisms: This voluntary partnership with industry provides a website, workbooks and information on energy efficiency/best practices to disseminate information. Once joined, members also become part of a national network of Greenhouse Challenge businesses, with workshops and conferences for networking amongst themselves. Challenge newsletter is distributed to all members and to wider community to encourage involvement. The Greenhouse Challenge works with firms that are Australia's leaders in emission management and control. The Challenge Programme showcases these greenhouse leaders through case studies, the newsletter, conferences and annual program reports.

\section{The Australian Greenhouse office- Greenhouse gas abatement program (GGAP) [15]}

Description: The GGAP is a major Commonwealth Government initiative to assist Australia in meeting its commitments under the Kyoto Protocol. A \$400 million (\$200 million August 2002 US) has been allocated to the Program. GGAP is targeting opportunities for large-scale, costeffective and sustained abatement across the economy. GGAP will only support projects that will result in quantifiable and additional abatement not expected to occur in the absence of GGAP funding. Priority will be given to projects that will deliver abatement exceeding 250,000 tonnes of $\mathrm{CO}_{2}$ equivalents annually.

Goal: To reduce Australia's net greenhouse gas emissions by supporting activities that are likely to result in substantial emission reductions or substantial sink enhancement, particularly in the first commitment period under the Kyoto Protocol (2008-2012).

Achievements: Applications for the first investment round closed on September 5, 2000. The Australian Greenhouse Office received 107 applications. More information on successes can be found on the website (including, for example, projects on cogeneration, renewables, waste coal mine gas reuse and turbine replacement) [15].

Products and Services: Money for emissions reduction projects.

Delivery Mechanisms: Website.

\section{Renewable Energy Equity Fund (REEF) [16]}

Description: Approximately A \$30 million (equivalent to \$16 million August 2002 US) will be provided over 10 years (A $\$ 20$ million from the Australian Greenhouse Office (AGO) and A \$10 million from private sources). REEF became effective in 1999. REEF provides venture capital funds to small, innovative companies for the development of renewable technologies. Also provides technical support for most promising projects.

Goal: Assist small innovative companies in renewable technologies

Products and Services: Venture capital and managerial advice for small renewable energy companies. 
Delivery Mechanisms: Website [16], fact sheet and article in the AGO newsletter.

4. Energy Efficiency Best Practice Programme (EEBP) [17]

Description: Began mid 1998. The government has allocated A $\$ 10.3$ million (equivalent to $\$ 5.8$ million 2002 US) over a 5-year period. \$2.2 million (\$1.2 million August 2002 US) is allotted for 2002-03. EEBP uses the tools and goals of benchmarking and best practice in both sector and cross-sector work in areas identified as having opportunities for cost-effective improvements in energy efficiency.

Achievements: Sectors involved include bread baking, vehicle fleet management, aluminum, beverage and containers manufacturing, wine making, dairy processing, resource processing and pulp and paper.

Products and Services: EEBP provides a range of promotional and advisory materials, training modules, information dissemination and benchmarking tools. Cross-sector activities include development of products relating to motors, energy performance contracting and energy management facilitation. Specific products include best practice guides, online software, case studies, newsletters and information sheets.

Delivery Mechanisms: Mechanisms include industry partnerships, workshops, tailored EEBP training and training modules for involved (partnered) industries and the Energy Best Practice newsletter (also available online [17]). Technology roadmaps help industries define visions and goals for technology development.

5. Environment Australia's Business of Sustainable Development Program

Description: Actions to improve the eco-efficiency of Australian industry.

Delivery Mechanisms: Voluntary agreements are being developed with industry associations. Agreements promote, demonstrate and monitor improved eco-efficiency practices that have been signed with various departments in the federal government.

\section{Sustainable Energy Development Authority (SEDA) (New South Wales) [18]}

Description: Begun August 1996, SEDA is an agency created by the New South Wales Government to reduce the level of greenhouse gas emissions in the state by promoting investment in the commercialization and use of sustainable energy technologies.

Products and Services: SEDA provides an Energy Smart Toolbox, a step-by-step guide to effective and profitable energy management, including a combination of organizational and technical tools: an energy savings manual, an energy management guide, an interactive $\mathrm{CD}$ with calculators and a greenhouse tutorial and a directory of energy efficient service and product provider. SEDA also provides compressed air and lighting calculators, which calculate energy savings from energy efficiency measures, as well as a financial calculator that calculates monetary savings from energy efficiency measures. SEDA also invests in cogeneration projects; it has invested more than $\mathrm{A} \$ 1.5$ million ( $\$ 800,000$ August 2002 US) over the past four years to 
help organizations in New South Wales to use cogeneration in their buildings and industrial sites.

Delivery Mechanisms: Website [18] including energy saving tips and calculators (see above); library of resources on energy efficiency (as well as global warming and sustainability information); "The Energy Smart Allies Directory" which includes over 270 organizations who provide energy efficient products and services.

\section{SEDA'S Energy Smart Business Program [19]}

Description: SEDA started the Energy Smart Business Program in 1997 in New South Wales. The program is a partnership with businesses to focus on energy efficiency.

Achievements: 170 businesses in NSW are now saving over A $\$ 12.9$ million (\$6.8 million August 2002 US) each year.

Products and Services: Members receive technical advice, assistance with verification of savings, exclusive technical seminars, SEDA's Energy Smart Business logo to use on marketing materials, recognition amongst peers and industry, access to database of energy efficiency case studies, discounts on special energy efficiency products and services, communication materials for staff awareness on energy efficiency and greenhouse gas emissions and publicity of achievements.

Delivery Mechanisms: Website [19], seminars, regular newsletters on energy efficiency, publicity, marketing logo and communication materials for staff awareness on energy efficiency and greenhouse gas emissions. All Energy Smart Business Partners are required to report their energy savings. In return, they are in the running to win a bronze, silver or gold Energy Smart Green Globe Award. Award winners are prominently featured in trade publications and local media [18].

\section{The Sustainable Energy Authority (Victoria) [20]}

Description: The Sustainable Energy Authority is a Victorian Government agency established to contribute to the reduction of greenhouse gases and to support and facilitate the development and use of sustainable energy options to achieve environmental and economic benefits for the Victorian community.

Products and Services: "Info sheets" on compressed air, boilers, variable speed drives, etc. and case studies.

Delivery Mechanisms: Website [20]

\section{The Enterprise Energy Audit Programme (EEAP)}

Description: Operated 1991 to 1997 by the Commonwealth Government. This scheme reimbursed $50 \%$ of the cost of an energy audit up to A $\$ 5,000$ (equivalent to $\$ 28002002$ US). The program demanded nearly $\$ 4$ million (US) over 7 years. Improvements to lighting systems were recommended in almost three out of every four audits and were the most common measure. The next most popular measures were air conditioning (45 percent of audits), water heating (35 percent) and industrial equipment (34 percent). 
Achievements: Approximately 1,200 firms participated throughout the life of the program. The average firm spent about A $\$ 400,000$ (\$200,000 August 2002 US) per year on energy, which represented about $4 \%$ of its operating costs. 854 enterprises indicated the median annual potential gains per enterprise were about $1,000 \mathrm{GJ}$ (roughly 11\%) of energy use, a reduction of 223 tonnes of $\mathrm{CO}_{2}$ per year. On average, 5.8 recommendations were made per firm and 4.7 $(81 \%)$ of these measures were actually installed.

Products and Services: Reimbursement of 50\% of the price of an energy audit, up to A $\$ 5000$ (equivalent to $\$ 28002002$ US). The energy saving tool put out by The Environmental Management Programme: A Business Approach, helps companies quantify the energy savings through energy efficiency.

Delivery Mechanisms: The Environmental Management Programme: A Business Approach helps companies quantify energy savings. The Institution of Engineers who was commissioned by The Commonwealth Government manages a registry of accredited energy auditors. The audits themselves proved to be delivery mechanisms, leading to increased energy efficiency awareness and being the springboards for other energy investigations.

\section{Australian Energy News (AEN) [16]}

Description: Quarterly magazine published on behalf of the former Department of Industry, Science and Resources (now called the Department of Industry, Tourism and Resources) to provide up to date info on energy policy, programs and practices. AEN was published regularly from 1986 to June 24, 2002 (previously called Australian Energy Management News). Articles obtained from Commonwealth and State Governments, public agencies, energy utilities, private industry, industry associations, and energy consultants and researchers.

Goal: To promote innovation and greater efficiency in the energy sector and in energy end-use.

Achievements: 12,000 readership. Of these, nine out of ten believe it provided information they needed to assist in using energy more efficiently.

Products and Services: Articles on energy efficiency.

Delivery Mechanisms: Newsletter.

\section{Energy Utilities-Demand Management and Energy Efficiency}

Description: Energy utilities help companies to implement energy management strategies, develop and distribute videos and pamphlets dealing with climate change, develop energy conservation promotional campaigns, conducted billing energy management seminars and provide consumer advice and conservation leaflets.

Goal: Encourage energy conservation/efficiency and develop energy management strategies. 
Products and services: Videos and pamphlets dealing with climate change, energy conservation promotional campaigns, billing energy management seminars and consumer advice and conservation leaflets put out by the utilities.

Delivery Mechanisms: Seminars, pamphlets and videos.

\section{References:}

1. Australian Greenhouse Office (AGO) website: http://www.greenhouse.gov.au

2. Environment Australia/Department of the Environment and Heritage website: http://www.ea.gov.au

3. Department of Industry, Tourism and Resources website: www.isr.gov.au/netenergy

4. Ministerial Council on Mineral and Petroleum Resources website: http://www.industry.gov.au/content/controlfiles/display_details.cfm?ObjectID=1B3956CCD71C-4C97-B610608631BB230A

5. Ministerial Council on Energy website: http://www.industry.gov.au/content/controlfiles/display_details.cfm?ObjectID=1C92DAAD$\underline{\text { 8F2B-4BFD-8D06513B424C83B8 }}$

6. Australian Department of Foreign Affairs and Trade website: http://www.dfat.gov.au/environment/climate/

7. New South Wales_Environment Protection Authority website: http://www.epa.nsw.gov.au/

8. Queensland-Environmental Protection Agency website: http://www.env.qld.gov.au/

9. South Australia—Department for Environment and Heritage website: http://www.environment.sa.gov.au/

10. South Australia_Environment Protection Agency website: more efficient http://www.environment.sa.gov.au/epa/

11. Tasmania-Department of Primary Industries, Water and Environment website: http://www.dpiwe.tas.gov.au/

12. Victoria-Department of Natural Resources and Environment website: http://www.nre.vic.gov.au/

13. Victoria-Environment Protection Authority website: http://www.epa.vic.gov.au/ 
14. Western Australia_-Department of Environmental Protection website:

http://www.environ.wa.gov.au/

15. Greenhouse Gas Abatement Program website:

http://www.greenhouse.gov.au/ggap/index.html

16. Renewable Energy Equity Fund (REEF) website: http://www.cvcreef.com.au/ See also: http://www.ausindustry.gov.au/content/level3index.cfm?ObjectID=DFFF302A-6EC0-42FA8F07DD99D0DE84F8\&L2Parent=91C779C9-E2FF-4B9B-8A3C0EC058CE647C

17. Energy Efficiency Best Practice Programme website:

http://www.industry.gov.au/content/controlfiles/display_details.cfm?ObjectID=4797DE4D9619-4C79-A10D935C6FE25ED1

18. Sustainable Energy Development Authority (SEDA) website: http://www.seda.nsw.gov.au/

19. Energy Smart Business Program website: http://www.energysmart.com.au/WESBus.shtml

20. The Sustainable Energy Authority website: http://www.seav.vic.gov.au/index2.html

\section{Other useful websites:}

21. Environment Portal website: http://kaos.erin.gov.au/

22. International Energy Agency (IEA) documents:

http://www.iea.org/pubs/newslett/eneeff/au.pdf 


\section{Canada}

\section{Country Goals}

Canada committed to 6\% GHG reduction by 2008-2012 from 1990 levels under the Kyoto Protocol.

\section{Main organizations involved in energy}

Federal, provincial/territorial and municipal governments share jurisdiction over policy areas relevant to climate change.

National Climate Change Process (NCCP)

Canada's Voluntary Challenge \& Registry Inc. [1]

Federal Department of Natural Resources (NRCan) (Office of Energy Efficiency) - primary agency responsible for energy policy formulation and implementation.

\section{Relevant documents (general)}

National Implementation Strategy (NIS) and National Business Plans

Canada's National Report on Climate Change: Actions to Meet Commitments under the UN Framework Convention on Climate Change (1992, 1997, Feb. 2002)

Climate Change Action Plan for Canada

\section{Programs, agencies}

1. Canadian Industry Program for Energy Conservation/ Programme déconomie dénergie dans l'industrie canadienne (CIPEC/PEEIC) [2]

Description: CIPEC is a sector-level performance based voluntary program with industry created in 1975 and funded by the Industrial Energy Efficiency Initiative (IEE) of NRCan. The goal of CIPEC is to foster industrial energy efficiency, to contribute to economic competitiveness and to stabilize emissions. Support comes from more than 40 trade associations representing over 95\% of secondary industrial energy demand in Canada. CIPEC's board is made of CEOs and VPs of some of the largest energy users in industry. The Industrial Energy Innovators Initiative (IEII) is the company level program under CIPEC (which operates on a sector level). See OEE, below.

Goal: To help Canadian industry use energy efficiency investments to improve competitiveness and to contribute to Canada's climate change goals [2].

Achievements: Participation: 43 trade associations and company groups representing more than 5000 companies and over $95 \%$ of secondary industrial energy end use are involved in CIPEC. 323 companies had signed up as innovators (in IEII) by March 2002. 25,000 people attended the community and employee awareness events at four Innovator facilities in Ontario and Quebec in 2001.

Products and Services: Publications, energy management planning documents, tracking and regular reporting assistance, workshops, an international technical information network and 
various technical, financial and information services, such as the Energy Efficiency Guides for certain sectors.

Delivery Mechanisms: Training sessions and networks to learn about energy efficiency, seminars on new technologies and operating practices. CIPEC Website [2]. Industry partnerships. Voluntary agreements: CIPEC works with numerous industries to establish energy efficiency improvement targets, action plans and tracking and reporting on a per unit of production basis. CIPEC also hosts training and networking sessions, such as the "Dollars to \$ense" series of workshops on energy management and efficiency. CIPEC publishes and distributes the "Heads Up! CIPEC" bimonthly newsletter with a readership of 6000, regular features in the trade magazines and brochures for its members. CIPEC also provides case studies and benchmarking guides for industries, e.g., "Energy Consumption Benchmark Guide: Cement Clinker Production". CIPEC members receive access to ON-SITE, a source of qualified low-cost technicians who help to design and implement energy efficiency plans. CIPEC has an Executive Board whose members include senior executives from mining and manufacturing companies and who serve on the Council of Champions, who is affiliated with Canada's Climate Change Voluntary Challenge and Registry Inc. (VCR Inc.) to ensure a link between the programs. Regular sector task force meetings provide a way for companies to share noncompetitive information. The Task Force Council and individual sectors work to broaden participation and bolster public awareness. CIPEC publishes an annual report with industry results, success stories and sector reports.

\section{Natural Resources Canada (NRCan)}

Description: Primary agency responsible for energy policy formulation and implementation. The Office of Energy Efficiency (OEE, see number 3, below) is part of NRCan.

Delivery Mechanisms: Financial support for a number of "Advanced Technology Programs", mainly research and partnerships with industry. Center for Research in Cleaner Manufacturing helps develop policy for guiding innovation of cleaner processes. The Industrial Process Integration Program supports the use of Process Integration in various industries. The Industrial Research Assistance Program (IRAP) helps companies identify and adopt technology solutions. Technical advice and consultations from a network of over 250 IRAP advisors. Technology development of energy efficient processes, products, systems and equipment, in partnership with industry through the Industry Energy Research and Development Program. Conducted with all industrial sectors. Industry Heat Management Research Program helps develop and disseminate knowledge and technology that reduce GHG emissions. Research is in-house in collaboration with manufacturers, service providers and end users. NRCan works with other organizations like cement and concrete, mining research, heavy oil, fuel cells, petroleum, catalysis, hybrid systems and renewable energy on $R \& D$ specific to their needs.

\section{Office of Energy Efficiency (OEE, formerly Energy Efficiency Branch) [3]}

Description: Established within NRCan to strengthen and expand Canada's commitment to energy efficiency in order to help address the challenges of climate change. OEE emphasizes partnerships and economic investments. 
Products and Services: Leadership, information, voluntary actions, financial incentives and regulations. InfoSearch, a CD that includes how-to manuals, training materials, technical reports and energy savings guides. It also contains contact information of about $175 \mathrm{EE}$ organizations around the world, with hyperlinks, InfoSource-a repository of published case studies (including those in the CADDET database) and other documents, information about products, publications and workshops provided by the Industrial, Commercial and Institutional Programs Division (ICIPD) of the OEE. The CD-ROM also contains Energy Management Action Plan tools, including a carbon dioxide $\left(\mathrm{CO}_{2}\right)$ calculator, guidelines and a template. Benchmarks are developed from the energy efficiency of facilities in each subsector that is targeted.

Delivery Mechanisms: Assist in "Dollars to \$ense" workshops hosted by CIPEC, provide numerous training materials, "Heads Up Energy Efficiency" monthly Newsletter provides client success stories, new technologies, and other product lines and programs of the OEE, a products catalogue detailing available information. Industrial Energy Innovators (IEI), a company level voluntary agreement between industry and government (through OEE). Website [3]. Directory of Energy Efficiency and Alternative Energy Programs in Canada - an on-line inventory of programs offered by governments (federal, provincial, territorial, municipal) and utilities to promote the efficient use or conservation of energy at the end-use level and/or the use of alternative energy in Canada.

\section{Environment Canada's Environmental Technology Verification Program}

Description: Technology transfer assistance through the independent verification of new industry energy efficiency technology.

Delivery mechanisms: Provides validation and independent verification of performance claims of technology.

\section{CANMET Energy Technology Centre (CETC) (S\&T for Industrial Energy Efficiency) [4]}

Description: Energy S\&T delivery arm for NRCan's energy sector. Works in partnership with industry and all major stakeholders in the Canadian energy and R\&D sectors. $77 \%$ of the budget of C \$44.5 million (equivalent to $\$ 29$ million 2002 US) goes to energy efficiency and alternative energy R\&D. CETC emphasizes partnerships and economic investments.

Goal: To encourage the development and deployment of Canada's energy resources through supporting opportunities to develop cutting-edge energy innovations aimed at reducing greenhouse gas emissions. The Centre works in partnership with industry and stakeholders to develop energy-efficient, alternative energy and advanced hydrocarbon technologies. The program areas include oil and gas, renewable energy, transportation fuels, buildings technologies, community energy systems, renewable energy for remote communities, and design programs such as software and training to help industry build optimum energy-efficient technologies

Products and Services: Leadership, information, scientific and technical expertise, laboratory services, funding programs, publications, software modeling design and analysis tools, R\&D programs to generate knowledge and develop innovative technologies. 
Delivery Mechanisms: Three regional offices: CANMET Energy Technology Centre in Ottawa, Ontario, CANMET Energy Technology Research Centre in Devon, Alberta, and CANMET Energy Technology in Varennes, Quebec.

6. Voluntary Challenge and Registry Programme (VCR)/British Columbia's pilot emissions trading programme [5]

Description: Voluntary reporting and reward program for early action on reducing GHGs, report on achievements of participants and provide credit to industry for taking early action to reduce GHG emissions. 904 organizations currently registered (2002).

Goal: Entice companies to reduce GHG emissions quickly

Products and Services: Annual report of progress. Credit for early action on GHG emissions reductions.

Delivery Mechanisms: A Technical Advisory Committee provides recommendations concerning technical issues. It is comprised of representatives from academia, labor, environmental nongovernment organizations, the aboriginal community, industry and governments. Newsletter, "Champion News", on latest news, success stories and trends within the Climate Change sector as well as at VCR Inc. Leadership Awards recognize VCR Inc. registrants for their achievements in reducing Canada's greenhouse gas (GHG) emissions, nominated by other participants. Website [5]

\section{Climate Change Action Fund - Technology Early Action Measures (TEAM) [6]}

Description: TEAM, a part of the Climate Change Action Fund, offers financial support to federal programs that fund technology projects to reduce GHG emissions. TEAM investments accelerate the demonstration and deployment of new technologies into the marketplace. TEAM began with an initial investment of C $\$ 60$ million (\$40 million October 2002 US) over 3 years (1998/99-2000/01) and has been extended for another three years, through 2003/04, with an additional C \$35 million (\$22 million October 2002 US).

Products and Services: Federal funds for innovative technologies to reduce GHGs. TEAM proponents will be eligible for cost-sharing the formal verification of their technology performance and GHG reduction up to a maximum of $\mathbf{C} \$ 30,000$ (\$20,000 October 2002 US) from TEAM. Demonstrations of new technologies and processes that reduce GHG emissions.

Delivery Mechanisms: Website [6]

8. Alberta Economic Development Authority and Government of Alberta's provincial Climate Change Round Table and C3 partnership

Description: Over 100 leaders from industry, academia, municipal governments, and environmental groups and the public produced a consensus to take immediate action on climate change in 1999. 
Delivery Mechanisms: Provincial coordinating body called Climate Change Central (C3), a public/private sector partnership established in the fall of 1999, promotes implementation of actions, is a catalyst and coordinator, and monitors and reports on progress.

\section{Canadian Initiative for International Technology Transfer (CIITT) [7]}

Description: A Government of Canada Initiative, CIITT provides support for the identification and development of climate-change technology transfer projects. CIITT is centrally administered by the CANMET Energy Technology Centre (CETC) of Natural Resources Canada.

Products and Services: Assists in development of Canada's technology prospects by offering financial assistance to viability studies, proposal development and brokering, knowledge sharing and relationship management. In the future will provide success stories.

\section{Sustainable Development Technology Fund (SDTF)}

Description: SDTF is administered by a third-party foundation and is designed to stimulate the development and demonstration of environmental technologies, particularly those aimed at reducing GHG emissions, such as fuel cells and new process technologies, as well as those designed to improve air quality, such as clean coal technologies.

Products and Services: Federal funds for private sector-led projects aimed at development and demonstration of technologies and processes to reduce GHG emissions.

\section{Other local agencies}

Description: many of the local governments have established R\&D funds and centers, as well as voluntary agreements with industry, workshops, training sessions and auditing programs. Some of these include the Government of Alberta's workshops on international action for industry, Alberta's flaring programs, British Columbia's Oil and Gas Commission Environmental Fund, the Northwest Territory's Integration of Climate Change in Environmental Assessments, Nova Scotia's Light Better for Less program, Prince Edward Island's \$mart Energy Management program and Quebec's Promotion of Energy Efficiency program. 


\section{References:}

1. Canada's Voluntary Challenge \& Registry Incorporated website: www.vcr-mvr.ca

2. CIPEC website: http://oee.nrcan.gc.ca/cipec/ieep/index.cfm

3. Office of Energy Efficiency (OEE) Website: http://oee.nrcan.gc.ca/english/

4. CANMET Energy Technology Branch website: http://www.nrcan.gc.ca/es/etb/index.html

5. Voluntary Challenge and Registry Programme (VCR)'s website: http://www.vcr-mvr.ca/

6. TEAM website: http://www.climatechange.gc.ca/english/actions/action fund/techno.shtml

7. Canadian Initiative for International Technology Transfer (CIITT) website: http://www.nrcan.gc.ca/es/etb/cetc/ciitt/

8. International Energy Agency (IEA) documents: http://www.iea.org/pubs/newslett/eneeff/cn.pdf 


\section{Denmark}

\section{Country Goals}

Committed to reducing $\mathrm{CO}_{2}$ emissions by $21 \%$ from 1990 to 2008-2012 under the Kyoto Protocol and EU's Burden Sharing Agreement (Also, 5\% from 1990-2000). Already on track for $20 \%$ reduction from 1988 to 2005, with $11 \%$ realized as of 2000.

\section{Main agencies involved in energy}

Parliament

Baltic Energy Efficiency Group (BEEG), a working group on energy efficiency, including CHP and district heating (DH). Co-chaired by Denmark and Poland and consisting of the 11 Baltic countries plus the EU. Focusing on new financial instruments, coordination and follow-up on activities taken by other international institutions and organizations and development of CHP and DH (including target setting).

Danish Energy Authority [1]

The Ministry of the Environment [2] and its Environmental Protection Agency [3]

Ministry of Foreign Affairs [4]

\section{Relevant documents (general)}

Plan of Action on Environment and Development, 1988.

Energy 2000, 1990, introduced sustainable energy practices goal, national objective of $20 \%$ reduction in $\mathrm{CO}_{2}$ from 1988-2005.

Energy 21, April 1996, international market, overall challenges associated with energy.

Klima 2012, March 2000, complete overview regarding energy.

Bills: Energy Conservation Bill, Natural Gas Supply Bill and Heat Supply Bill.

Heat Supply Act, March 2000, introducing demands on the producers of heat to promote energy efficiency and reduce the costs related to the production of heat.

\section{Programs, agencies}

\section{Voluntary Agreements with industry - Danish Energy Authority [1]}

Description: Enterprises with specific energy intensive activities or with energy tax exceeding $3 \%$ of value added can reduce their tax rate (on energy, $\mathrm{CO}_{2}, \mathrm{SO}_{2}$ ) through a voluntary energy 
savings agreement. Companies commit to implementing energy efficiency investments based on an energy audit prepared by an independent certified consultant. Generally, companies must commit to all investments with four year paybacks or less (or propose alternatives). Companies, in return, receive tax reimbursements and grants for other energy efficiency measures. Energy management is also an essential part of the agreement. The agreements are three years.

Goal: Reduce energy reduction use through negotiated agreements, tax savings and a subsidy program.

Achievements: 230 enterprises, accounting for $35 \%$ of total energy consumption in industry, concluded an agreement with the Energy Agency. Of these, 101 were individual agreements and 129 were through sector-wide agreements (milk condensing, greenhouse gardening, brick burning).

Delivery Mechanisms: Tax reimbursements (Green Tax Package) - cuts in taxes on employing labor and employer social security contributions. Voluntary agreements with industry. Investment grants for energy saving measures that are not expected to be undertaken otherwise. Up to $30 \%$ of capital outlay on projects with paybacks between 2-9 years. Subsidies were used as temporary means to improve energy efficiency from 1993 until the end of 2001 [1]. Subsidies were available for a variety of projects including: investments in energy efficient equipment; investments in heat and electricity production with less $\mathrm{CO}_{2}$ emission; energy audits; energy management; energy efficient design; development and demonstration of energy efficient technologies; and, information projects. Several demonstration projects have been carried out in Denmark. Website with program information and documents.

\section{Utilities}

Description: Provide products; many offer them free of charge, arrange with stores and electricians for low-energy light bulbs, buying back inefficient appliances when new ones are sold.

Goal: Encourage energy efficiency

Products and Services: Energy efficiency products at discount or no cost. Efficient light bulbs made available through stores and electricians by utilities and an old appliances buy back service when efficient ones replace older ones.

Delivery Mechanisms: Extensive information and consultancy schemes provided by utilities.

\section{Ministry of the Environment [2]}

Description: Covers environmental issue in general, including energy efficiency and GHG savings.

Delivery Mechanisms: Miljøbutikken is an information center, providing information related to the environment and on Danish legislation and policies. Phone or email advice available. Free brochures and (for purchase) all publications issued by the Ministry are available. The Ministry 
publishes a newsletter. Searchable database on publications by the National Environmental Research Institute (NERI), a section of the Ministry.

\section{References:}

1. The Danish Energy Authority website: http://www.ens.dk/sw1212.asp

2. Danish Ministry of the Environment website: http://www.mem.dk/ukindex.htm

3. Danish Environmental Protection Agency website:

http://www.mst.dk/homepage/default.asp?Sub=http://www.mst.dk/links/

4. Ministry of Foreign Affairs website: http://www.um.dk/english/

5. International Energy Agency (IEA) documents: http://www.iea.org/pubs/newslett/eneeff/dn.pdf 


\section{European Union}

\section{EU Goals}

The European Union (EU) has signed and ratified the Kyoto Protocol. The overall target for the EU is a reduction of GHG emissions to 8\% below 1990 emission levels. Although all of the EU member countries have ratified the Kyoto Protocol, the targets vary by country based on burden sharing within the "bubble." Besides the Kyoto Protocol, various other policy targets affect energy policies and programs, such as deregulation of a common energy market, increased share of renewable energy sources in the fuel mix, security of supply and a drive towards increased environmental sustainability. The overall mandate of the EU also includes increasing European integration and sustainable growth. To improve European integration, increasingly more EUwide programs are implemented, partially replacing national programs in the various member states.

\section{Main agencies involved in energy}

There is not a chapter on energy in the EU Treaties, therefore energy policies are based on other legal basis such as the internal market or environment. EU Energy Policy is generally developed by the European Commission (Commission or EC) in Brussels, Belgium. The adoption of legal acts such as Directive is done by the EU Parliament and the Council under the co-decision process, following a proposal by the Commission. The EC is subdivided in various DirectoratesGeneral (DG) responsible for policy development in various areas. The organizational structure of the EC has changed over the past few years. Energy policy is the main responsibility of DG Transport and Energy (DG-TREN). However, parts of the energy policy is influenced or developed jointly with the DG Research, DG Environment and DG Enterprise.

Furthermore, the EU has also developed a research infrastructure to support policy-development, consisting of Joint Research Centres in various countries (e.g. Italy, Spain), the European Environmental Agency (Denmark), as well as Innovation Relay Centres (see below).

\section{Programs}

The EC has managed and is managing a variety of programs implemented by different DGs. However, coordination of part of the research programs is achieved through a centrally developed "Framework Programme." Currently in 2003, the $6^{\text {th }}$ Framework Programme is ongoing (2002-2006). The $5^{\text {th }}$ Framework Programme (1998-2002) had a budget of Euro 17.5 Billion. The Framework Programme provides a broad guideline for the main research themes, as well as organization of the research. "Energy, Environment and Sustainable Development" was one of the four thematic programs of the 5th Framework Programme. The $6{ }^{\text {th }}$ Framework Programme [1] focuses on sustainable development, global change and ecosystems, and includes the energy R\&D program, which cover advanced buildings, renewables and CONCERTO.

Besides programs, the Commission also puts out calls for proposals for specific topics. The calls are posted on Commission's website, as well as distributed through a network of national 
agencies (liaison agencies in each member state, that help with submitting proposals to the program).

Below we list the programs relevant for industry. DG-TREN also manages other programs: SYNERGY (aimed at international collaboration with developing countries and former centralplanned economies in the area of energy), ALURE (energy collaboration with South and LatinAmerica), ETAP (development of energy analysis tools) and SURE and TACIS (help reduce the risks of nuclear energy and weapons in the former Eastern-European countries).

\section{Energy Framework Programs (Intelligent Energy for Europe) [2]}

Intelligent Energy for Europe will provide financial support to local, regional and national initiatives in the fields of renewable energies, energy efficiency, energy aspects of transport and their international promotion. There are several policy support programs that were a part of the Energy Framework Programs (now the Intelligent Energy for Europe Program, as of 2003). Some of these include SAVE, ETAP, Synergy and ALTENER (I and II). Those relevant to industrial energy efficiency programs are explained in further detail below.

\subsection{ALTENER (ALTENER II) [3]}

Description: ALTENER is the only EC program focusing exclusively on the promotion of renewable energy sources. ALTENER ended its five-year term at the end of 1997. It has now been succeeded by ALTENER II, an initiative that will extend activities in the renewable energies field and make a major contribution to the implementation of the renewable energy strategy developed by the Commission. ALTENER II is focusing on renewable energy sources that are already viable or approaching viability: biomass, solar energy, small-scale hydroelectricity, wind power and geothermal energy.

Products and Services: Studies, technical assessments, the formulation of standards, and pilot studies for renewable energy development have been a part of both Altener I and II. ALTENER II also provides increased support for information dissemination activities proposed by the Commission and third parties and for targeted actions designed to speed up investment in renewable energy technologies.

\subsection{SA VE Programs and ManagEnergy [4]}

Description: The SAVE Program is the principal focus of the Community's non-technological action on energy efficiency. It is the only EU-wide program dedicated exclusively to promoting energy efficiency and encouraging energy-saving behavior in industry, commerce and the domestic sector as well as in transport. Since 2000, SAVE has been part of the "Framework Programme" of the EC. The SAVE II initiative incorporated community action on regional and urban energy management. ManagEnergy is one of the SAVE Program agencies.

Goal: The aim of SAVE II was to stimulate a 'bottom up' approach to energy management by encouraging local and regional action for energy efficiency, the use of local energy resources and the creation of optimum energy-supply conditions at the local level.

Products and Services: Case studies available online. Pilot projects carried out by public and private companies, existing community networks or temporary networks formed for this purpose. 
Ongoing evaluation and monitoring improvements in energy efficiency within the EU and each State.

Delivery Mechanisms: Policy measures, information, studies and the creation of local and regional energy management agencies. ManagEnergy promotes collaboration between agencies through conferences, workshops, "study tours" that visit installation sites, working groups, training sessions, coaching seminars, online chats and discussion boards and other online events on energy saving and renewable energy. Events are free and many are virtual to permit those who cannot afford to travel to attend. The website itself serves as an information center with links to over 400 energy agencies and events, case studies, funding, legislation and energy agencies across Europe [4]. The site offers free online conferencing and a partner search to help find participants for new energy projects among energy agencies, municipalities, consultants, industry and other energy experts.

The SAVE program also supports dissemination activities and efforts to organize (regional) actors in energy-efficiency and energy-policy. The ManagEnergy-program website focuses on support of energy management [4]. SAVE II part-funded the collaborative creation of autonomous Energy Management Agencies at the local and regional level, establishing networks to disseminate to local and regional authorities throughout with the help of FEDARENE (Network for Regions), ENERGIE-CITE (Network for Cities) and ISLENET (Network for Islands). A large number of regional energy management agencies are a member of this group, which is led by the Swedish Energy Agency (STEM). More information on the participants and effort is available online [4].

\section{R\&D Programs}

\subsection{EESD (on sustainable development, global change and ecosystems) [5]}

Description: EESD is an R\&D program managed by DG-Research, as part of the $6^{\text {th }}$ Framework Program. The current active EESD program focuses on clean and renewable energy technologies, including renewable energy sources, fuel cells, distributed power systems, integration of distributed generation, gas-based power generation, and clean transport. The current program has no specific focus on energy-efficient industrial technologies.

\subsection{ENERGIE (JOULE)}

Description: JOULE was the energy R\&D program managed by DG Research until 1998. It has been replaced by ENERGIE.

Products and Services: Research topics cover many areas, including industry. For industry, research includes development and demonstration of processes and process control technologies aimed at reducing energy demand in the manufacturing and agriculture sectors.

\section{Demonstration Programs}




\subsection{CARNOT [6] - (now expired, as of 2002)}

Description: CARNOT promoted the use of clean and efficient technologies in industrial plants using solid fuels. The term "solid fuels" covers hard coal, lignite, peat, oil shale and the heavy fraction of petroleum products. When mixed with solid fuels, biomass and refuse-derived fuel can also be considered.

Goal: To limit emissions including carbon dioxide emissions from solid fuels and to encourage the uptake of advanced clean solid fuel technologies in order to achieve improved Best Available Technologies (BAT) at affordable cost.

Delivery Mechanisms: Financial assistance for the promotion of information exchange between national, the EC and international entities. Between 50 and 100\% of the total cost of such measures is financed. Financial assistance for industrial cooperation in the form of workshops and seminars, industrial on-site visits, studies, evaluation and working groups. Funding for these measures is between 30 and $50 \%$ of the total costs.

\section{Websites and Internet Resources}

\subsection{Community Research \& Development Information Service (CORDIS) [7]}

Description: European institutes maintain a vast array of websites. However, in CORDIS, a "one-stop" site has been developed to help access information on available support programs, reports, databases, etc.

Products and Services: Case studies available on the website [7].

Delivery Mechanisms: The CORDIS site provides tools to submit proposals, contains information on ongoing projects, finds partners (as many EU-proposals must have partners from different member states) and provides other sources of information on the results and open research programs. The CORDIS website also supports the formation of Internet discussion groups [8]. The website provides both 'open forums' which are accessible to all users, and 'closed forums' which are accessible for members only. The CORDIS website lists only a few very general topics, and it seems that there are no specific ones focusing on energy-technologies. We are unable to evaluate the actual use and user-friendliness of this delivery channel.

\section{Networks}

The European Union maintains a number of networks to help disseminate information on the opportunities and results of Community programs. The networks also increase integration of the member states and support networking throughout the EU. Most of the networks have a specific mandate.

\subsection{Innovation Relay Centres (IRC)}

Description: Since 1995, throughout the EU-member states and other European countries (the so-called newly associated countries) a network of 68 centers has been formed. The IRC network is a European network for the promotion of technology partnerships and transfer mainly between small and medium-sized companies (SMEs). The IRCs are innovation support service providers 
mainly hosted by public organizations such as university technology centers, chambers of commerce, regional development agencies or national innovation agencies. Most IRCs are set up as consortia.

Goal: The centers have been created in order to facilitate the transfer of innovative technologies to and from European companies or research departments.

Delivery Mechanisms: Service centers for technology partnerships, technology transfer and networking. Each center is staffed by experts who have extensive knowledge of the technological and economic profile of the companies and regions they serve.

\subsection{Organisations for the Promotion of Energy Technologies (OPET) [9]}

Description: The OPET Network is an initiative of the EC that aims to disseminate information on, and promote the benefits of, new innovative energy technologies. These energy technologies cover the areas of renewable energy sources, rationale use of energy in industry, buildings and transport, solid fuels and hydrocarbons. The OPET Network is supported by the Enterprise Directorate-General in collaboration with the Energy Directorate-General (DG-TREN). The OPET Network comprises both public and private bodies with expertise in the promotion of new and innovative energy technologies. There are 38 OPETs within the European Union, Norway, Iceland and Israel, and 14 OPETs within the candidate countries of Central and Eastern Europe and Cyprus. Each OPET works to meet the specific information needs of the market within a specific geographical area or technical sector. Potential clients for OPET services include industry, public authorities, educational/training bodies, the financial sector and the final consumer.

Products and Services: Market studies. Activities include the production technology profiles, market analyses, publication reviews, assistance at events.

Delivery Mechanisms: The OPET-centers supply technology training sessions, technical evaluations, specialized workshops and exhibitions, partner searches. OPETs can also draw upon the expertise of a number of Sectoral Technical Experts (STE). Selected as recognized specialists in their particular energy field, these Experts can provide advice to members of the OPET Network. The aim of the STE service is to ensure the Network has access to technological stateof-the-art and to ensure that all OPETs can benefit from work carried out.

\section{IPPC Directive [10]}

Description: General environmental obligations for operators of industrial installations, including energy efficiency. Permits are issued for fulfilling obligations. The responsible DG is DG Environment.

Delivery Mechanisms: EC organizes exchange of information on Best Available Technologies (BAT). A technical working group prepares the BAT Reference Document (BREF).

\section{The EMAS Regulation [11]}

Description: The EU Eco-Management and Audit Scheme (EMAS) is a management tool for companies and other organizations to evaluate, report and improve their environmental 
performance. The scheme has been available for participation by companies since 1995 (Council Regulation (EEC) No 1836/93 of 29 June 1993) and was originally restricted to companies in industrial sectors.

Since 2001, EMAS has been open to all economic sectors including public and private services (Regulation (EC) No 761/2001 of the European Parliament and of the Council of 19 March 2001). In addition, EMAS was strengthened by the integration of EN/ISO 14001 as the environmental management system required by EMAS; by adopting an attractive EMAS logo to signal EMAS registration to the outside world; and by considering more strongly indirect effects such as those related to financial services or administrative and planning decisions.

Participation is voluntary and extends to public or private organizations operating in the European Union and the European Economic Area (EEA) - Iceland, Liechtenstein and Norway. An increasing number of candidate countries are also implementing the scheme in preparation for their accession to the EU.

Products and Services: Good examples/case studies of other companies and organizations

Delivery Mechanisms: Logo, public recognition through the logo. EMAS verifier provided to evaluate the company's environmental review, the environmental management system and the environmental audit.

\section{Voluntary agreements}

Description: Voluntary agreements both at the EU level for end-use equipment and cars and member states with specific industrial branches, such as the Long Term Agreement Scheme in the Netherlands. Agreements usually preceded by a pilot project or feasibility study (by SAVE or other agency).

Delivery Mechanism: Voluntary agreement. Set up with the chemical, pulp and paper, steel, cement and textile industries.

\section{Emissions Allowance Trading Scheme [12]}

Description: Large carbon dioxide emitters are allocated allowances annually through national allocation plans. In turn, the companies are required to limit emissions to the restrictions set by the allowances. If they reduce emissions below their allowable emissions, they may sell excess allowances to other companies or keep them for future use. (Companies that exceed their limits can buy allowances on the market to match their emissions.) Members are also allowed to take part in international trading schemes under the rules set out in the Kyoto Protocol. That is, European companies may carry out emission reduction projects worldwide and convert the credits earned into emissions allowances under the EU emissions allowance trading scheme. (This builds on the so-called market-based flexible mechanisms "Joint Implementation" and the "Clean Development Mechanism" of the Kyoto Protocol.)

Goal: To reach the global emissions reduction targets in the most cost-effective way and to transfer advanced technology to other countries. 


\section{Motor Challenge Programme [13]}

Description: The Motor Challenge Programme is a voluntary program, launched in February 2003, through which industrial companies are aided in improving the energy efficiency of their motor systems. Any enterprise or organization can participate.

Products and Services: Aid in defining and carrying out an Action Plan to reduce energy related operating expenses while maintaining or improving reliability and quality of service. Several training modules on energy management, motors, compressed air, pumps, fans and drives to estimate savings, provide guidelines, provide forms for assessments and energy management. Case studies available online.

Delivery Mechanisms: Public recognition through plaques, press releases, website [13], motor challenge logo, partnership catalogue, Motor Challenge Awards.

\section{Other products and delivery channels of the EU:}

- Technology procurement

- EuroDEEM electric motor system database (linked to energy efficiency measures in motors)

- Brochures (on specific projects or technologies)

- Reports

- Books

- CD-ROMs

- Conferences

- Technical Workshops

- Audits

\section{References:}

1. 6th Framework Programme website: http://europa.eu.int/comm/dgs/energy_transport/rtd/6/call_2/index_en.htm

2. Intelligent Energy for Europe Program website: http://europa.eu.int/comm/energy/res/intelligent_energy/index_en.htm

3. Altener website: http://europa.eu.int/comm/energy/en/pfs_altener_en.html

4. ManagEnergy website: http://www.managenergy.net/

5. EESD website: http://www.cordis.lu/eesd/

6. CARNOT website: http://europa.eu.int/comm/energy/en/pfs_carnot_en.html

7. CORDIS website: www.cordis.lu

8. CORDIS discussion groups: http://bbs.cordis.lu/ 
9. OPET website: http://www2.stem.se/opet/index.html

10. IPPC website: http://europa.eu.int/comm/environment/ippc/index.htm

11. EMAS website: http://europa.eu.int/comm/environment/emas/about/summary_en.htm

12. Proposal for a Directive for Emissions Trading website:

http://europa.eu.int/comm/environment/climat/emission.htm

13. Motor Challenge Programme website:

http://energyefficiency.jrc.cec.eu.int/motorchallenge/index.htm

14. Bertoldi, P. of the European Commission, Directorate General JRC, and O. Starzer, and M. Sattler, of the Austrian Energy Agency. (2003). Combining Long Term Agreements with Emissions Trading: An Overview of the Current EU Energy Efficiency Policies for the Industrial Sector and a Proposal for a New Industrial Efficiency Policy. Presented at the American Council for an Energy Efficiency Economy Summer Study, July 29-August 1, 2003. 


\section{France}

\section{Country Goals}

France signed the UNFCCC at UNCED in 1992 and ratified it in March 1994. France is currently a participant in the Kyoto Protocol and the Burden Sharing Agreement of the EU. It has set its national GHG-emission reduction goal at returning to 1990 levels for the period of 2008 and 2012. Following Kyoto, the French government decided to allocate FR 500 million (\$84 million 2003 US\$) per year to help implement the government's climate change policy.

\section{Main agencies involved in energy}

French energy efficiency policy is defined by the Direction générale de l'énergie et des matières premières (DGEMP, Directorate-General for Energy and Raw Materials), which is now split into an upstream section, Direction des resources énergétiques et minérales (DIREM, the Division for Energy and Mineral Resources) and a downstream section, Direction de la demande et des marchés énergétiques (DIDEME, Division for Energy Demand and Markets).

Energy policy is carried out by numerous organizations. Agence de l'Environnement en de la Maîtrise de l'Energie (ADEME, Agency for the Environment and Energy Efficiency) implements energy efficiency policies and programs and is considered France's main energy efficiency institution [2]. ADEME, set up in 1991, brought together the former energy conservation agency, Agence Françasie pour la Maitrise de l'Energie (AFME), the waste agency, Agence Nationale pour la Récupération et l'Elimination des Déchets and the air quality agency, Agence pour la Qualité de l'Air. ADEME also coordinates the ODYSSEE European project which aims to establish energy efficiency indicators for the various sectors of the economy in order to set up a permanent technical structure and to monitor energy efficiency improvements in France and also in Europe [3]. Besides national programs, various regional authorities support energy-efficiency through specific programs outside the national control.

\section{Relevant documents (general)}

First national report to UNFCCC entitled Programme National de Prévention du changement de Climat (National Program for the Mitigation of Climate Change) in February 1995.

Second report, République Française: Second National Communication of France Under the Climate Convention in November 1997.

Third National Communication, November 2001. Confirmed France fulfilled its Rio Convention commitment to stabilize GHG emissions in 2000 at 1990 levels.

Souviron Report, a synthesis report of the conclusions of the national debate of January 1994 to improve the security, environment and efficiency of energy supply.

December 1996 Law (96-1236) on Air and Rational Use of Energy replaced existing legislation relating to energy efficiency. 
Energy 2010-2020 Report, major directions of French energy policy, 1998.

Loi d'orientation pour l'aménagement et le développement durable du territoire (LOADT, Framework Law on Regional Planning and Sustainable Development), June 25, 1999, presented a new strategy for regional energy use.

Programme national de lutte contre le changement climatique (National Program to Combat Climate Change) by the Mission Interministérielle sur l'Effet de Serre (MIES, Inter-ministerial Mission on Climate Change), January 2000. It outlines measures needed for achieving 2008/2012 target. 313 measures to obtain a $4 \mathrm{MtC}$ reduction in industry (as well as measures for reducing $4 \mathrm{MtC}$ in transport, $2.7 \mathrm{MtC}$ in buildings and $2.6 \mathrm{MtC}$ in the energy sector).

National Energy Efficiency Plan (Plan national d'amélioration de l'efficacité énergétique, PNAEE), December 6, 2000.

\section{Programs, agencies}

1. Agence de l'Environnement et de la Maîtrise de l'Energie (ADEME, Agency for the Environment and Energy Efficiency) [2]

Description: ADEME implements energy efficiency policies and programs. Set up in September 1991, bringing together three agencies (see above). In addition to energy efficiency, it also helps implement other environmental programs for the government. ADEME has a staff of 700 in Paris, Angers and Valbonne. 26 regional offices exist throughout France.

Achievements: Almost all investments with a rate of return of less than three years have been implemented following the audits.

Products and Services: For energy intensive companies, ADEME develops process improvement aids that include demonstration projects and best practice energy-efficient techniques and equipment. Demonstration projects are defined here as projects to demonstrate a new innovative technology, or to demonstrate application in a specific industrial sector, or a new innovative application of an existing technology.

Delivery Mechanisms: R\&D support funds are available for basic research (up to 100\%), industrial research (up to 50\%) and for development (25\%). The program is administered by ADEME. Basic research funds can be used to support fellowships for students for $R \& D$ at universities and within companies. An annual RFP for R\&D proposals is used to solicit projects. The RFP is sent out through a network within the scientific and engineering communities through the press and mailings.

Engineers with the regional offices assist in support applications of demonstration projects. Financial support is limited to a small share of the costs of the total project $(7.5 \%$ for large enterprises, $15 \%$ for small enterprises), or limited to $10-40 \%$ of the additional costs for switching 
to the innovative technology as part of a demonstration projects. The program is managed through the regional offices.

Decision-making processes for companies are supported in three possible ways: pre-diagnostic (simple audit, support limited to Euro 2300 or $90 \%$ of costs), diagnostic (detailed audit, support limited to Euro 30,000 or 50\% of costs) and feasibility studies (support limited to Euro 75,000 or $50 \%$ of costs). The subsidy is used to pay for outside consultants. Mandatory audits of energy efficiency are required for energetic equipment like large boilers.

In addition to making energy management and environmental policy known to decision-makers, elected representatives and opinion leaders, and raising awareness of legal deadlines and international commitments, such as those made at Kyoto, scientific and technical information is also communicated to engineers and technicians in companies and local authorities via regular publications and events. Communication, information and training programs on energy efficiency are initiated by ADEME and carried out by professional and technical organizations such as chambers of commerce and industry, technical centers, ATEE (engineering association in charge of energy management in enterprises) and AFITE (environmental engineering and technician association). ADEME partners with professional organizations and consultancies to train trainers for small and medium-sized businesses and industries. ADEME runs numerous seminars and events presenting best available technologies and best practices.

Information is also made available via the press and publication of awareness-raising documents. The agency reports on its work through publications and meetings and via its website. Quarterly (international) newsletter published by ADEME.

\section{Voluntary Agreement program}

Description: The French government has a negotiated agreement with industry to improve energy efficiency and reduce GHG emissions. This program was re-vamped in 2002 through the creation of AERES (Association des Entreprises pour la Reduction de l'Effet de Serre: the French Association of Companies for the Reduction of the Greenhouse Effect) which includes 18 major companies operating in France that have committed to reducing their GHG emissions within a more rigorous negotiated agreement scheme that includes strict measurement, reporting, and verification, a registry, emissions trading, compliance mechanisms, and penalty fees for noncompliance.

Achievements: Voluntary agreements were signed with six partners (branches or industries): aluminum, cement industry, fat lime and magnesia lime manufacturers, the French steel federation, glass packaging industry, the "3 Suisses"-France (a large mail order company).

Examples:

Pechiney (aluminum production): signed in 1996. Commitment to reduce the GHG emissions between 1990 and 2000 by 39\% (specific objectives: absolute $\mathrm{CO}_{2}+2.4 \%$, specific $\mathrm{CO}_{2}-19 \%$, absolute $\mathrm{CF}_{4}-63 \%$. Results: specific $\mathrm{GHG}-41 \%$ (absolute $\mathrm{CO}_{2}-2.7 \%$ while production increased by 30\%). New commitment in 2001: reduction of the GHG emissions in 2012 by $15 \%$ compared to 1990 level. 
Glass production industry: 8 companies (27 sites), signed in 1997. Objectives: $\mathrm{NO}_{\mathrm{x}}-58 \%, \mathrm{SO}_{\mathrm{x}}$ $59 \%$, waste $-49 \%$, absolute $\mathrm{CO}_{2}-10 \%$, specific $\mathrm{CO}_{2}-27 \%$.

Lafarge Ciments (cement): the leading French cement producer, has voluntarily pledged to reduce its net carbon dioxide $\left(\mathrm{CO}_{2}\right)$ emissions by 30.8\% in France by 2010 in comparison to 1990 levels. This pledge, which was approved by AERES in February 2003, will result in Lafarge Ciments cutting its $\mathrm{CO}_{2}$ emissions by 2,000 Kt/year by 2010.

Products and Services: The new AERES negotiated agreement scheme includes common measurement, calculation, and verification guidelines as well as the use of a climate change "label" for participating companies to certify their cooperation in the fight against global warming.

Delivery Mechanisms: Negotiated agreements. The new AERES scheme includes fines for noncompliance.

3. Fonds de Garantie des Investissements de Maîtrise de l'Energie (FOGIME):

Description: FOGIME is a revolving investment guarantee fund started by ADEME, and a French Development Bank, and supported by the main electric utility (EdF) and coal-companies $(\mathrm{CDF})$.

Delivery Mechanisms: Investment funds available for small and medium-sized enterprises (less than 500 employees) for a maximum of Euro 762,245 per guarantee, or a maximum of $70 \%$ of the investment. The total fund is 76 million Euros. The fund is administered by the development bank and ADEME through its regional offices.

\section{SOFERGIE}

Description: Beginning in 1980, funds for energy efficiency investments in industry were available through this group of companies that finance energy saving investments, to facilitate lease financing for energy management.

Achievements: The role of this funding has been very small and may not continue.

Delivery Mechanisms: Financial support for energy efficiency investments.

\section{References}

1. International Energy Agency (IEA), 2002. Energy Policies of IEA Countries, 2002 Review.

2. Agence de l'Environnement en de la Maîtrise de l'Energie (ADEME) website: http://www.ademe.fr

3. Odyssee project website:

http://www.ademe.fr/partenaires/odyssee/angl/projet/projet_frame.htm 
4. International Energy Agency (IEA) document used in this report http://www.iea.org/pubs/newslett/eneeff/fr.pdf

Other Useful Resources:

5. Börkey P., Glachant M. et Lévêque F. (1999). Voluntary Approaches for Environmental Policy in OEDC Countries: An Assessment, CERNA.

6. Chidiak, M. and Glachant, M. (2000). Voluntary agreements - Implementation and efficiency The French Country Study: Case studies in the sectors of Packaging Glass and Aluminium, CERNA.

7. Péchiney (2001). Rapport Environnement 2001 - Health and Security (Santé et sécurité).

8. Ministry of the Environment. Voluntary Agreements of greenhouse gas transmissions reductions in the French industry. (updated October 30, 2001). Internet website: http://www.environnement.gouv.fr/actua/cominfos/dosdir/DIRPPR/reducgaz.htm. 


\section{Germany}

\section{Country Goals}

Germany has committed to a reduction of GHG emissions by $21 \%$ between 2008 and 2012 relative to 1990 emissions under the burden sharing arrangement of the European Union for the Kyoto Protocol. Germany has also set a national target of $25 \% \mathrm{CO}_{2}$ emissions reduction in 2005 compared to 1990 levels. Energy policy in Germany is directed towards a sustainable energy future for Germany. This is combined with goals to improve economic growth and innovation by focusing on sustainable development.

\section{Main agencies involved in energy}

Energy policy is mainly developed and implemented by the federal government, but also by the governments of the 16 Länder (Bundesländer or states), as well as by many local governments (municipalities). The activities vary among the Länder and among the local governments. Some of the Länder are more active in energy-efficiency, while others have a strong focus on renewables or industrial technology. Most of the programs in the Länder and cities aim at small and medium-sized enterprises (SMEs), as well as households. The federal government programs are developed by the Bundesministerium für Wirtschaft und Arbeit (BMWA, Ministry of Economics and Technology; since Autumn 2002: BMWA, Federal Ministry of Economics and Labour), Bundesministerium für Umwelt (BMU, Federal Ministry for the Environment) and the Bundesministerium für Bildung und Forschung (BMBF, Ministry of Education and Research). The main responsibility at the federal government for energy policy is BMWA. BMWA was also is in charge of support for renewables but since autumn of 2002, BMU is now in charge.

Federal programs are often implemented through an intermediary. For the programs of BMWA and BMBF, this is currently the Forschungszentrum Jülich GmbH [1]. This is the former KFA Jülich, and is comparable to a national laboratory in the U.S. focusing on mainly energy. Forschungszentrum Jülich also maintains contacts to other federal programs and selected programs in the Länder, which are managed through the Projektträger Jülich (PTJ) [2]. Most of the programs of the Länder managed through PTJ do not focus on industrial energy efficiency. The website of the Forschungszentrum Jülich maintains links to most of the federal and Länder programs [1]. More information is provided below under the Projektträger Jülich (PTJ) program.

\section{Relevant documents (general)}

First National Report to the UNFCCC, Environmental Policy: Climate Protection in the Federal Republic of Germany pursuant to the UNFCCC, September 1994.

Second National Report, Climate Protection in Germany pursuant to the UNFCCC, 1997.

Third Report in accordance with the UNFCCC, July 2002.

Sustainable Energy Policy to Meet the Needs of the Future, published October 2001 by the Federal Ministry of Economics and Technology. 
Germany's Climate Protection Programme, published in October 2000 by the Federal Ministry for the Environment.

\section{Programs, agencies}

\section{Projektträger Jülich (PTJ) [2]}

Description: PTJ serves as the main central intermediary for federal government programs and selected Länder-programs. On the one hand, it's a funding agency for the government and some states, and on the other, a partner to the scientific, industrial and community and to the public. PTJ offers a "one-stop shop" for federal energy programs available to energy efficiency project applicants. PTJ also supports the Federal Ministry for Science and Education (BMBF), the Federal Ministry for Economy and Labour (BMWA), the Federal Ministry for the Environment (BMU) and Ministries of several Federal States by preparing and implementing programs providing financial support for research.

Delivery Mechanisms: PTJ offers a "one-stop shop" website for organizations actively looking for programs supporting energy efficiency technology development and implementation [2]. It has brief descriptions of all the programs in the federal government programs and selected Länder-programs. The website contains a program to assist in the development of project proposals, by offering easy access to all the forms in one place, called EASY (Elektronisches Antrags bzw Angebots System, or Electronic Proposal and Offerings System). EASY offers computer programs to prepare a proposal for each of the different program areas. The PTJ website also offers access to research publications about the programs as well as for finished projects. Potential applicants proposing energy efficiency projects can also contact a PTJ representative for help with the preparation of the proposal. The applicant submits a summary of the project to the representative. There is one designated contact/representative for each field. There is one contact for industrial energy programs.

PTJ organizes "roundtables," seminars and workshops on specific research topics to bring together participants from industry, suppliers and the research community to discuss the R\&D needs, opportunities and directions in a specific area. Each roundtable consists of a one-day workshop. The results of the roundtables are provided on the PTJ website, as well as lists of participants. Subject areas have been: vacuum insulation technology, turbulent flows and membrane technology. Future subject areas are: electrochemical energy storage, lighting technology, and others.

PTJ also assists government and state programs in the preparation of invitations for project proposals and research announcements, and offers advice to the ministries (as well as potential applicants), acting as the go-between for government and industry.

\section{Bundesministerium für Wirtschaft und Arbeit (BMWA, Ministry of Economics and} Labour) [3]

Description: Federal government level agency that develops programs on energy efficiency and policy. BMWA has the main responsibility at the federal government level for energy policy. 
Generally, implementation is through the intermediary, Forschungszentrum Jülich GmbH and the German Energy Agency DEnA.

Delivery Mechanisms: BMWA has programs providing financial assistance for research and demonstration programs up to a maximum of $50 \%$ for selected areas. Areas include combustion and power generation, energy efficiency, energy-efficient industrial process technology, energy storage, fuel cells, renewable energy, distributed power generation, and system analysis and policy tools. Demonstration projects also funded. Some of the energy programs are implemented through DEnA (German Energy Agency, see below). Also, general financial programs to promote energy efficiency and renewables financed by the BMWA and/or the new KfW Mittelstandsbank (former Kreditanstalt für Wiederaufbau (KfW) and Deutsche Ausgleichsbank (DtA): e.g. $\mathrm{CO}_{2}$ Building Rehabilitation Programme of the KfW.

3. Bundesministerium für Bildung und Forschung (BMBF, Ministry of Education and Research) [4]

Description: Federal government level agency doing research and development on a number of themes. Energy is not a direct theme but part of the Program for a Sustainable Economy and Integrated Environmental Protection. Generally, implementation is through the intermediary, Forschungszentrum Jülich GmbH.

Delivery Mechanisms: BMBF provides financial assistance through the Program for a Sustainable Economy and Integrated Environmental Protection (where energy is a part of but not the entire program). Proposals for the Program can be driven by an industry, or have a more general impact. The program concentrates on a number of industries: agriculture, forestry, food industries, textile and leather industries, packaging industries and construction industry. PTJ is the agency that collects proposals within this program.

\section{Bundesministerium für Umwelt (BMU, Ministry for Environment) [5]}

Description: Federal government level agency that develops programs directed towards demonstration and development of renewable energy supply, including solar, wind, biomass, and geothermal applications, including seasonal energy storage (heating and cooling).

Products and Services: Publication of German Environmental Report annually.

Delivery Mechanisms: BMU has programs providing financial assistance; industry is eligible for these projects. Proposal submission is managed by PTJ. "Common Ground," Newsletter published triannually on Germany's environment, available online.

\section{Deutsche Energie Agentur (DEnA, German Energy Agency) [6]}

Description: Established September 2000, Deutsche Energie Agentur GmbH (DEnA) (German Energy Agency) is an independent agency privately owned (formally a private $\mathrm{GmbH}$, but the owners are mainly public: 4 Federal Ministries and the KfW Mittelstandsbank, which is mainly owned by the state, too) implementing programs for various federal ministries. DEnA manages a number of programs for the Federal German Government in the area of energy efficiency and renewable energy. DEnA's task is to obtain lasting improvements in energy efficiency and a more efficient use of energy in private households, companies and public administration as well 
as the utilization of renewable energy resources. A number of programs aim at industrial energy efficiency improvement, i.e. REN Strom, Combined Heat and Power, Climate Change.

Delivery Mechanisms: Running pilot projects using new technologies together with industry. Information campaigns. DEnA operates the Energy Hotline, toll-free telephone service for advice to both companies and private individuals on the rational use of energy in buildings, cogeneration and renewable energy sources.

REN Strom (Rationelle Energienutzung Strom; Efficient Energy Use: Electricity) has several dedicated efforts. Currently, the program aims at the introduction of U.S. EPA's ENERGY STAR label in Germany (as part of a wider European recognition program of the ENERGY STAR label). For industry, there is a program aimed at improving the efficiency of compressed air systems through audits, benchmarking, financing aid, as well as competitions for extremely energy-efficient compressed air systems. DEnA, BMWA and the Fraunhofer Institute implement the program for Systems and Innovation Research ISI (belonging to a nationwide network of applied science research institutes).

Delivery Mechanisms: Integrated system of audits, benchmarking, financing aid, as well as competitions for extremely energy-efficient compressed air systems.

Cogeneration. The German government recognizes cogeneration (combined heat and power or $\mathrm{CHP)}$ as a major opportunity to reduce greenhouse gas emissions. However, the ongoing deregulation in Europe (and Germany) is seen as an impediment to the further expansion of cogeneration. To warrant further expansion of cogeneration in industry, buildings and district heating, cogenerated electricity (if produced according to specified efficiency standards) is eligible to a small subsidy (equivalent to $1-1.7$ cents/kWh) under the KWK Bonus program (however only if the electricity is fed into the public grid, which in general is not the case of industrial companies which use the electricity on their own). The lower figure is given for less efficient cogeneration units, and the higher figure for efficient and new cogeneration units. The program is in place from 2002 until 2006. DEnA administers the program.

Delivery Mechanism: Financial assistance to support efficient cogeneration.

\section{Consultancy Service on Energy Conservation}

Description: Support for small and medium-sized companies on economic, organizational, and technical questions related to energy savings.

Delivery Mechanisms: Consultancy services. Subsidies of up to $40 \%$ of the costs up to a maximum of 3200 DM (about \$1600 July 2000 U.S.\$).

\section{Tax breaks}

Description: The Ecological Tax Reform introduced an Eco-tax on oil, gas and electricity beginning in 1999. Manufacturing receives some exemptions on the tax $(60 \%$ of normal rate as of 2003). The revenue from the tax is used for a reduction of the non-wage labor costs and the promotion of renewables. 
In the framework of the Eco-tax Reform, smaller block cogeneration power plants were exempted from the petroleum tax and sometimes the electricity tax. As a part of the amendments to the Mineral Oil Tax Act within the Tax Amendment Act of February 28, 1992, tax breaks for cogeneration were expanded, on the condition that an annual average of $70 \%$ of the generated heat and power are used, in relation to the amount of oil consumed. Overall, eco-tax is revenue neutral, generated taxes are redistributed among industry and the public by reducing other charges (pensions, etc.).

Delivery Mechanisms: Tax exemptions for cogeneration. Full exemption for cogeneration with a utilization rate of $70 \%$ or more.

\section{Eco-audit Directive/Negotiated agreement}

Description: Audits performed by government approved environmental auditor outlined in the EC Eco-audit Directive. Company must supply information to auditor and the public in the form of an environmental statement.

Delivery Mechanisms: Preference to companies under the Privilege Ordinance that participate in the eco-audits, resulting in concessions in environmental monitoring, reporting obligations and notification and information reporting obligations. EMAS (European eco-management system) logo awarded to companies that have undergone an eco-audit.

\section{Demand Side Management (DSM)}

Description: Public utilities are very involved in least-cost planning and DSM.

Delivery Mechanisms: Utilities advise consumers on energy savings. Annual expenditures for information and consulting amount to about 800 million DM (\$400 million U.S.\$).

10. The Environmental Commission of the German Chamber of Commerce (Umweltkommunikations- und informationssystem der deutschen Industrie- und Handelskammern) [7]

Description: The German Chamber of Commerce is an independent industry and business organization. It is not a governmental organization. The Environmental Commission aims to help members to find support for more sustainable business practices.

Delivery Mechanisms: Website with a database of all environmental assistance programs available to German industries, including those offered by the federal government, Länder and the European Commission [7].

\section{Voluntary Agreements}

Description: In 1995, the Federal Association of German Industries (Bundesverband der deutschen Industrie, BDI) together with five other trade and industry associations published a declaration in which German industries voluntarily agreed to increase energy savings or decrease $\mathrm{CO}_{2}$ emissions by up to $20 \%$ from 1987 to 2005 . Fifteen industrial associations, accounting for two thirds of industrial energy consumption, signed the first declaration. In 1996, a second declaration ("Updated and Extended Declaration by German Industry and Trade on Global Warming Prevention") was presented, changing the base year to 1990 and adding a transparent 
and verifiable monitoring process. Four new associations joined the initiative, making 19 total, representing over $71 \%$ of industrial energy consumption (14 associations) and more than $99 \%$ of public power generation (4 associations) in Germany. Agreements with each sector varied depending on individual energy saving potentials. On November 9, 2000, a new declaration was published which stated new goals of reducing specific $\mathrm{CO}_{2}$ emissions by $28 \%$ and the six GHG emissions $\left(\mathrm{CO}_{2}, \mathrm{CH}_{4}, \mathrm{~N}_{2} \mathrm{O}, \mathrm{SF}_{6}, \mathrm{HFCs}\right.$ and PFCs) by 35\% by the year 2005 (compared to 1990 levels). Most energy intensive industries are included: steel, cement, paper-making, chemicals, non-ferrous metals, sugar, textiles, oil refining gas and water utilities. Unlike more voluntary agreements, not only the industrial (end use) associations sign this declaration, but also the main energy supply associations. On June 25, 2001, the federal government and German businesses signed another agreement for the promotion of CHP.

Products and Services: Low interest loans, especially for CHP projects. KfW Mittelstandsbank (formerly Kreditanstalt für Wiederaufbau and Deutsche Ausgleichsbank until the merger at the end of 2002) provides the funding.

Delivery Mechanisms: Voluntary agreements. Formerly there existed special third party monitoring and verification performed by Rheinisch-Westphalian Economic Research Institute (RWI) with annual reporting, identification of deficits, suggestions on ways to save energy and optimizing its use and benchmarking (this monitoring was only valid for the agreements of 1995/96, not for the agreement of 2000; for the moment no institute is yet retained for the monitoring).

\section{Länder (States)}

Description: In addition to federal policies and programs, much like the states in the U.S., the Länder are the 16 states in Germany and have some influence on energy policy in general. Most of the Länder have their own energy agency responsible for information dissemination, implementation of regional and local energy policy instruments. Several cities (e.g. Berlin, Bremen, Heidelberg) also operate energy agencies.

Delivery Mechanisms: Nordrhein-Westfalen (NRW) offers a financing program (REN) for the support of selected innovative technologies (including renewables) for small and medium-sized enterprises. Requests for under roughly Euro $\$ 500,000$ are provided as a subsidy, and for larger amounts as an interest-free loan. The government of NRW, in collaboration with the Investionsbank NRW (a semi-public regional investment bank), runs the program. NordrheinWestfalen also offers a program to increase the use of waste heat for district heating, which is available for small and medium-sized enterprises. Various other Länder (e.g. Bayern, SachsenAnhalt) and cities (e.g. Berlin) offer incentives for specific renewable energy technologies to all participating sectors. Some of these programs include heat pumps.

\section{References:}

1. Forschungszentrum Jülich website: http://www.fz-juelich.de/portal/

2. Projektträger Jülich (PTJ) website: http://www.fz-juelich.de/ptj/ 
3. Bundesministerium für Wirtschaft und Technologie (BMWi, Ministry of Economics and Technology) website http://www.bmwi.de/Homepage/English\%20pages/index.jsp (in English):

4. Bundesministerium für Bildung und Forschung (BMBF, Ministry of Education and Research) website: http://www.bmbf.de/en/index.php3

5. Bundesministerium für Umwelt (BMU, Ministry for Environment) website (in English): http://www.bmu.de/english/fset1024.php

6. German Energy Agency. Website: http://www.deutsche-energie-agentur.de/

7. The Environmental Commission of the German Chamber of Commerce (Umweltkommunikations- und informationssystem der deutschen Industrie- und Handelskammern) website: http://www.ihk-umkis.de/foerderung/index.html

8. International Energy Agency (IEA) documents: http://www.iea.org/pubs/newslett/eneeff/de.pdf 


\section{Japan}

\section{Country Goals}

At COP3 of the UNFCC, Japan committed to 6\% reduction of emissions from 1990 to 20082012.

\section{Main agencies involved in energy}

- $\quad$ Ministry of Economy, Trade and Industry (METI, formerly Ministry of International

Trade and Industry, MITI) [1]

- $\quad$ Ministry of the Environment [2]

- $\quad$ National Institute of Advanced Industrial Science and Technology (AIST) [3]

- $\quad$ Global Warming Prevention Headquarters

- $\quad$ Agency for Natural Resources and Energy (ANRE) [4]

- $\quad$ The Energy Conservation Center (ECC) [5]

- $\quad$ The Japan Institute of Energy (JIE) [6]

\section{Relevant documents (general)}

Long Term Energy Supply and Demand Outlook, 1990, by the advisory board of MITI. Revised in 1994, June 1998, and July 2001. Set fundamental objectives of Japan's energy policy, the 3Es: economic growth, energy security and environmental protection.

Energy Conservation Law (or the Law Concerning the Rational Use of Energy). Revised June 1998 - most important development in energy efficiency in Japan, establishing stricter efficiency standards for factories, automobiles and appliances.

Energy Conservation Assistance Law (or the Law Concerning the Rational Use of Energy and Recycled Resource Utilization) applies to voluntary actions by businesses to conserve energy.

\section{Programs, agencies}

\section{The Energy Conservation Center (ECC) [5]}

Description: Audits began in 1978.

Achievements: about 5,600 assessments have been done nation-wide.

Products and Services: Audit report with a prioritized list of areas needing improvement and suggested measures to address these areas. Case studies available through website.

Delivery Mechanisms: Audits, diagnostic and advisory services. They carry out free detailed audits for companies with a capital of less than 100 million Yen (equivalent to \$0.8 million 2002 US) or less than 300 employees, or audits with a fee for large and medium sized companies. 
Concrete measures are suggested to address areas that need improvement, and a proposal is made of the expected costs and benefits of these measures. Website with information and case studies [5]. Counseling service via e-mail on energy-saving equipment, the Energy Conservation Law, energy reform taxation, energy conservation promotion and measures. (E-mail soudan@eccj.or.jp). Publicizes and disseminates details of the taxation system, manages a certification system for equipment for which the taxation system is applicable. Contests and awards for designated energy management facilities (both regional and national, see below). Monthly correspondence courses, short-term courses for soon-to-be energy managers. Follow-up education training, symposiums, technical courses and factory inspections for energy managers. Manages Japan's Energy Managers' Society. Produces promotional goods, such as signboards for designated energy management facilities.

2. The Japan Federation of Economic Organizations (Keidanren)'s Voluntary Action Plan on the Environment [7]

Description: Keidanren is a comprehensive economic organization begun in May 2002 by amalgamation of Japan Federation of Economic Organizations and Japan Federation of Employers' Associations. Includes 36 industries and 137 organizations. Includes nonmanufacturing industries as well (transportation, distribution, etc.), making it unique. First review was scheduled for 1998. Industries voluntarily establish quantitative targets for adopted measures in an Action Plan. The Action Plan is made public and reviewed.

Achievements: E.g., the Japan Mining Industry Association decided that by 2010, the nonferrous metal industry will reduce its energy input per unit of output by $12 \%$ from 1990; The Japan Chemical Industry Association is aiming to reduce the industry's energy output to $90 \%$ of 1990 levels by 2010.

Delivery Mechanisms: Voluntary agreements with industry, newsletter on energy conservation available to industry associations. Public review.

\section{Other negotiated agreements with industry}

Description: Under the Energy Conservation Assistance Law, under effect for 10 years (19942004).

Goals: To assist businesses who voluntarily undertake rationalization of energy use or utilization of recycled resources, using very low interest rates, bonds (under Industrial Foundation Improvement Fund) and exemptions from taxations.

Products and Services: Low interest loans and bonds (from Japan Development Bank).

Delivery Mechanisms: Voluntary agreements with industry, tax exemptions.

\section{National Institute of Advanced Industrial Science and Technology (AIST) [3]}

Description: Begun on April 1, 2001, the new AIST is a research organization that comprises 15 research institutes previously under the former Agency of Industrial Science and Technology (the former AIST) in the Ministry of International Trade and Industry (MITI) and the Weights and Measures Training Institute. The new AIST is Japan's largest public research organization. 
AIST collaborates with industrial, academic and governmental organizations. One of the main research topics is global climate change and energy efficiency.

Products and Services: Research and development in energy and the environment. AIST unites the research potentials of universities, the private sector and government agencies.

Delivery Mechanisms: Website [3] that includes several databases on energy and efficiency technologies collected by industrial, academic and governmental organizations (available to industries via nationwide network). A new Manufacturing Technical Support Office and Collaboration Center at each research base functions as a center for counseling small and medium-sized industries on regional technology. PR department releases information to the press and periodically publishes the latest research results as well as various other publications.

The Sunshine Project began in 1974 in order to develop new energy technology. The Moonlight Project was started in 1978 to develop energy conservation technology. The New Sunshine Program begun in 1993 unifies the existing Sunshine Project, Moonlight Project, and Research and Development Project for Environmental Technology [8]. Financial support from district level is provided for (energy and environmental technology and) energy conservation technology research and development to encourage development. Projects include fuel cell power generation, ceramic gas turbines and distributed energy storage.

\section{Designated energy management factories (through METI)}

Description: Standards applying to businesses with annual fuel consumption equivalent to at least 3,000 kiloliter of crude oil or annual electricity consumption of at least $12 \mathrm{GWh}$. About 3,500 factories included. Requires facility to hire a certified energy manager and report the status of their consumption every year to METI and the ministry responsible for the appropriate sector. Any operators who fail to do these tasks have their case publicized and are subject to a penalty.

Goal: Reduce domestic energy consumption by at least $1 \%$ annually on average for all operations. Targets announced through METI ordinance.

Delivery Mechanisms: Lectures on energy conservation. Industrial standards. Mandatory reporting (preparation of a plan and annual reporting) and fines and public disclosure for failure to comply.

\section{Medium sized designated energy management factories}

Description: Same as number 7 but applying to businesses with annual fuel consumption equivalent to at least 1,500 kiloliter of crude oil or annual electricity consumption of at least 6 GWh. About 9,000 medium sized factories are included.

Goal: Reduce domestic energy consumption by at least $1 \%$ annually on average for all operations. On-site surveys began April 2001 and all designated energy management factories are to be checked within about 5 years. In FY 2001, steel, paper and pulp, and the non-ferrous metals industries were to be checked. 
Delivery Mechanisms: Lectures on energy conservation. On site surveys with a focus on enhancing and broadening awareness of the Energy Conservation Law. Mandatory reporting (preparation of a plan and annual reporting) and fines and public disclosure for failure to comply.

\section{Asia Pacific Energy Research Centre (APERC) [9]}

Description: Research institution conduction research in the following areas:

- Energy demand/supply outlook,

- Natural gas storage in the APEC region,

- Natural gas utilization in the industrial sector,

- Energy efficiency indicators and potential energy savings in APEC economies,

- Emerging energy options in the APEC region,

- Oil security in the APEC region,

- APEC energy overview,

but main research is on demand/supply outlook.

Products and Services: Research on above topics, including energy efficiency and potential savings. Reports on research available through the website (but currently only on demand/supply outlook).

\section{Institute of Applied Energy (IAE) [10]}

Description: The Institute of Applied Energy is an independent and non-profit research institute focusing on energy issues. IAE collects information on energy issues in Japan and other countries, reviews and analyzes energy and energy technologies, provides recommendations for policy, studies and evaluates future energy systems and encourages communication among government, private and public organizations and research institutions.

Products and Services: Reports on research.

Delivery Mechanisms: Website [10] with listing of current and ongoing research. International symposium and conference.

\section{New Energy and Industrial Technology Development Organization NEDO [11]}

Description: The New Energy and Industrial Technology Development Organization (NEDO) was established in October 1980, immediately after the second oil crisis, as a semi-governmental organization under the Ministry of International Trade and Industry (now METI). NEDO works to coordinate the public and private sectors in Japan. NEDO's activities include the following: development and promotion of new energy and energy conservation technologies, management of industrial technology research and development projects, as well as restructuring of Japan's domestic coal mining industry, production of industrial alcohol, and restoration of damaged coal mining areas.

Products and Services: Published reports on research and compilations of international work.

Delivery Mechanisms: Research grants for research on energy efficiency (and others). Website [11], which includes details of projects undertaken. Public Library with domestic and foreign (and NEDO) books, periodicals and documents on energy topics. 


\section{New Energy Foundation (NEF) [12]}

Description: The New Energy Foundation (NEF) was established as a non-profit organization in September 1980, immediately after the second oil crisis. The role of the NEF is to perform surveys, research, introduction and spreading of new or unused energy. NEF polls private circles and presents proposals (based on these polls) to the government organizations concerned, in efforts to realize them.

Delivery Mechanisms: NEF subsidies for projects utilizing cogeneration or for power generation using geothermal and other renewable energy. Amount of loan per project up to 500 million yen. Website [12]. Surveys of private companies to target future research. New Energy Award for new energy equipment/system or new energy system application. Award given at award ceremony and publicized on website. New Energy Plaza Newsletter published and distributed triannually.

\section{Energy Conservation Programme (for medium to small businesses)}

Description: Experts provide detailed instruction for energy conservation, support of surveys of systems and development of energy-savings techniques

Delivery Mechanisms: Financial support provided from district level for development of energy - saving techniques to get them to market acceptance level. Industry experts. Support of surveys of systems.

\section{21st Century's Lighting Programme}

Description: Encourage and support development of LEDs incorporated into lighting equipment

Goal: Commercial products on the market by 2007

Delivery Mechanisms: Financial support from district level.

\section{Financial support for CHP}

Description: Special taxation and financial support system to stimulate the introduction of cogeneration.

Delivery Mechanisms: $15 \%$ assistance towards the equipment cost for large-scale CHP projects; up to $1 / 3$ of project cost for new utilities CHP projects with new energy or natural gas. Debt guarantee for CHP projects by New Energy and Industrial Technology Development Organization (NEDO, see above). Tax breaks (special depreciation of 30\% of the cost obtained first year or tax exemption of 7\%. Low interest rate loans (from the Japanese Development Bank or other government financial institutions).

\section{Other financial measures}

Products and Services: Low interest loans have been instituted by banking institutions for the installation of energy efficiency equipment or to promote energy efficiency.

Delivery Mechanisms: Financial support to NGOs for energy conservation promotion projects. Financial support for local governmental energy-saving demonstration projects. Demonstration 
projects for high-performance furnaces carried out in factories of various industries to verify practical performance, reliability, etc. Financial support for future energy saving activities to businesses that have already implemented energy saving efforts or that are engaged in development of energy efficiency technology.

\section{The Institute of Energy Economics, Japan (IEEJ) [13]}

Description: The Institute of Energy Economics, Japan is established in June 1966. IEEJ is an independent and non-profit research institute focusing on energy economic issues. Purpose of IEEJ is to carry on research activities specialized in the area of energy from the viewpoint of the national economy as a whole in a bid to contribute to sound development of the Japanese energysupplying and energy-consuming industries and to the improvement of people's life in the country by objectively analyzing energy problems and providing basic data, information and reports necessary for the formulation of policies.

Products and Services: Reports on research.

Delivery Mechanisms: Website [13] with listing of current and ongoing research.

\section{References:}

1. Ministry of Economy, Trade and Industry: http://www.meti.go.jp/english/

2. Ministry of the Environment: http://www.env.go.jp/en/index.html

3. National Institute of Advanced Industrial Science and Technology: http://www.aist.go.jp/index_e.html

4. Agency for Natural Resources and Energy (English page temporarily down 11/02): http://www.enecho.meti.go.jp/

5. The Energy Conservation Center (ECC) website: http://www.eccj.or.jp/index_e.html

6. The Japan Institute of Energy (JIE) website: http://www.jie.or.jp/indexe.htm

7. Keidanren Voluntary Action Plan on the Environment: http://www.keidanren.or.jp/english/policy/pol058/intro.html

8. New Sunshine Project website: http://www.aist.go.jp/www_e/guide/gyoumu/nss/index.html

9. Asia Pacific Energy Research Centre website: http://www.ieej.or.jp/aperc/

10. Institute of Applied Energy (IAE) website: http://www.iae.or.jp/ 
11. New Energy and Industrial Technology Development Organization website: http://www.nedo.go.jp/ (http://www.nedo.go.jp/english/index.html for English version)

12. New Energy Foundation (NEF) website: http://www.nef.or.jp/english/index.html

13. The Institute of Energy Economics, Japan web site: http://eneken.ieej.or.jp/en/index.html

14. International Energy Agency (IEA) documents:

http://www.iea.org/pubs/newslett/eneeff/jp.pdf 


\section{The Netherlands}

\section{Country Goals}

To achieve sustainable energy economy by $1 / 3$ improvement in energy efficiency by 2020 compared to 1990 , and increased renewables from $1 \%$ to $10 \%$. Industrial sector goal of improving energy efficiency by $20 \%$ from $1989 / 90$ to 2000. Market-based instruments are central in influencing behavior; the Regulatory Energy Tax was doubled between 1999 and 2001 as a result. Accepted a national target of 6\% reduction of GHG emissions in the period 20082012 compared to the 1990 level if the EU put in place additional regulations to support emissions reduction.

\section{Main agencies involved in energy}

At the level of the central government, domestic energy policy is the responsibility of the Ministry of Economic Affairs (EZ). The Ministry of Housing, Spatial Planning and the Environment (VROM) [1] also plays a major role in shaping energy policy through climate and other environmental policies. Policy is developed by the government, and most often implemented through two implementing agencies: Novem [2] and Senter [3]. Novem (the Netherlands Organization for Energy and Environment) has responsibility for the implementation of many industrial energy policies, such as the Long-Term Agreements (LTA) and R\&D policies. Novem was until recently an independent agency, but has recently been reintegrated with the Ministry of Economic Affairs [4]. Novem has two offices. Senter (Agency for technology, energy and the environment) manages most of the more general subsidy and taxincentives. Senter has one office in The Hague.

Furthermore, several provinces have developed active industrial energy programs, as part of efforts to achieve a more sustainable regional economy. The efforts vary by province.

\section{Relevant documents (general)}

Third White Paper on Energy Policy proposes a variety of reforms in the energy sector.

National Environmental Policy Plan (NEPP) (1989 and 1990) announced targets and measures, followed by NEPP-II (1993), the Second Memorandum on Energy Conservation (12/93), and NEPP-III (1998).

Memorandum on Energy Conservation (EBN) higher investments and taxes on consumers and industry.

The Fourth National Environmental Policy Plan published June 2001. Investing in Energy, Choices for the Future, Energy Report 2002 by the Ministry of Economic Affairs. 


\section{Programs, agencies}

\section{Voluntary Agreements}

1.1 Long Term Agreements (LTAs)

Description: LTAs are the key instrument in energy conservation for industry. NOVEM [2] is the government agency in charge (see below). Mainly cover the large and energy intensive organizations. The sectoral association, individual firms in the sector, the Ministry of Economic Affairs and Novem, and often the Association of the Provinces of the Netherlands sign the LTA. Only homogenous (both in process and product) sectors consuming 1 PJ of energy or more or companies with individual energy consumption of $0.1 \mathrm{PJ}$ or more which do not belong to a branch organization may participate. Energy consumption of the participating companies must account for at least $80 \%$ of the total energy consumption in the sector and the branch organization must be well organized and committed to actively stimulating the LTA implementation.

Goal: 20\% increase in energy efficiency by the year 2000 from 1989 levels.

Achievements: The first LTA was signed in 1992 and ultimately 29 LTAs were established with about 1250 industrial firms representing $90 \%$ of the total industrial energy consumption of the Netherlands. Industry sectors demonstrate a positive perception of the LTA approach. By the end of the program (2000), cumulative energy-efficiency improvement was equal to $22 \%$ (exceeding the target). Evaluations show support and no sector has dropped out of an agreement. The success-rate of the results varied by sector.

Products and Services: Energy efficiency guides and factsheets are provided for each sector as well as information on energy management systems. A variety of instruments (scans) help the companies to find out what topics are of interest or benefit to them and to make the first steps.

Delivery Mechanisms: The Ministry of Economic Affairs approaches an industry association asking them to make a long-term agreement. In addition, there are the actual industry organization partnerships-agreements (LTAs) between the Ministry of Economic Affairs and representatives from economic sectors (through agreement, industry voluntarily agrees to reduce energy intensity) and individual member companies.

Other delivery mechanisms include: detailed energy audits of industries' facilities (including both an assessment of energy consumption in a base year and an inventory of the sector's energy conservation potential), subsidies for clean technologies and increases for programs that do better than expected and tax abatement (if investments in clean technologies are realized), regulatory relief in environmental permit renewal (agreement by government not to further regulate on energy efficiency in the industry ${ }^{6}$ ), a quantified energy efficiency index for the sector involved, created from a yearly monitoring system based on an annual report of individual members, helping participating companies to achieve the set targets, consultative groups that

\footnotetext{
${ }^{6}$ Companies not participating in and meeting either the LTAs or the benchmark agreements (see below) will face energy requirements in their environmental permits.
} 
meet annually to discuss aggregate results of energy monitoring in the sector and that help set up an initial Energy Conservation Plan.

Novem (see below) also organizes meetings of participants to discuss specific technological challenges for specific sectors (e.g. drying in the textile industry, monitoring and targeting in the food industries). In addition, NOVEM provides workshops, newsletters. Intensive monitoring makes achievements visible.

The LTA-approach for energy-intensive industries ended successfully in 2000, with an overall energy-efficiency improvement of 22\% between 1989 and 2000. The Benchmarking Agreement for selected energy-intensive industries has now replaced the LTA-approach (see below).

NOVEM (Nederlandse onderneming voor energie en milieu, the Netherlands agency for energy and the environment) is the delivery organization that discusses and evaluates potentials for energy conservation with the association and participating companies. NOVEM also may make an inventory for energy efficiency projects, collects data of improvements, helps industry if needed and estimates the quality of energy efficiency improvements. Novem collects the annual reporting data, and aggregates the data for reporting to the government and public. NOVEM also provides some subsidies. (From 1989 to 1993, NOVEM subsidized 1000 projects implemented by and in collaboration with industry. These projects included research and development (350 projects), demonstration projects (200), application of existing technologies (350) and cogeneration (100).) Finally, NOVEM provides a website.

\subsection{Long-Term Agreements - II}

Description: A follow-up of the previous LTA-program focusing on the industries that do not participate in the Benchmarking agreement (see below). Program is a follow-up of the first LTAprogram for less energy-intensive industries (medium sized companies) with a completely new focus. The first LTA focused mainly on process efficiency; the new LTA has made a shift towards energy efficiency over the product life cycle and a more integrated policy.

Goals: Instead of a pre-set target, the companies in the second long-term agreement are given the opportunity to formulate their own targets. Each company must draw up an Energy Conservation Plan (ECP). It describes measures for improving energy efficiency in the company's production processes. The energy conservation plans of individual companies form the basis for setting targets at the sectoral level. The energy efficiency improvement target for a sector is at least equal to the weighted sum of the targets of its member companies. In addition, each company is screened and needs to comply with the ALARA principle (their energy consumption should be As Low As Reasonably Achievable). Companies must also introduce all suitable process efficiency measures with a pay back time of five years or less and introduce an energy management system in line with ISO 14001 within two years after signing the LTA. (The obligation to introduce efficiency measures with a pay back time of five years or less applies to non-LTA companies as well, however they receive no government support). The most notable difference between the first and second LTA is the introduction of 'expansion themes' of renewable energy and energy-efficient product development. Concrete measures for achieving energy efficient product development include sustainable products, sustainable industrial estates and the optimization of transport, logistics and product chains. These non-process efficiency 
measures in the period 2001-2004 are optional, but each sector is challenged to investigate which themes it is willing and able to address.

Achievements: Most companies have now produced an energy conservation plan and many pilot projects concerning the energy efficient product development have been started.

Products and Services: Development of sector wide 4-year energy-efficiency plans, and access to (financial and networking) supporting policies (see below). Energy efficiency tools like LESS, which calculates the potential energy savings of renewable energy and energy-efficient product development projects.

Delivery Mechanisms: Energy conservation plans for sectors and companies, access to other supporting instruments. Knowledge exchange in workshops.

\subsection{Benchmarking}

Description: Voluntary agreements to reduce energy intensity, open to all corporate facilities in the Netherlands with an annual energy consumption of at least $0.5 \mathrm{PJ}$, in exchange for no further regulations. The target of the agreement is that the participating industries are among the top energy-efficient producers in 2012. Top can be defined as the most efficient $10 \%$ plants in the world or the three most efficient regions (defined as geographic areas with a production capacity similar to the Netherlands). .

Achievements: An agreement was reached in 1999 between the Ministry of Economic Affairs, Ministry of Environment, Federation of Netherlands Industry (VNO_NCW) and 5 sectors organizations-chemicals, paper and cardboard, electricity generation, metallurgical and refineries. Other participating industries are breweries and starch production.

Products and Services: Benchmarks provided. Agreement-no additional specific governmental measures aimed at energy conservation or $\mathrm{CO}_{2}$ emissions (for the energy-intensive companies offering to be/become among the best in the world in terms of energy efficiency). Beginning in 2006, benchmark companies that are not yet among the best in the world will have to take all energy conservation measures that generate enough savings to cover the costs of borrowed capital [5].

Delivery Mechanisms: Voluntary agreements with industry.

\section{Subsidy Programs}

The names and goals (e.g. targeted industries, scope) of the different subsidy programs have changed over time. Below we discuss some of the programs that have been implemented in recent years.

\subsection{Light Manufacturing Strategy}

Description: For small and medium sized firms, the remaining 10\% that are not covered by the LTA. Aimed at energy management and conservation for small companies without long-term agreements. 
Goal: 19\% energy conservation improvement in 2000 compared to 1989.

Products and Services: An energy registration system, an energy management system and an overview of suitable conservation technologies. Information and monitoring, energy advice and energy scans, leasing and pre-financing of energy management techniques for heat recovery (provided by the energy distribution sector (MAP 2000).

Delivery Mechanisms: Industry associations and agreements, the energy distribution sector (MAP 2000) and developing energy management systems. Two websites were available to help small and medium-sized enterprises find financial support in the areas of energy-efficiency and cleaner production (closed 2003).

\subsection{Energy Conservation and Environmental Consultancy Subsidy Scheme (EMA)}

Description: Subsidies are provided for companies to use consultants to undertake audits for energy efficiency and the environment. The maximum subsidy is $40 \%$ of the cost of an audit. The program has been ended, and is being replaced by different programs to assist small and medium-sized enterprises.

Products and Services: subsidies and audits

Delivery Mechanisms: Audits

\subsection{Cleaner Production Programme}

Description: Joint initiative of the state government and the provinces from 1996-2003. Budget is NLG 4.6 million/year (equivalent to \$1.9 million $2002 \mathrm{US}$ ).

Goal: Make small and medium sized businesses more environmentally aware

Products and Services: Subsidies up to $66.6 \%$ (or NLG 0.2 million, equivalent to $\$ 0.1$ million 2002 US) are provided per project, subsidies for engaging consultants to audit and advise with regard to energy conservation (and other), up to $50 \%$.

Delivery Mechanisms: Consultants (the auditors), trade and industrial organizations are reinforced and supported through this program

\subsection{The Industrial Energy Conservation Tenders Subsidy Scheme (TIEB)}

Description: Cover all industry, primarily focusing on companies with LTAs (90\%). Began in the early 1990's. Budget is NLG 10 million/year (equivalent to \$4 million 2002 US). Encourages new technologies.

Goal: Stimulate demonstration and market introduction projects for industrial energy conservation.

Products and Services: Subsidies of up to 30\% for energy efficiency demonstration projects, and $20 \%$ for market introduction of energy efficiency technologies, $50 \%$ for feasibility studies, $40 \%$ for demonstration projects. 
Delivery Mechanisms: Subsidy requests were competed in an annual RFP. Requests were for audits, feasibility studies and demonstration projects.

\subsection{Energy Conservation Technologies Subsidy Scheme (BSET)}

Description: Subsidy program that focuses mainly on the small and medium-sized enterprises. Encourages investments in energy efficiency projects, relating to both thermal and electricity demand. Budget set in 1995 was 12 million ECU per year (equivalent to \$11.8 million US). In 1994, there were about 500 applicants.

Products and Services: Subsidies for energy efficiency projects, up to $25 \%$ of the costs for specific technologies. Government supplies consultancy for the projects.

\subsection{Energy Savings through Innovation}

Description: Subsidies for feasibility studies and demonstration projects in industry, replacing many of the previous programs (BSET, TIEB).

Goal: Stimulate innovative energy-efficient technologies for industrial energy efficiency improvement.

Products and Services: Subsidies for feasibility studies (budget of Euro 0.9 Million) and demonstration projects (budget of Euro 20 Million).

Delivery Mechanisms: Implemented through contact with Senter (see above).

\section{Tax Incentives}

\subsection{Energy Investment Tax Deduction (EIA)}

Description: The EIA allows income-tax paying companies to deduct up to $55 \%$ of the investment costs of the profits for selected technologies.

Goal: Reduce energy-consumption of companies and introduce innovative technologies.

Products and Services: Partial tax deduction for selected energy-efficiency equipment and renewable energy sources.

Delivery Mechanisms: Through Tax Services (compare to IRS) after approval by Senter.

\subsection{Accelerated Depreciation Environmental Investments (VAMIL)}

Description: Similar to the EIA, VAMIL allows to subtract up to $40 \%$ of the investments of selected environmental-friendly technologies of the company profits. The share of the investments that can be subtracted varies with technology and degree of innovation. VAMIL covers primarily environmental technologies. Technologies are different than those covered under the EIA. The Ministry of Environment (VROM) adapts the list annually.

Goal: Stimulate cleaner production practices and technologies 
Products and Services: Partial tax deduction for investments in selected innovative environmental equipment. Expenses of feasibility-studies are eligible for VAMIL under very specific and strict conditions.

Delivery Mechanisms: Through Tax Services (compare to IRS).

\section{Research and Development}

\subsection{Economy, Ecology and Technology (EET)}

Description: R\&D program for environmental (energy) technologies directed at industry and the research community.

Goal: Stimulate innovative environmental technology, research capabilities, and improve environmental performance of products.

Products and Services: Subsidies for research projects (basic research, pre-competitive, and product development) are provided through a tender process, repeated each 8 months.

Delivery Mechanisms: Request for proposals through tender-process, managed through Senter (see above). Website, mailing and contacts. A conference on the challenges and opportunities has been organized at the $5^{\text {th }}$ anniversary of the program.

\subsection{New Energy Research (NEO)}

Description: R\&D program for new and innovative energy technologies directed at industry and the research community.

Goal: Stimulate innovation in energy-technology development.

Products and Services: Relative small subsidies for research projects (basic research, precompetitive) are provided through a tender process, repeated each 8 months.

Delivery Mechanisms: Request for proposals through tender-process, managed through Novem (see above). Website, mailing and contacts.

\section{Non-governmental Programs}

\subsection{Gasunie Plan}

Description: Gasunie is the company responsible for the domestic supply of natural gas. Carrying out the Environmental Plan for Industry for improved energy conservation in industry

Products and Services: Support for process-integration analysis, audits and feasibility studies.

Delivery Mechanisms: Technical assistance. Gasunie is the direct gas supplier for many large gas users. Program is offered through customer representatives. A separate department within 
Gasunie with engineers experienced in pinch-analysis and other process-integration approaches manages the program.

\subsection{Milieu Actie Plan or MAP-II}

Description: Energy distribution companies' second environmental plan. The program is mainly aimed at achieving GHG emission reductions supporting actions by small energy consumers (incl. small industrial users), as well as CHP. Large gas users are served directly by Gasunie.

Products and Services: Subsidies are available through utilities within the framework of MAPII. The subsidies are mainly for energy management as well as to stimulate feasibility studies, demonstration and market introduction projects. Also, products through energy distribution companies include information and monitoring, energy advice and energy scans, leasing and prefinancing of energy management techniques for heat recovery. Joint ventures for cogeneration projects with industries (up to $50 \mathrm{MWe}$ ) are also offered to industries in the service territory of the utilities.

Delivery Mechanisms: Energy distribution companies provide services listed above.

\section{References}

1. Ministry of Housing, Spatial Planning and the Environment website: http://www.vrom.nl/international/

2. Novem website: $\underline{w w w . n o v e m . n l}$

3. Senter website: $\underline{w w w . s e n t e r . n l}$

4. Ministry of Economic Affairs website: www.minez.nl

5. Netherlands Energy Research Foundation (ECN) website: http://www.ecn.nl/main.html

6. Long Term Agreements on Energy Efficiency, Progress in 1996. Available at http://info.minez.nl/

7. Other documents used in this report:

7. http://www.iea.org/pubs/newslett/eneeff/nl.pdf

8. http://www.iea.org/pubs/studies/files/danish/dan2/07-dan2.htm\#ID21 


\section{Norway}

\section{Country Goals}

Norway ratified the UN Framework Convention on Climate Change (UNFCCC) in July 1993 and the Kyoto protocol on May 30, 2002. Under Kyoto, Norway committed to limit the increase in GHG emissions to $1 \%$ between 1990 and 2008-2012.

\section{Main organizations involved in energy}

Previously from 1994 to 2001, responsibility for energy efficiency was the Norwegian Water Resources and Energy Directorate (NVE) and the electricity companies. NVE delegated energy efficiency executing responsibilities to different operating agents. Regional Energy Efficiency Centers had also been set up in each of the 19 counties in Norway.

Currently, the Institute for Energy Technology (IFE) is an international research center that focuses on nuclear and petroleum energy and on energy and environmental technologies [1]. The Industrial Energy Efficiency Network (IEEN) is a national programme initiated by IFE and the industry. The programme is funded by Enova SF and focuses on environmentally friend and energy efficient measures [2]. Enova SF, a public enterprise, was established June 2001 and began operation on January 1, 2002 (see below) [3]. Enova SF is responsible for energy efficiency and renewables.

\section{Relevant documents (general)}

Energy Act, January 1, 1991, introduced requirements for local energy utilities to provide customers with information and advice on energy efficiency.

White Paper on Energy Efficiency and New Renewable Energy Sources, 1993

White Paper on Environmental Policies for Sustainable Development

White Paper on the Norwegian Implementation of the Kyoto Protocol, June 1998.

White Paper on Energy Policy, March 1999.

White Paper, June 2001

White Paper on Climate Change Policy, March 2002.

Parliamentary Bill on Green Taxes, June 1998.

First National Communication under the UNFCCC, September 21, 1994.

Second National Communication under the UNFCCC, April 1997. 
Quota Commission report, December 1999.

\section{Programs, agencies}

1. Industrial Energy Efficiency Analysis Model and Program

Description: Program tests the influence of using different raw materials on energy efficiency. Pilot projects have been carried out on the Non-ECSC ferro-alloys and pulp and the paper and paperboard industries.

Goal: Increase energy efficiency by switching of raw material inputs.

Achievements: Found average energy reduction of electricity was between 5 and $10 \%$, sometimes with little or no capital investment.

Products and Services: R\&D.

Delivery Mechanisms: Pilot studies for two industries (see above).

2. Institute for Energy Technology - Industrial Energy Efficiency Network (IEEN) [2]

Description: The Industrial Energy Efficiency Network is an industry guided energy efficiency program managed by the Institute for Energy Technology (IFE) [1]. The Network has approximately 800 member companies from various industrial sectors, representing half of the industry's total energy use. IEEN promotes the development and implementation of energy efficient and environmentally friendly uses of energy. A main function of IEEN is to offer benchmarking among the members and improve the decision-making process and energy consumption patterns of companies. Interactive web-based benchmarking will be available for members of the network from 2004.

Achievements: In 2001, the member companies of the Network have carried out energy saving measures amounting to $400 \mathrm{GWh}$, or 60 million NOK (equivalent to over $\$ 6$ million 2001 U.S.\$).

Products and Services: Support is given to energy management on a company level. Annual reports are available online, in addition to sector-specific reports that contain statistics, results and experiences within the sector. Reference projects (case studies) are distributed to members. IFE also carries out testing of energy efficient equipment for third parties and has an energy auditing laboratory for energy measurements in industry. IFE has developed mathematical models and simulation software for optimizing plants in the petroleum, petrochemical and other land-based industries. IEEN offers benchmarking to the members to improve the decisionmaking process and energy consumption patterns of companies. Interactive web-based benchmarking will be available for members of the network from 2004.

Delivery Mechanisms: Website [2]. In the past, reports and brochures were sent to all members. There were annual networking meeting for consultants, sector specific networking conferences, internet based courses on energy management in industry held in collaboration with VVS 
fjernundervisning, and a quarterly newsletter. Currently, priority has been given to continue the benchmark scheme and a modified audit scheme, as well as publishing case studies and promotional materials. Brochures on energy efficiency technologies have been developed, for example, the brochure "Energy efficient operation of electric motors - a basis for improved competitiveness." However, other technical and financial support is now given through Enova SF (see below).

\section{Voluntary Agreements}

Description: Agreements between the government and industry. So far, only one agreement has been concluded with the aluminum industry, which has agreed to reduce GHG emissions by 55\% by 2005 . Resistance related to quota discussions.

Delivery Mechanisms: Voluntary agreements.

\section{ENOVA SF [3]}

Description: New government owned national agency officially established June 22, 2001, with operations beginning in January 12002 , to promote energy efficiency and renewable energy. In 2001, the state energy fund that finances ENOVA's activities was equivalent to 62 million EURO.

Products and Services: Benchmarking of member companies in the Industry Network. Information, advice and campaigns include regular national television advertising campaigns. Information and advice are provided free of charge through a national energy information helpline. Local sub-contractors that represent Enova in the field handle queries that require concrete on-site follow up.

Delivery Mechanisms: Administers the Energy Fund, NOK 550 million/year (\$74 million March 2003 U.S.\$). Nation wide public information and guidance service. Energy audits and analysis of specific energy use in industrial companies. Training and education are provided through several programs like the programme for development of teaching materials and learning concepts, the programme for developing continuing education course in energy for technical personnel and engineers (accredited), and training of maintenance personnel in commercial buildings and industry.

\section{Research Council}

Description: The Research Council provides R\&D funding in three divisions: Energy and Industry, Science and Technology, and Environment and Development. Many of the programs focus on industry objectives.

Products and Services: Funding for R\&D in energy and industry. 


\section{6. $\mathrm{CO}_{2}$ tax}

Description: Tax on electricity, fuel oil for residential heating (to avoid a shift to the use of boilers), coal and coke, mobile energy use, and mineral oil. Industry, mining, greenhouses heat pumps and households in Northern-Troms and Finnmark counties are exempt. District heating is also exempt. About $64 \%$ of the total $\mathrm{CO}_{2}$ emissions are covered by this tax.

\section{Quota System}

Description: The system is under development. Quotas will be zero for companies exempt from the $\mathrm{CO}_{2}$ tax if these companies reduce GHG emissions by 30\% from 1990 to 2008-2012. Quotas can be bought from other companies. The system is expected to include the metal, petrochemical and cement industries as well as oil refineries and gas terminals.

\section{References}

1. Institute for Energy Technology (IFE) website (in English): http://www.ife.no/english/omIfe/index.jsp

2. Industrial Energy Efficiency Network (IEEN) website (in English): http://www.ife.no/english/prosjekter/project_details.jsp?projectId=6451\&omId=2306\&nav=1

3. Enova website: http://www.enova.no

4. International Energy Agency (IEA) documents http://www.iea.org/pubs/newslett/eneeff/no.pdf 


\section{Sweden}

\section{Country Goals}

Energy policy was revisited by the Riksdag (Parliament) in the 1991 Energy Policy Bill with the new purpose of creating long-term sustainable energy policies, securing the availability of electricity and other energy in the long and short term at prices that are competitive on the world market. Burning fossil fuels is to be avoided whenever possible through active energy conservation and using renewable energy sources. In January 1998, a seven-year program for an ecologically sustainable energy system was begun, further supporting those goals of increased renewable energy sources and energy efficiency.

Sweden has signed and ratified the UNFCCC. Sweden is currently a participant in the Kyoto Protocol and the Burden Sharing Agreement of the EU. Under Kyoto, Sweden is allowed to increase its emissions of GHG to 4\% above 1990 levels for the period of 2008 to 2012. In addition, on November 30, 2001, the government issued a Bill on Climate Change Strategy proposing that Swedish GHG emissions should be at least 4\% lower in 2008 to 2012 than in 1990, without carbon sinks or flexible mechanisms (significantly less than the Kyoto target). In 2000, the government devoted about 646 million Swedish Krona (\$83 million June 2003 US\$) to energy-related R\&D, $36 \%$ of that on energy conservation.

\section{Main organizations involved in energy}

The Riksdag initiated energy policy in 1991 with the Energy Policy Bill (see above). The Minister of Industry, Employment and Communications is the lead in developing energy policy. The Swedish National Energy Administration (STEM), known as the Swedish Energy Agency (in English) was created on January 1, 1998 and is the central government authority responsible for most functions related to energy, including implementation of most of the country's energy policy programs and coordination of the various energy policy changeover and introductory measures [1]. The Swedish National Board for Industrial and Technical Development (NUTEK) responsibilities have been transferred to STEM.

Other administrations have a role in implementation of energy policy programs as well, including: the Swedish Board of Housing, Building and Planning (for households), the Swedish Consumer Agency (for testing, labeling and certification of energy in equipment), the local transport authorities (Vägverket, Sjöfartsverket, Luftfartsverket, Banverket, for the transport sector), the Swedish Research Council for Environment, Agricultural Sciences and Spatial Planning (FORMAS) [2] (for building research, formerly under the Swedish Council for Building Research, BFR, and for the parts of the Swedish Environmental Protection Agency responsible for the supervision of environmental issues under the energy policy program), the Swedish Agency for Innovation Systems [3] (taking over the activities of the Swedish Transport and Communications Research Board, KFB, and parts of NUTEK), the Swedish Research Council [4] (for energy-relevant basic research, formerly pursued by the Swedish Natural

Science Research Council, NFR, and the Swedish Research Council for Engineering Sciences, TFR). 
The Environmental Objectives Council was established on January 1, 2002 to coordinate the country's emission reduction activities.

\section{Relevant documents (general)}

The Energy Policy Bill by the Riksdag (Parliament) in 1991 framed energy policy as long-term and sustainable (see above).

In May 1993, the Bill Strategies against Climate Change was adopted. The goal was stabilizing $\mathrm{CO}_{2}$ emissions from fossil fuels at the 1990 level in 2000 and decline after that.

First National Communication to the UN FCCC, Sweden's National Report under the UN Framework Convention on Climate Change, was adopted on September 15, 1994.

Second national communication, Sweden's Second National Report under the UN Framework Convention on Climate Change, was adopted April 17, 1997.

The 1997 Bill on A Sustainable Energy Supply emphasized energy efficiency.

Environmental Quality Objectives Bill presented in May 2001 and accepted in November 2001.

Third National Communication to the UN FCCC (NC3) was adopted in November 2001.

Bill on Climate Change Strategy issued on November 30, 2001.

Report presented in October 2001 by the Interministerial Working Group for Rational Energy Consumption (appointed March 1, 2001) More Efficient Energy Consumption: Proposals for Market-Based Measures. It called for establishment of long-term voluntary agreements between government and energy intensive companies.

On March 21, 2002, the Energy Policy Bill Cooperation for a Secure, Efficiency and Environmentally-Friendly Energy Supply was introduced. It was approved by Parliament on June 11,2002 , restating the country's established energy policy objectives.

\section{Programs, agencies}

1. The Swedish National Energy Administration (STEM) or the Swedish Energy Agency [1]

Description: The Swedish National Energy Administration was created on January 1, 1998. It is the central government authority responsible for most functions related to energy, including implementation of most of the country's energy policy programs and coordination of the various energy policy changeover and introductory measures. STEM supports research on renewable energy, technology procurement of energy efficient products and grants for development of renewables (see appropriate sections, below). STEM is also the authority on strategic energy planning of the central and the local governments. 
Goals: The main goal of STEM is to implement the energy policy of the Swedish Parliament established in 1997.

Products and Services: Fact sheets available online for lighting, motors, heating and ventilation. "Energy-saving tips" pages. Research on process integration and electricity use in buildings and small and medium-sized industry (through ELAN [1]). ELAN ran from 1998 to 2002 with a budget of 15 million Swedish Krona (\$2 million June 2003 US\$). It was implemented in coordination with colleges and industry.

Delivery Mechanisms: Website [1] has information on energy efficient technology and grants applications, other publications and links to other EU programs. Schedules for planned energy events also available on the website. Voluntary agreements (see \#3 below).

\section{NUTEK's Technology Procurement Program}

Description: Technology procurement of energy efficient products and systems helps encourage the development and marketing. The methodology was developed by NUTEK. (NUTEK is Sweden's Business Development Agency for industrial policy issues. [5]) Technology procurement aims to improve energy efficiency using companies' competitive abilities to make better products and thus move the market. The program gathers potential buyers of a particular item, process or system together with energy experts to draft the energy efficient performance parameters, together with other requirements for the equipment, process, etc., to be developed. The customers make functional demands (e.g., a higher efficiency high frequency electronic ballast) in return for an indication of their willingness to buy if conditions are met. Suppliers then compete based on design and price. About \$13 million June 2003 US\$ has been assigned over a five-year period for the development and introduction of energy efficient technology through technology procurement.

Goals: The life-long annual running costs of the equipment, process or system must be lower than existing equipment, processes or systems already on the market today.

Achievements: NUTEK initiated about 30 technology procurement projects and over 1,500 other projects. About 100 incentive agreements have been signed.

Products and Services: Demonstrations of existing procurements.

Delivery Mechanisms: NUTEK subsidizes the purchasers with a certain proportion of the purchasing costs of the new products, with the condition that the product installation can be used for demonstrations. NUTEK also provides assistance with marketing the new product.

\section{EKO Energi - Voluntary Agreements [6]}

Description: EKO Energi was a voluntary agreement program within STEM (see \#1 above) directed at larger energy-intensive industrial companies. It started in 1994 and ended in 2002. Companies set energy and environmental targets and developed action plans and long-term energy and environmental policy in accordance with Eco Management and Audit Scheme (EMAS) or ISO 14001. The company also established ENEU 94 as the standard method to 
purchase energy efficiency machines and tools. (ENEU 94 is a guide for procurement that uses life-cycle analyses in investment calculations, not pay-off analysis. Hence, purchasing became a long-term activity that initiated energy issues into everyday life within the company.) In exchange, STEM provided the products and services listed below. EKO Energi was terminated in 2002 and all agreements with the companies were fulfilled.

Goals: Decrease $\mathrm{CO}_{2}$ emissions and replace Barsebäck nuclear electricity production by increased energy efficiency, labeling energy as one of a company's most significant environmental impacts, and working within environmental management programs as EMAS and/or ISO 14001.

Achievements: 47 Swedish companies and over 70 plants were involved in EKO energy. Energy efficiency was mainly achieved in ventilation (27\%), motors and drives (22\%), lighting (2\%), compressed air (7\%), heating (8\%) and process measurement areas (32\%). In 1998, energy savings in the ten companies reporting were $0.098 \mathrm{TWh}$ (12\% of their total energy consumption), 0.036 TWh in electricity. Savings per EE measure ranged from 4 to $28 \%$.

Products and Services: STEM provided a comprehensive inventory and analysis of energy use in the company's production and premises, including a list of suggested actions to be taken. STEM provided a comprehensive material flow analysis as well as an introductory comparison of the company's environmental awareness and management and guidelines based on EMAS or ISO 14001 standards. An education package was available on the process of energy-efficient industrial purchasing, ENEU 94.

Delivery Mechanisms: Inventory, analysis and action list delivered to company. STEM reviewed the action plan set up by the company based on reasonably economically viable measures suggested by the inventory and analysis. STEM arranged "goodwill activities" like spreading success stories in the news and awarding the most successful EKO energy company of the year in a ceremony covered by the media. On August 31,2000, the government appointed a special negotiator in the Ministry of Industry to prepare background material and a proposal for longterm agreements with energy intensive industries. STEM gave courses to companies addressing how equipment should be purchased using life cycle cost analyses. Managers from each company attended the courses. Help was given with obtaining ISO 14001 or EMAS certification. EKO Energi label.

\section{Corporate Commitments}

Description: Launched by large chain stores with their own manufacturing facilities. Chain stores agree with their suppliers, customers, NUTEK and STEM that energy efficient products are to be used or produced in virtually all stages of production and distribution, including all semi-manufactured goods, production processes, products used in distribution and marketing of goods (such as lighting), and as a selection of energy efficient products offered by the companies to their customers.

Products and Services: Companies receive a small subsidy to defray some of the cost of adjusting their inventories and production methods. 


\section{Voluntary Standards}

Description: Standards have been set for lighting, fans, pumps, ventilation systems and other products used in production. Mandatory standards and regulatory measures are now a part of the program for energy efficiency in industry.

Achievements: Production standards have been set for the engineering, plastics, metals, saw mill, rubber and pulp and paper industries.

\section{Tax Levies}

Description: Three different levies on energy products: energy tax, $\mathrm{CO}_{2}$ tax and sulfur tax. The manufacturing, agriculture, forestry and aquaculture sectors have been granted complete exemption from the energy tax (as of July 1, 2000) and a 70\% exemption from the $\mathrm{CO}_{2}$ tax (as of 2002). Energy intensive industries can obtain even higher tax exemption rates (above 70\%). The tax rate on $\mathrm{CO}_{2}$ is 630 Swedish Krona per tonne of $\mathrm{CO}_{2}$ (\$81 June $2003 \mathrm{US} \$ /$ tonne of $\mathrm{CO}_{2}$ ).

Delivery Mechanisms: Tax levy and exemptions for energy efficiency.

\section{References}

1. The Swedish National Energy Administration (STEM) website: www.stem.se

2. The new Swedish Research Council for Environment, Agricultural Sciences and Spatial Planning (FORMAS) website: www.formas.se

3. The Swedish Agency for Innovation Systems website: www.vinnova.se

4. The Swedish Research Council website: www.vetenskapsradet.se

5. NUTEK's website (in English): http://www.nutek.se/sb/d/112

6. Åstrand, K. A Voluntary Agreement in the Swedish Energy Sector - the Implementation of the Eco-Energy Program in a Swedish Company. Paper presented at "The Politics of New Environmental Policy Instruments," ECPR Joint Sessions, Grenoble, April 6-11, 2001.

7. International Energy Agency (IEA) documents: http://www.iea.org/pubs/newslett/eneeff/sw.pdf 


\section{Switzerland}

\section{Country Goals}

Switzerland's political system is made of a federal government, parliament and court. There are 26 cantons (states), each which has its own government, parliament and cantonal courts. Responsibilities are shared between the federal level and the cantons. The cantons are sovereign unless legislative power is explicitly attributed to the federal level. Responsibility for energy matters traditionally falls with the cantons and municipalities, although in 1991, a Constitutional Energy Article authorized the federal government to carry out a national energy policy in pursuit of specific energy goals, like energy efficiency.

Switzerland signed the United Nations Framework Convention on Climate Change (UNFCCC) on May 9, 1992. The First National Communication under the UNFCCC commitment was submitted on September 21, 1994. The Second National Communication of Switzerland 1997 Greenhouse Gas Inventory 1995, April 1997, documents activities. In 1997, Switzerland also signed the Kyoto Protocol and thereby committed itself to reducing the emission of greenhouse gases to $92 \%$ in 2010 compared to 1990 . The federal law on $\mathrm{CO}_{2}$ emissions (Law on $\mathrm{CO}_{2}$ ), May 1,2000 , states energy related $\mathrm{CO}_{2}$ emissions should be reduced $10 \%$ by 2010 compared to 1990 . $83 \%$ of Switzerland's total $\mathrm{GHG}$ emissions are $\mathrm{CO}_{2}$-emissions. The other 5 Kyoto gases are controlled by laws and decrees. Therefore reaching the target of the $\mathrm{CO}_{2}$ law means Switzerland fulfils its Kyoto target. The first phase of the law involves negotiated agreements, the second, taxes (see below). The Third National Communication under UNFCCC was submitted in 2001.

\section{Main organizations involved in energy}

Swiss Federal Office of Energy (SFOE) - formulation of national energy policy, energy supplies and energy utilization [1]

Swiss Agency for the environment, forests and landscape (SAEFL), formulation of national environmental and climate policies [2]

Energie-Agentur der Wirtschaft (EnAW), private sector energy agency [3]

Agence suisse des énergies renouvelables et de l'efficacité énergétique (AEE), Swiss Agency for Renewable Energy and Energy Efficiency.

Agence de l'énergie pour les appareils électriques (EAE), Energy Agency for Electric Appliances

Agence suisse pour l'efficacité énergétique (S.A.F.E.), Swiss Agency for Energy Efficiency [4]

\section{Relevant documents (general)}

Three documents form the basis of energy policy at the federal level: 
- $\quad$ Federal Energy law, January 1999 (replaced the Decree on Energy Use)

- $\quad$ Federal decree on Energy Use, December 1998 - 26 cantonal energy laws and respective decrees, deal especially with energy in buildings

- The federal law on $\mathrm{CO}_{2}$ emissions reduction (Law on $\mathrm{CO}_{2}$ ), May 1, 2000

Confédération Suisse, the First National Communication regarding UNFCCC commitment, September 21, 1994.

The Second National Communication of Switzerland 1997 - Greenhouse Gas Inventory 1995, April 1997.

The Third National Communication under UNFCCC.

\section{Programs, agencies}

\section{Energy 2000 Action Plan (Energy 2000)}

Description: Begun November 6, 1990. Federal government financing was \$329 million 2000 US\$, mostly aimed at promoting voluntary actions. Ended in 2000 (replaced by SwissEnergy, see below). Around 120 companies with annual energy costs over \$100,000 US\$ each, representing $18 \%$ of the energy consumption in industry were involved in negotiated agreements, achieving between 15 to 30\% of Energy 2000's goals for 2000.

Goal: Stabilize the use of fossil fuels and $\mathrm{CO}_{2}$ emissions by 2000 and reduce thereafter, based mainly on energy efficiency.

Achievements: Energy savings in commercial and industrial sector in 2000 were 12.4 PJ. Overall energy savings from 1990-2000 were 165.5 PJ.

Delivery Mechanisms: Voluntary agreements for energy efficiency. Among industries included are cement, pulp and paper and plastic injection moulding. Interest groups for discussions of controversial themes related to energy. Two energy management courses and ten motivation campaigns for employees of the companies in the negotiated agreements.

\section{Swiss Energy Action Plan (SwissEnergy) [1]}

Description: This federal 10 year program was begun on January 30, 2001 as a continuation of Energy 2000 for the efficient use of energy and introduction of renewables. Annual budget is $\$ 32$ million 2000 US\$. It brings together representatives from all levels of government (federal, cantonal, and local level), utilities, supply companies, industry, consumer groups and environmental organizations. This program is also responsible for all activities regarding the reduction of $\mathrm{CO}_{2}$ emissions according to climate agreements such as Kyoto.

Goal: Government set targets to reduce consumption of fossil fuels by $10 \%$, to limit the increase of electricity consumption to 5\% between 2000 and 2010, to retain hydropower's contribution to 
net demand and to increase the contribution made by other forms of renewable energy to total electricity production by $0.5 \mathrm{TWh}$ or $1 \%$, and to heating energy by $3 \mathrm{TWh}$ or $3 \%$.

Current status: Some 65 groups with approx. 800 companies representing $25 \%$ of the Swiss private sector $\mathrm{CO}_{2}$-emissions.

Products and Services: Brochures, annual and other reports downloadable from the website [1].

Delivery Mechanisms: Voluntary agreements for energy efficiency signed between the Federal Office of Energy and users (mainly big and medium companies (energy consumers) from industry, trade and services sector). SwissEnergy provides a coordinator. Interest groups for discussions of controversial themes. Website. Energie Extra is the joint newsletter of the Swiss Federal Office for Energy and SwissEnergy. Public library. Advice centers. Research and training courses.

\section{Federal Energy Law (Energy Law) and decree on energy use}

Description: Replaced Decree on Energy Use of 1991. Began enforcement January 1, 1999. Gives priority to voluntary actions rather than regulations.

Goal: Reduce energy consumption in transportation, building, and energy supply sectors and increase energy efficiency.

Products and Services: Information energy efficiency, pilot installations and demonstration installations.

Delivery Mechanisms: Financial incentives for energy efficiency and advice, education, training and research on energy efficiency. Possibility to outsource organization and enforcement of voluntary action to private organizations (e.g. the EnAW).

\section{Energei-Agentur der Wirtschaft (EnAW), private sector energy agency}

Description: Established in 1999. Total budget for 2001-2003 is about 8 million 2002 US\$. Main activity is the Agreements.

Goal: By end of 2003, half of the companies must be informed about AEnEC activities and about the Agreement process, and at least $40 \%$ of the industry and service sector must be covered by agreements.

Delivery Mechanisms: Voluntary agreements. Elaboration of negotiated agreements, support with realization of measures, exchange of experiences, possible exemption from $\mathrm{CO}_{2}$ tax under certain conditions (e.g., ambitious $\mathrm{CO}_{2}$ reduction), The monitoring system for EnAW members is compatible with SwissEnergy or for independent partners.

\section{Swiss Agency for the Environment, Forests and Landscape - Law on $\mathrm{CO}_{2}$}

Description: The Swiss Agency for the Environment, Forests and Landscape is the implementing agency for the $\mathrm{CO}_{2}$ tax, Phase II of the Law on $\mathrm{CO}_{2}$. Phase I of the Law on $\mathrm{CO}_{2}$ incorporates all enterprises willing to contribute on a voluntary basis to reduce $\mathrm{CO}_{2}$ emissions. If 
Phase I is not sufficient, the introduction of Phase II in 2004 will be discussed. In Phase II, all negotiated agreements adopted and fulfilled by companies that meet ambitious $\mathrm{CO}_{2}$ reduction targets can be converted into legally binding commitments. Companies having a legally binding commitment will be exempt from the tax on $\mathrm{CO}_{2}$. Only large companies or associations that together emit over 10,000 tonnes of $\mathrm{CO}_{2}$ per year are eligible for the legally binding commitment.

Delivery Mechanisms: In addition to the negotiated agreements under the $\mathrm{Law}$ on $\mathrm{CO}_{2}$ (administered by SwissEnergy), if the $\mathrm{CO}_{2}$ tax is implemented, there will be potential tax exemptions for eligible companies.

\section{References}

1. SwissEnergy website: http://www.energie-schweiz.ch/bfe/en/index.html

2. Swiss Agency for the environment, forests and landscape (SAEFL) website: http://www.umwelt-schweiz.ch/buwal/eng/

3. Energie-Agentur der Wirtschaft (private sector energy agency), www.enaw.ch website in German and French

4. Agence suisse pour l'efficacité énergétique (S.A.F.E.), Swiss Agency for Energy Efficiency website (German): www.topten.ch

5. Updated Swiss overall energy statistics (http://www.energieschweiz.ch/bfe/en/statistik/gesamtenergie/) and GHG inventory (http://www.climatereporting.ch/ghg.html)

6. International Energy Agency (IEA) documents: http://www.iea.org/pubs/newslett/eneeff/ch.pdf 


\section{United Kingdom}

\section{Country Goals}

The UK met its commitment under the UN Framework Convention on Climate Change (FCCC) of returning $\mathrm{CO}_{2}$ emissions to 1990 levels by 2000. It has now set its commitment at $12.5 \%$ reduction in GHG emissions by the period of 2008-2012 from 1990 levels under the EU's Burden Sharing Agreement. In addition, the UK has set a national target of $20 \%$ reduction of $\mathrm{CO}_{2}$ emissions by 2010 from 1990 levels. On February 24, 2003, the UK government released its Energy White Paper "Our Energy Future - Creating a Low Carbon Economy" that commits to take a path to cut the UK's carbon dioxide emissions - the main contributor to global warming by some $60 \%$ by about 2050 with real progress by 2020 .

\section{Main agencies involved in energy}

Sustainable Energy Policy Network, Chaired by Secretaries of State for Trade and Industry and for Environment, Food and Rural Affairs [1]

Contact:

General Information: Marjorie Williams. (020) 72152672

marjorie.williams@dti.gsi.gov.uk

Department for the Environment, Food and Rural Affairs (DEFRA) (formerly the Department of the Environment, Transport and the Regions (DETR)) [2]

Contacts:

H.E.Rt. Hon. Margaret Beckett — Secretary of State for DEFRA

Brian Bender - Permanent Secretary, DEFRA

Bill Stowe - Minister for the Environment, DEFRA

Nobel House, 17 Smith Square, London, SW1P 3JR

Tel: $(+44 / 207) 238.56 .09$ Out of hours: $(+44 / 207) 270.89 .60$

Fax: (+44/207) 238. 55.29

energy.efficiency@defra.gsi.gov.uk - energy efficiency policy (note that the Department of Trade and Industry - (DTI) - is responsible for overall energy policy, including energy supply and renewable energy)

Ms. Marie Pender - Climate Change Agreements

6/F7, Ashdown House, 123 Victoria Street, London SW1E 6DE

Tel. (+44/207) 944.5344

Email: marie.pender@defre.gsi.gov.uk

Department of Trade and Industry's Energy Group [3]

Contact:

Director General Joan MacNaughton

Other contacts:

heca@defra.gsi.gov.uk - for queries about energy efficiency activity by local authorities, including the Home Energy Conservation Act 
best.practice@defra.gsi.gov.uk - for queries about the Energy Efficiency and Environmental Technology Best Pwractice Programmes, and activities to help business meet the obligations of the Climate Change Levy

levy.agreements@defra.gsi.gov.uk - for enquiries about agreements with businesses in relation to the Climate Change Levy. chp@defra.gsi.gov.uk - for enquiries about Combined Heat and Power and community heating.

Environment Agency [4]

Devolved Administrations (Parliament, Scottish Executive, National Assembly for Wales, Northern Ireland Assembly, Northern Ireland Executive)

Task Force on Curbing Business Energy Use

Scottish Energy Efficiency Office [5]

\section{Relevant documents (general)}

UK Climate Change Programme [6]

Our Energy Future: Creating a Low-Carbon Economy (Energy White Paper), available at: http://www.dti.gov.uk/energy/whitepaper/ourenergyfuture.pdf [1]

\section{Programs, Agencies}

\section{Sustainable Energy Policy Network [1]}

Description: On 24 February 2003 the Government launched its Energy White Paper "Our energy future - creating a low carbon economy." The White Paper marks a radical change to energy policy, bringing environment concerns to the heart of policy, by defining a long-term strategic vision for energy policy combining our environmental, security of supply, competitiveness and social goals.

\section{Goal:}

"Four goals for our energy policy:

- $\quad$ to put ourselves on a path to cut the UK's carbon dioxide emissions - the main contributor to global warming - by some $60 \%$ by about 2050 with real progress by 2020 ;

- $\quad$ to maintain the reliability of energy supplies;

- $\quad$ to promote competitive markets in the UK and beyond, helping to raise the rate of sustainable economic growth and to improve our productivity; and - to ensure that every home is adequately and affordably heated."

Within the White Paper, there are over 130 commitments that must be delivered. Some of these are specific new undertakings, others reinforce existing policies and programmes while others provide a wider policy framework. These have been broken down into 11 overall work streams, each with a single person with overall responsibility for delivering that work stream. The work streams are: Climate Change, Reducing UK Emissions, Energy Efficiency, CHP, Renewables, 
Social including Fuel Poverty, International Energy Relations, Innovation, Education, Skills and Research, Transport, Security of Supply and Delivery Partnerships.

\section{Climate Change Levy}

Description: The Climate Change Levy is a tax on the use of energy (natural gas, coal, liquefied petroleum gas, and electricity) in industry, commerce and the public sector. The tax is revenue neutral because the funds are recycled via offsetting cuts in employers' National Insurance Contributions, exemptions and reductions to the tax through climate change agreements (see below) and support for The Carbon Trust (see below). The levy forms a key part of the Government's overall Climate Change Programme.

Goal: To reduce energy use by non-domestic consumers in support of efforts to meet Kyoto and national GHG emissions reduction goals, which are $12.5 \%$ and 20\%, respectively, below 1990 baseline by 2010 .

\section{Climate Change Agreements (through DEFRA)}

Description: Participating companies agree to greenhouse gas emissions reduction targets and if the targets are achieved the companies receive an $80 \%$ Climate Change Levy discount. DEFRA works with business sector associations to set the emissions reduction targets that cover the period 2002 to 2012. Targets may be absolute or relative (emission reduced per unit of product produced). The agreements are signed between DEFRA and the industry associations, which in turn sign agreements with individual companies. Companies that meet the target are granted an exception from the Climate Change Levy. [2] Companies that exceed the target can either sell their excess emissions through the UK Emissions Trading Scheme (see below).

Goal: Reductions in carbon emissions by individual companies that support the UK emissions reduction goals.

Achievements: Ten-year agreements signed with 44 sectors representing more than 5,000 companies operating more than 12,000 individual facilities. Reduction of $13.5 \mathrm{MtCO}_{2}$ (nearly 4 $\mathrm{MtC}$ ) against estimated 2000 baseline, which is three times above the target of $3.4 \mathrm{MtCO}_{2}$. 10,500 facilities (88\%) received the Climate Change Levy exemption (the remainder either did not supply data, dropped out, or failed to meet individual targets).

Products and Services: See The Carbon Trust (below).

Delivery Mechanisms: Negotiated agreements between industry association and DEFRA. DEFRA has a website [2] with contact and program information. DEFRA has guidance documents available through their website as well [2], and a database. Future Energy Solutions (formerly ETSU, part of AEA Technology Environment, an internationally recognized source of impartial information) receives the submissions from sectors, holds a number of meetings with the sector and collects the data. Future Energy Solutions also maintains a database of energy use and energy saving potential in the main industrial sectors. Tax levy discount up to $80 \%$ for participating companies. Guidance documents available through the DEFRA website [2]. 


\section{The Carbon Trust [7]}

Description: The Carbon Trust is an independent not for profit company set up by the Government in April 2001. Part of the UK's Climate Change Programme, the Carbon Trust encourages and promotes the development of low carbon technologies (both energy efficient technologies and low carbon energy supplies) to support the transition to a low carbon technology in the UK. Key to this aim is its support for UK businesses in reducing carbon emissions through funding, supporting technological innovation and by encouraging working practices that are more efficient.

Nonprofit begun in April 2001. $1^{\text {st }}$ year fund is 50 million GBP (equivalent to $\$ 77$ million July 2002 US), gained from the Climate Change Levy (CCL) and Energy Efficiency Best Practice Programme. Will manage, develop and promote the Enhanced Capital Allowance (ECA) Scheme for specified energy-saving technologies. Will operate in partnership with Devolved Administrations (who also contribute to the Trust)

Goal: To "take the lead on low carbon technology and innovation in this country, and put Britain in the lead internationally" (Tony Blair). Help businesses, public bodies, government and research community to move towards sustainable, lower carbon economy while maintaining competitiveness. Encourage investment in energy efficient technologies

Products and services: Audits and assessment reports, case studies, fact sheets, reports and guidebooks, and tools and software are all provided through Action Energy (see below).

Delivery mechanisms: Manages Action Energy and the Enhanced Capital Allowance Scheme (see below).

\section{Action Energy [8]}

Description: Action Energy, a program funded through the Climate Change Levy, helps businesses and public sector organisations save money through energy saving.

Goal: Promoting energy efficiency through provision of information and guidance.

Products and Services: Free on-site Energy Action surveys by an energy expert to identify achievable savings and provide a tailored action plan, industry profiles, good practice case studies, good practice guides, new practice profiles, new practice reports, energy consumption guides, fact sheets, fuel efficiency booklets, future practice profiles, future practice reports, general information leaflets, general information reports, videos, audio tapes, software, and an industrial estate benchmarking tool.

Delivery Mechanisms: Free conferences and trade shows, customer information center, financial assistance (0\% fixed interest loans of $£ 5,000$ to $£ 50,000$ to fund the purchase of equipment such as lighting, boilers or insulation through Action Energy loans for small and medium-sized businesses), specialized consultants and surveys, telephone "Action Energy Helpline," free onsite Energy Action surveys. Publications and information online through the website [8]. 


\section{Enhanced Capital Allowance Scheme [9]}

Description: Allows a business to claim 100\% first-year capital allowances on their spending on qualifying technologies. Businesses can write off the entire capital cost of their investments in energy-saving technologies against their taxable profits for the period during which they make the investment.

Goal: Help organisations invest in energy saving equipment in a cost-efficient way.

Products and Services: Energy awareness promotional materials designed to help manufacturers and suppliers promote, and purchasers select, the products and technologies that appear on the Energy Technology Product List. Promotional materials include a virtual exhibition, fact sheets, a movie and PowerPoint presentations.

Delivery Mechanisms: $100 \%$ first-year capital allowance for technologies on the Energy Technology Product List.

\section{Energy Saving Trust [10]}

Description: The Energy Saving Trust was set up by the UK Government after the 1992 Rio Earth Summit and is one of the UK's leading organizations addressing the damaging effects of climate change. Working with a range of partners, EST focuses on delivering practical solutions for households, small firms and the road transport sector - solutions which save energy and deliver cleaner air.

Goal: To achieve the sustainable and efficient use of energy, to cut the carbon dioxide emissions which are the key contributor to global warming.

Delivery Mechanisms: The Energy Saving Trust (EST) has a comprehensive support programme to help interested parties consider, evaluate and install Combined Heat and Power (see below).

\section{UK Emissions Trading Scheme [11]}

Description: The UK emissions trading scheme is the world's first economy-wide greenhouse gas emissions trading scheme. 34 organizations ('direct participants' in the scheme) have voluntarily taken on a legally binding obligation to reduce their emissions against 1998-2000 levels, delivering over 4 million tonnes of additional carbon dioxide equivalent emission reductions in 2006. The scheme is also open to the companies with Climate Change Agreements. These negotiated agreements between business and Government set energy-related targets. Companies meeting their targets will receive an $80 \%$ discount from the Climate Change Levy, a tax on the business use of energy. These companies can use the scheme either to buy allowances to meet their targets, or to sell any over-achievement of these targets.

Goal: This voluntary scheme allows companies with UK operations to develop trading expertise in advance of the opening of international markets.

Delivery Mechanisms: Incentives of up to $£ 215$ million over 5 years for firms who voluntarily take on emission reduction targets for greenhouse gases. This equates to $£ 30$ million per year after corporation tax. Any one firm can receive a maximum of $10 \%$ of the incentive monies. 


\section{Combined Heat and Power (CHP) support}

Description: A United Kingdom Strategy for Combined Heat and Power was published in 1996. It outlines government goals. Research, information and promotion is through the EEBPP, the Energy Saving Trust [10], the Carbon Trust, DEFRA and the Combined Heat and Power Association

Goal: Maintain the growth of CHP, set a target of 10,000 MW of "good quality CHP" capacity by 2010 at acceptable cost.

Products and Services: CHP club, run through the EEBPP, provides site-specific advice, guides, network, an Internet forum, a newsletter and events. Other benefits of CHP include exemption from climate change levy for all good quality CHP outputs (judged through the CHP Quality Assurance programme (CHPQA) (see website, below), eligibility for ECA scheme, changes to the licensing regime.

Delivery Mechanisms: Newsletters and other publications, websites of CHP club, the Quality Assurance programme for CHP (see http://www.chpqa.com/ and http://www.chpclub.com). Environmental Helpline.

\section{Making a Corporate Commitment Campaign (MACC and MACC2)}

Description: Began 1991 intended equally for industrial, commercial and public sector organizations. Organizations signing up to MACC2 make a commitment to reduce greenhouse gas emissions, publicly declare their commitment to achieve targets and what targets are, register and report annually on progress. Helps organizations improve their resource efficiency and environmental performance in a managed, targeted and transparent way.

Goal: Get top management commitment to responsible energy management.

Products and Services: Government registry for targets, MACC2 handbook, publicly available database of the commitments of all organizations that have signed a MACC2 agreement (public recognition). A Table of Commitment is available to help assess current levels of resource efficiency and set realistic targets for improvement.

Delivery Mechanisms: Website [12], environmental minister announcements, local government offices websites and local MACC2 contacts.

\section{Envirowise (formerly Environmental Technology Best Practice Programme, ETBBP) [13]}

Description: Began 1994. 54 million GBP (equivalent to $\$ 79$ million 2002 US) from 94/95 through 06/07. Promotes the use of better and economical environmental practices

Goal: Stimulate annual cost savings for industry of 580 million GBP (equivalent to $\$ 850$ million 2002 US) by 2015.

Products and Services: Provide information and advice on environmental technologies and techniques. Publications available both on and offline, events, online discussion groups and the 
"Environmental Helpline" Onsite waste review of facilities. Interactive online tools (e.g., how to run a workshop, waste management).

Delivery Mechanisms: Publications (available on and offline), events (workshops, showcases and networking meetings), telephone or email "Environmental Helpline", online discussion groups, site assessments, local agents to work directly with businesses, waste minimization clubs where companies share and network ideas for waste management.

\section{Guidelines for Company Reporting on Greenhouse Gas Emissions}

Description: Began 1999. Provide guidance on sources of emissions, how to gather the data and convert it into $\mathrm{CO}_{2}$ equivalents (all sectors are involved in this, not just industry). See www.defra.gov.uk/environment/envrp/index.htm

Goal: To help and encourage companies' measurement and reporting (publicly) on greenhouse gas emissions.

Products and Services: Assist companies in measuring and publicly reporting on GHG emissions, provide guidance information on sources of emissions, data gathering and conversion to $\mathrm{CO}_{2}$ equivalents.

Delivery Mechanisms: Website through DEFRA [2]

\section{Scottish Energy Efficiency Office [5]}

Description: Office runs a number of programs to aid businesses and other sectors to increase energy efficiency.

Products and Services: Scottish Clean Energy Demonstration Scheme (SCEDS): “A grant scheme to assist and encourage the development, demonstration, application and replication of energy efficiency measures and renewable energy technologies within Scotland" [5]. Grants of up to 80,000 GBP ( $\$ 124,000$ July 2002 US). Program mostly for small to medium sized businesses (as well as other nonprofit and other organizations). The Goal is to promote energy efficient and renewable projects with demonstration value. Loan Action Scotland: provides interest free loans of up to 5,000 to $25,000 \mathrm{GBP}(\$ 7,700$ to $\$ 39,000$ July 2002 US). Run by the Energy Saving Trust (a nonprofit company set up by Government and major energy companies). Lightswitch: rebates (up to 3,000 GBP\$4,600 July 2002 US), or for investment in energy efficient lighting, installation surveys for lighting switching that is not one for one, and controls systems on the lighting systems. Building Design Advice: offers independent and objective advice on the energy-efficient design of buildings. Part of Action Energy

Delivery Mechanisms: Website [5]. Case studies available on the website that have had success with the Loan Action Scotland.

\section{Eco-Management and Audit Scheme (EMAS)_European wide}

Description: Began April 1995. European-wide voluntary registration scheme. Voluntary opportunity for companies to register and gain public recognition for environmental commitment. Companies must implement an environmental management system and produce an independently validated public statement about their progress. 
Goal: Getting companies to implement management systems, reduce energy and report their progress.

Products and Services: Public recognition.

\section{References:}

1. Sustainable Energy Policy Network website: http://www.dti.gov.uk/energy/sepn/index.shtml

2. Department for the Environment, Food and Rural Affairs (DEFRA) (formerly the Department of the Environment, Transport and the Regions (DETR) websites: www.defra.gov.uk/environment/ccl/index.htm www.defra.gov.uk/environment/ccl/intro.htm http://www.defra.gov.uk/environment/envrp/index.htm

3. Department of Trade and Industry - Energy Section website: http://www.dti.gov.uk/energy

4. Environment Agency website: http://www.environment-agency.gov.uk/

5. Scottish Clean Energy Demonstration Scheme website: http://www.energyefficiency.org/howto/help/sceds/index.html

6. UK Climate Change Programme website: www.defra.gov.uk/environment/climatechange/cm4913/index.htm

7. The Carbon Trust website: www.thecarbontrust.co.uk

8. Action Energy website: http://www.actionenergy.org.uk/

9. The Enhanced Capital Allowance Scheme website: http://www.eca.gov.uk/

10. The Energy Saving Trust website: $\underline{w w w . e s t . c o . u k}$

11. UK Emissions Trading Scheme website: http://www.defra.gov.uk/environment/climatechange/trading/ukets.htm

12. Making a Corporate Commitment Campaign (MACC2) website: www.macc2.org.uk

13. Envirowise website: http://www.envirowise.gov.uk/ 


\section{United States}

\section{Country Goals}

The U.S. has committed to lower greenhouse gas (GHG) intensity - the ratio of GHG emissions to economic output - by $18 \%$ over the next 10 years. The U.S. is not ratifying the Kyoto Protocol. The U.S. is focusing on using the power of markets and technology to reduce GHG emissions, as described in the February 2002 Global Climate Change Initiative.

\section{Main agencies involved in energy}

Responsibilities for energy efficiency policies are divided among the federal government, the state and the municipal governments. The main federal agencies include:

The U.S. Department of Energy (DOE) [1]

- $\quad$ Office of Energy Efficiency and Renewable Energy (EERE) [2]

$>\quad$ Office of Industrial Technologies (OIT) [3]

$>\quad$ Federal Energy Management Program (FEMP) [5]

- The Energy Information Administration (EIA) [6] is the statistical agency of DOE. It provides data, forecasts and analyses for making policy and for promoting efficient markets and public understanding regarding energy.

- $\quad$ Office of Fossil Energy [7]

- $\quad$ Office of Nuclear Energy, Science and Technology [8]

- $\quad$ Office of Science [9]

- $\quad$ The National Laboratories of the DOE serve as the research centers for matters relating to energy and other areas.

The U.S. Environmental Protection Agency (EPA) [10]

\section{- $\quad$ ENERGY STAR Program [11]}

In October 2002, a cabinet-level Committee on Climate Change Science and Technology Integration was established that take direct responsibility for operational oversight of the federal interagency programs.

\section{Relevant documents (general)}

The National Energy Policy (NEP) issued in May 2001 defines the national energy strategy, containing 105 policy recommendations, 54 of which target energy efficiency.

The first national communication under the UNFCCC - Climate Action Report - Submission of the United States of America under the UN Framework Convention on Climate Change, published October 1994.

Second national communication - Climate Change Action Report - 1997 Submission of the United States of America under the UN Framework Convention on Climate Change, published July 1997. 
Third national communication - U.S. Climate Action Report - 2002, published June 2002. Interim Report of the Cabinet Level Review of U.S. Climate Change Policy, issued by the President in June 2001. Secretaries of Energy and Commerce and the EPA Administrator were directed to improve climate change technology research and development, enhance basic research, strengthen applied research through public-private partnerships, develop improved technologies for measuring and monitoring GHG emissions and support demonstration projects. The Report also included a Presidential Directive to the Secretaries of Energy and Commerce to develop a National Climate Change Technology Initiative (NCCTI)

\section{Programs, Agencies}

\section{DOE's Office of Industrial Technologies (OIT) [3]}

Description: The Office of Industrial Technologies works with U.S. industry to develop and deliver advanced technologies that increase energy efficiency, improve environmental performance and boost productivity. OIT consists of several programs, including the Industries of the Future Program, the BestPractices Program, Industrial Assessment Centers, Inventions and Innovations and $\mathrm{NICE}^{3}$. Each of these are described in more detail below, along with the products, services, and delivery mechanisms each provide.

Deliver Mechanisms: The delivery mechanisms for each of the individual programs in OIT are listed below. In addition, OIT offers the National Inventory of Manufacturing Assistance Programs (NIMAP) is a directory available to manufacturers looking for assistance with energyrelated plant technologies. NIMAP is a searchable database created by the Alliance to Save Energy for OIT that lists over 160 programs offering assistance to manufacturers. Individual program listings outline the services provided, offer contact information and provide a program overview. Available services include plant assessments, troubleshooting, outside consulting, tools, research and testing, technical assistance, training, and rebates and financial assistance. Many programs offer assistance on a low-cost or no-cost basis. The database is available online [4]. Climate VISION is run through the department of energy. It is a voluntary program with industry run through industry associations, in which the organizations voluntarily set a target for the industry and in return receive the assistance and services offered by DOE, EPA and other climate programs in the U.S.

\section{DOE's Office of Industrial Technologies (OIT) Industries of the Future (IOF) Program} [3]

Description: Partnerships are created with industry, government through the OIT program. National laboratories and institutions provide technology R\&D and deployment support. Industries of the Future (IOF) Program works with nine of the most energy intensive and waste intensive industries, including agriculture, aluminum, chemicals, forest products, glass, metal casting, mining, petroleum and steel.

Products and Services: R\&D. Plant wide assessment reports provided through OIT OIF website [12]. State OIF Program provides success stories. For each industry is a vision for the future and a technology roadmap to identify the key technologies that will be needed to reach that industry's goals. Verification and validation are provided through showcases and emerging 
technology demonstrations. State IOF fact sheets: two page fact sheets on each state identifying the benefits of IOF and opportunities. Several tools exist for companies to optimize utility systems, such as Motor Master+ 3.0, Pump System Assessment Tool (PSAT), ASD Master (Screening for Adjustable Speed Drive (ASD) upgrades), 3E Plus (Optimization of the insulation of boiler steam lines), AirMaster+ (Compressed air systems assessment and evaluation), Process Heating Assessment \& Survey Tool (PHAST), Steam Scoping Tool and Industry-Specific, Interactive CDs.

Delivery Mechanisms: Website [3]. Partnerships with industry. Energy Fairs - one day events designed to provide a professional, solutions oriented environment for industrial electricity users facing serious energy challenges. IOF Clearinghouse: toll free phone line (1-800-862-2086) provides answers to technical questions and information about OIT resources, training and Allied Partnership opportunities. IOF resource room: 1-202-586-2090 to order documents, software and other information. OIT Times newsletter. Cost sharing funding of R\&D projects in the nine industries.

\section{Inventions and Innovations (I\&I) [13]}

Description: Cost sharing program for development and establishment of technical performance of innovative energy saving ideas and inventions.

Delivery Mechanisms: Financial assistance up to $\$ 75,000$ for early development and establishment of technical performance of innovative energy saving ideas and inventions. Also, provide funding for prototype development or commercialization of a technology, up to $\$ 25,000$.

\section{OIT BestPractices Program [14]}

Description: The Best Practice Program works with industry to identify energy and process efficiency opportunities.

Products and services: Informational resources and tools. Technical assistance. Demonstrations of emerging technologies.

Delivery mechanisms: Plant-wide assessments, where plants are selected through a competitive solicitation process. Plants agree to a 50\% cost-share. A BestPractices team conducts the analysis. Quarterly newsletter Energy Matters provides news, technical tips and case studies from industry professionals. Website [14] has links to above.

\section{OIT Industrial Assessment Center (IAC) Program [15]}

Description: Teams of engineering faculty and students from universities conduct free comprehensive energy audits or industrial assessments. Audits last from one to two days and are free of charge to small to medium sized companies (generally 20 to 499 workers). Companies pay for all recommendations that they implement.

Achievements: Over 8,000 audits and assessments have been performed since 1978.

Products and Services: Confidential assessment reports provided to IAC customers within 60 days from site visit. Plant-wide assessment summary report published to promote replication of recommended energy conservation strategies. IAC database of plant and related assessment information (individual plants are not identified in keeping with Program policies). 
Delivery Mechanisms: Website [15] provides information, database, summary reports.

6. OIT National Industrial Competitiveness through Energy, Environment and Economics (NICE3) [16]

Description: A cost sharing program between state offices, industry and the federal government. Projects are selected through an annual solicitation and competition, a one time grant of up to $\$ 525,000$, with the industrial partner receiving up to $\$ 500,000$. Cost share must be at least $50 \%$.

Achievements: Over 100 projects have been sponsored. \$26.3 million in federal funding, and $\$ 81.8$ million in state and industry funds.

Delivery Mechanisms: Grants to states and their industries for projects that develop and demonstrate advances in energy efficiency and clean production technologies. Website [16] provides information on how to join.

7. EPA's ENERGY STAR® for Industry [11]

Description: An EPA voluntary partnership program between government and industry.

Products and Services: Information on energy management strategies and an energy efficiency best practice guide for focus industries.

Delivery Mechanisms: Industrial partnerships. Energy performance indicators tool to compare plants within an industry. Consultants that work with industries to provide information on energy efficiency and energy management. ENERGY STAR logo and awards. Website [11] provides information, guidebooks and contacts.

\section{Allied Partnerships}

Description: Manufacturers, associations, service and equipment providers, utilities, and other organizations that voluntarily work with DOE's Office of Energy Efficiency and Renewable Energy.

Products and Services: Hydraulic Institute provides case studies. Hydraulic Institute Assessment Tool provided through Allied Partnership.

Delivery Mechanisms: Exhibits at Allied Partners conferences. Partners, which include the American Institute for Chemical Engineers (AIChE), TAPPI and the Hydraulic Institute. Partners raise awareness, disseminate OIT information and resources and promote increased energy efficiency and productivity to industries that participate in EERE's Industries of the Future Program. Promote emerging technologies through websites and local sections, joint training events, conferences, calls, seminars, workshops and combining OIT with regional and national events. Industry experts, for example, representatives from Scales Air Compressor Corporation. Newsletters.

\section{Small Business Administration (SBA) [17]}

Description: The Small Business Administration provides several loan and loan guarantee programs for investments (including energy-efficient process technology) for small businesses. 
Delivery Mechanisms: Loans and loan guarantees.

\section{State programs}

Description: In addition to the federal policies and programs, many of the 50 states have general industry and business development programs that can be used to assist businesses in assessing or financing energy-efficient process technology or buildings. Most states have their own energy agency responsible for information dissemination, implementation of regional and local energy policy instruments. Below we summarize selected programs earmarked specifically for support of energy efficiency activities.

Delivery Mechanisms: Several programs provide financial assistance. The California Public Interest Energy Research (PIER) [17] provides funding for energy efficiency, environmental, and renewable energy projects in the state of California. Although there is a focus on electricity, fossil fuel projects are also eligible. California's Energy Innovations Small Grant Program (EISG)[19] provides small grants for development of innovative energy technologies in California, up to $\$ 75,000$. The Energy Policy Division of the Indiana Department of Commerce operates two industrial programs [20]. The Industrial Energy Efficiency Fund (IEEF) is a zerointerest loan program (up to $\$ 250,000$ ) to help Indiana manufacturers increase the energy efficiency of manufacturing processes. The fund is used to replace or convert existing equipment, or to purchase new equipment as part of a process/plant expansion that will lower energy use. The Distributed Generation Grant Program (DGGP) offers grants of up to $\$ 30,000$ or up to $30 \%$ of eligible costs for distributed generation with an efficiency over $50 \%$ to install and study distributed generation technologies such as fuel cells, micro turbines, cogeneration, combined heat \& power and renewable energy sources. Other programs support can support companies in the use of biomass for energy, research or building efficiency. Iowa's Alternate Energy Revolving Loan Program (AERLP) [21] was created to promote the development of renewable energy production facilities in the state. Proposals under $\$ 50,000$ are accepted yearround. Larger proposals are accepted on a quarterly basis. The New York State Energy Research \& Development Agency (NYSERDA) [22] operates various financial assistance programs for New York businesses. Different programs focus on specific topics, including process technology, combined heat and power, peak load reduction and control systems.

Wisconsin's Focus on Energy Program [23] has energy advisors that offer free services to identify and evaluate energy-saving opportunities, recommend energy efficiency actions, develop an energy management plan for business; and integrate elements from national and state programs. It can also provide training. Several states offer tax incentive programs, although none exist on the federal level. For example, New Jersey offers a tax exemption for cogeneration facilities on the purchase of natural gas and utility services that are used in the production of electricity. Maryland and Minnesota waive sales tax for the purchases of energy efficient products such as appliances, compact fluorescent lights, heat pump water heaters and efficient heating and cooling systems. Oregon through its Business Energy Tax Credit Program (BETC), Hawaii and California provide tax credits for renewable energy and energy efficiency.

\section{References:}

1. Department of the Energy website: http://www.energy.gov/engine/content.do 
2. Office of Energy Efficiency and Renewable Energy website: http://www.eere.energy.gov/

3. Office of Industrial Technologies (OIT) Program website: http://www.oit.doe.gov/

4. National Inventory of Manufacturing Assistance Programs website: http://www.oit.doe.gov/bestpractices/nimap/

5. Federal Energy Management website: http://www.eere.energy.gov/femp/

6. Energy Information Administration website: http://www.eia.doe.gov/

7. Office of Fossil Energy website: http://www.fossil.energy.gov/

8. Office of Nuclear Energy, Science and Technology website: http://www.ne.doe.gov/

9. Office of Science website: http://www.science.doe.gov/

10. Environmental Protection Agency website: http://www.epa.gov/

11. ENERGY STAR Program website: http://www.energystar.gov/

12. OIT's Industries of the Future Program website: http://www.oit.doe.gov/industries.shtml

13. Inventions and Innovations (I\&I) website: http://www.oit.doe.gov/inventions/

14. OIT's Best Practice Program website: http://www.oit.doe.gov/bestpractices/

15. Industrial Assessment Center (IAC) Program website: http://www.oit.doe.gov/iac/

16. National Industrial Competitiveness through Energy, Environment and Economics (NICE3) website: http://www.oit.doe.gov/nice3

17. Small Business Administration website: http://www.sba.gov/

18. California - Public Interest Energy Research (PIER) website: http://www.energy.ca.gov/pier/funding.html

19. California - Energy Innovations Small Grant Program website: http://www.energy.ca.gov/research/innovations/index.html

20. Indiana - Industrial Programs website: http://www.in.gov/doc/businesses/EP industrial.html

21. Iowa - Alternate Energy Revolving Loan Program website: http://www.energy.iastate.edu/funding/aerlp-index.html 
22. New York - Industry Research and Development Programs website: http://www.nyserda.org/industry/industrialprograms.html

23. Wisconsin - Focus on Energy website: http://focusonenergy.com/page.jsp?pageId=4

24. International Energy Agency (IEA) documents: http://www.iea.org/pubs/newslett/eneeff/us.pdf 